Portland State University

PDXScholar

6-29-1989

\title{
The Degree of Assimilation of the Second and Third Generation of Japanese Americans in the Portland Area
}

Hisako Matsuo

Portland State University

Follow this and additional works at: https://pdxscholar.library.pdx.edu/open_access_etds

Part of the Sociology Commons

Let us know how access to this document benefits you.

Recommended Citation

Matsuo, Hisako, "The Degree of Assimilation of the Second and Third Generation of Japanese Americans in the Portland Area" (1989). Dissertations and Theses. Paper 4299.

https://doi.org/10.15760/etd.6186

This Thesis is brought to you for free and open access. It has been accepted for inclusion in Dissertations and Theses by an authorized administrator of PDXScholar. Please contact us if we can make this document more accessible: pdxscholar@pdx.edu. 
AN ABSTRACT OF THE THESIS OF Hisako Matsuo for the Master of Arts in Sociology presented June 29, 1989.

Title: The Degree of Assimilation of the second and Third Generation of Japanese Americans in the Portland Area APPROVED BY THE MEMBERS OF THE THESIS COMMITTEE:
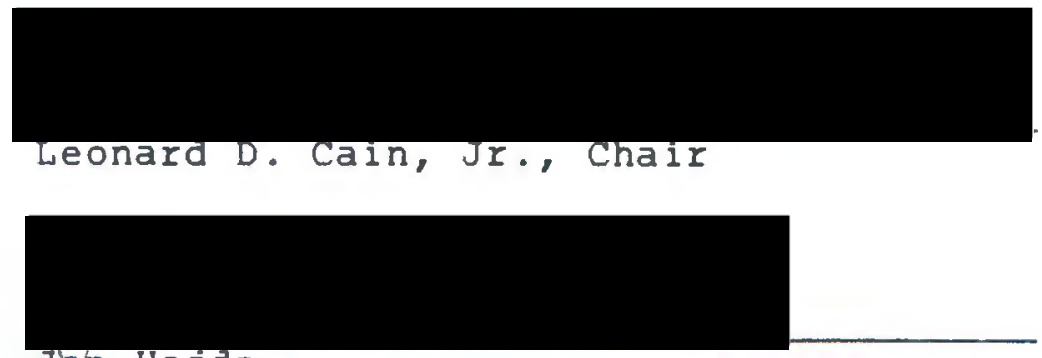

$J a n$ Hajaa

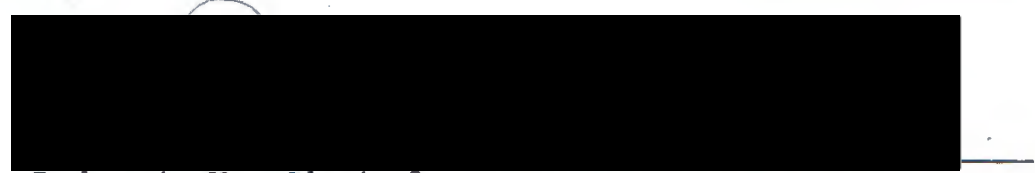

Robert W. ghotola

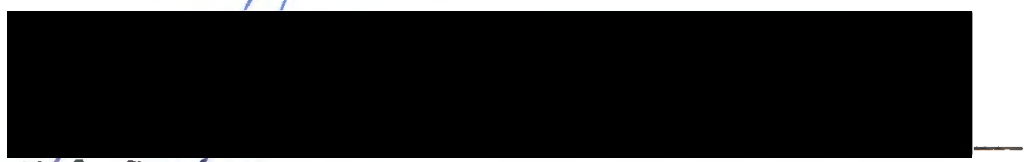

Mél Gurfov

Japanese Americans have been identified as one of the most successful minority groups in the United states of America because of their achievement of high socioeconomic status. This study focuses on the degree and process of assimilation of Japanese Americans in this country in order to reconsider multiple assimilation theories of minority 
groups. Three questions were raised: 1) the extent to which both the second and third generation of Japanese Americans are assimilated into American society; 2) how far the third generation is assimilated compared to the second generation; and 3 ) what the identity of the second and third generation are.

Based upon Gordon's assimilation theory (1964), five domains were defined: ethnic identity, socioeconomic status, exogamous marriage with whites, ethnic ties, and societal hostility. Four hypotheses were posited in order to answer the three questions mentioned above: 1) those who have achieved horizontal mobility are more likely to perceive themselves as Americans than those who have not achieved horizontal mobility; 2) those who feel societal hostility are likely to have stronger ethnic ties and are also more likely to perceive themselves as Japanese than those who do not feel societal hostility; 3) those who perceive themselves as Americans are more likely to choose exogamous marriage with whites than those who perceive themselves as Japanese; and 4) there is a difference between the second and the third generation in achieving upward mobility and horizontal mobility, and in perceiving themselves either as Japanese or as Americans.

The second generation were chosen as the first sample from the member lists of Japanese American organizations in the Portland area, then their children conveniently became 
the second sample.

All except the second hypothesis were verified. However, there was no correlation between ethnic ties and socioeconomic status, and there was a positive correlation between societal hostility and socioeconomic status. The findings revealed that the second generation whose social interaction pattern was mainly with Japanese Americans rather than whites have not achieved "structural assimilation." In contrast, the third generation have achieved both "structural" and "marital assimilation."

In comparing the differences between the second and third generation in "identificational assimilation," the second generation have Japanese-leaning identity, the third generation have American-leaning identity. Yet, the third generation have not achieved one hundred percent American identity. They are aware of the fact that Japanese Americans sometimes become a target of irritation on the job whenever the relationship between the United States and Japan is aggravated. Both the second and third generation see the connection between them and the country where their ancestors came from.

This study indicated that it may take a few more generations for Japanese Americans to be fully incorporated in this society. 
THE DEGREE OF ASSIMILATION OF THE SECOND

AND THIRD GENERATION OF JAPANESE AMERICANS

IN THE PORTLAND AREA

by

HISAKO MATSUO

A thesis submitted in partial fulfillment of the requirements for the degree of

\author{
MASTER OF ARTS \\ in \\ SOCIOLOGY
}

Portland state University

1989 
TO THE OFFICE OF GRADUATE STUDIES:

The members of the Committee approve the thesis of Hisako Matsuo presented June 29, 1989.

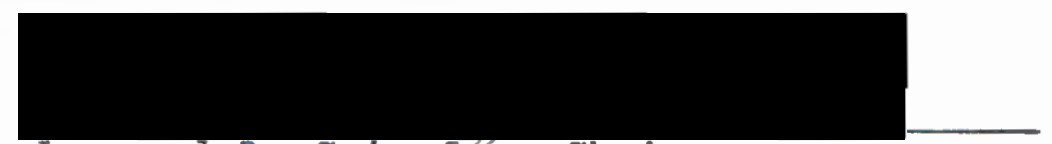

Leonard D. Cain JP., Chair

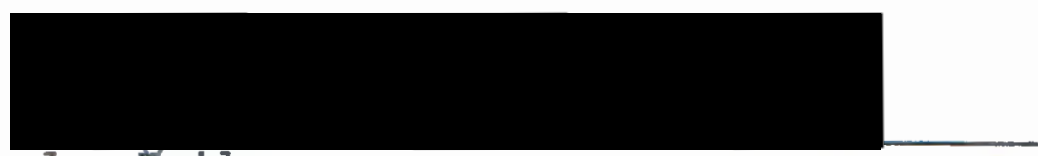

Jan Hajda

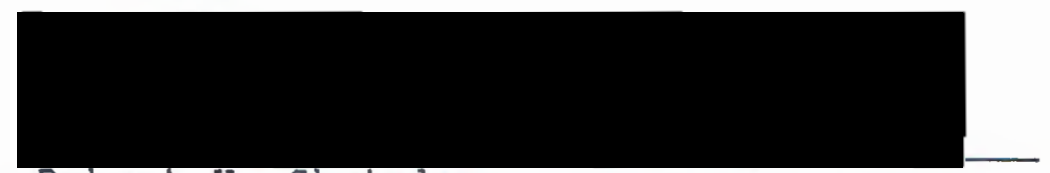

Robert W. Shotola

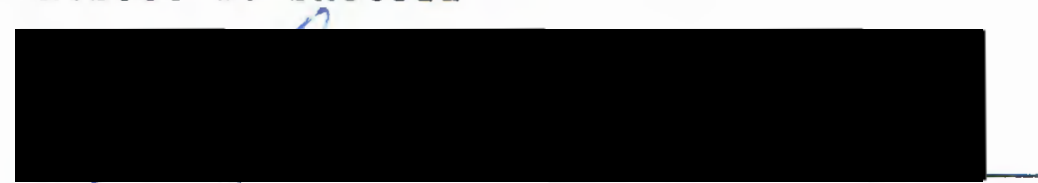

Me'l Gurtov

APPROVED :

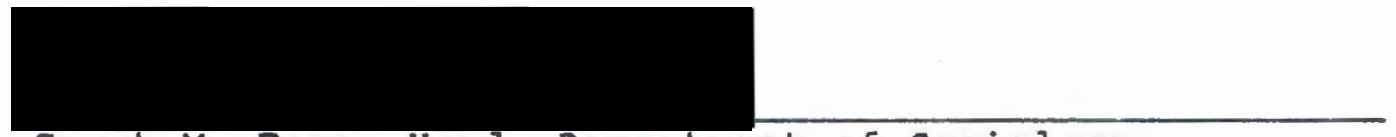

Grant M. Farr, Head, Department of Sociology

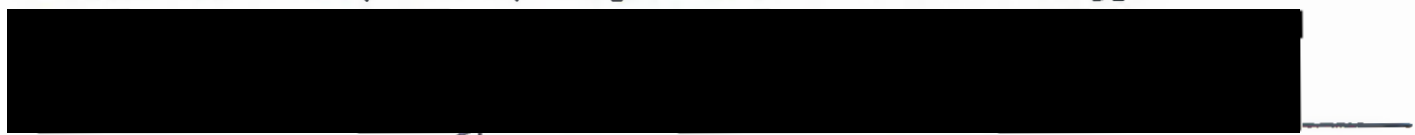

C. William SaverX Interim Vice Provost for

Graduate studies and Research 
THIS STUDY IS DEDICATED TO RACIAL MINORITY GROUPS 


\section{ACKNOWLEDGMENTS}

This study would have been impossible without the help of the members of my thesis committee -- Dr. Leonard D Cain, Dr. Jan Hajda, and Dr. Robert $M$. Shotola. The writer would like to express heartfelt appreciation to Dr. Cain, who served as Chair of the thesis committee, for his thoughtful advice and for his elaborate proofreading which must have taken hours and hours. The writer would also like to thank Dr. Hajda, who was my graduate adviser, for his kind instructions and intellectual stimuli throughout my graduate study, which have greatly influenced my theoretical perspective. My debt also goes to Dr. Shotola, who has trained me in methodological knowledge and skills not only for this thesis but also throughout my graduate study. I would also like to thank the Department of Sociology for its material and nonmaterial support throughout my graduate study. However, I must point out that I am solely responsible for any mistakes found in this thesis.

Many individuals have contributed to this study. The writer gratefully acknowledges:

sister Mary Chewning, who has provided vital insight and information pertaining to this study for two years; Mr. George I. Azumano, who gave me historical insight on 
Japanese American community in the Portland area and made some suggestions in constructing the interview schedule and the questionnaire; Mr. Michael Irinaga, who helped me collect membership lists of Japanese American organizations and provided important information in many aspects; leaders of Japanese American organizations, who kindly provided membership lists which made this study possible; and Ms. Bahar M. Jaberi, Ms. Kathy Tharp, Mr. Alex Lim, and Mr. John Sheley, who offered me both material and nonmaterial help. I would also thank First Christian Church for its cooperation during the period of this research.

My appreciation also goes to Mr. Gerald Kopta and Mrs. Shirley Kopta, who have extended warm support during my stay in Portland for two years.

It should be emphasized here that but for kind cooperation of the second and third generation Japanese Americans who participated in the research project, this study could not have been accomplished. I would especially like to express my appreciation to the interviewees for their candid opinions about race relations in this society.

Last but not least, I am grateful to my parents for their love and warm support during their daughter's graduate study in the United states.

Hisako Matsuo

Portland, Oregon

July 1989 
TABLE OF CONTENTS

PAGE

ACKNOWLEDGMENTS

LIST OF TABLES

viii

CHAPTER

I

INTRODUCTION • • • • . • . . . . . . . . . 1

statement of the Problem . . . . . . . . 1

Reconsideration of

Assimilation Theory . . . . . . . . . . . . 4

Definition of Assimilation

Adopted for This study. . . . . . . . 15

I I STUDY OF JAPANESE AMERICANS . . . . . . . . . . . 19

Conveniences of study . . . . . . . . 19

Historical Background. . . . . . . . . . 21

Geographical Distribution... . . . 25

Heterogeneity of

Japanese Americans. . . . . . . . . 27

Interpretation of "Middleman-

Minority Theory" . . . . . . . . . . 29

Dynamics of Ethnic Identity . . . . . 35

II I STUDY HYPOTHESES . . . . . . . . . . . . . . . 39

Major Domains in This Study. . . . . . 39

Hypotheses . . . . . . . . . . . . . . 41 

METHODOLOGY . . . . . . . . . . . . . . . . 50

Operational Definition of . . . . . . 50 the Variables

Sample . . . . . . . . . . . . . 55

Data Collection........... . 61

Data Analysis Procedure . . . . . . 62

Characteristics of the Samples. . . . . 63

V FINDINGS . . . . . . . . . . . . . . 69

Variables to Measure Ethnic Identity . . 69

Verification of the First Hypothesis. . 72

Verification of the Second Hypothesis . . .81

Verification of the Third Hypothesis . . 90

Verification of the Fourth Hypothesis. . 107

VI CONCLUSION AND FURTHER STUDY . . . . . . . . 131 ENDNOTES . . . . . . . . . . . . . . . . . . . . . . 140

REFERENCES . . . . . . . . . . . . . . . . . . . . 143 APPENDICES
A THE NISEI AND SANSEI'S SOCIOECONOMIC STATUS
B INTERVIEW SCHEDULE AND QUESTIONNAIRE . . . . . 154
C CODING GUIDE . . - 188 


\section{LIST OF TABLES}

PAGE

TABLE

I Correlations among Variables to Measure Ethnic Identity . . . . . . . . . 70

I Correlations Between Ethnic Ties, Ethnic

Identity, and socioeconomic status . . . 73

II Correlations Between Societal Hostility,

Ethnic Ties, and Ethnic Identity . . . . . 82

IV Correlations Between societal Hostility

and Socioeconomic status . . . . . . 86

V Correlations Between Ethnic Preference

In Marriage and Ethnic Identity . . . . 93

VI Correlations Between Ethnic Identity,

Opinion about Children's Socialization,

and Opinion about Marriage . . . . . . 96

VII Correlations Between Ethnic Preference

in Marriage and Ethnic Ties

(The Sansei Sample) . . . . . . . . . . 98

VIII Correlations Between Ethnic Preference

in Marriage and Socioeconomic status . . 100

IX Correlations Between Ethnic Preference

in Marriage and Societal Hostility . . . 102 
$X \quad$ Difference Between the Nise $i$ and the Sansei in Education, Occupation, and Income.. 108

XI Difference Between the Nisei and the Sansei

in Socialization in School Days . . . 111

XII DIfference Between the Nisei and the Sansei

in Discrimination . . . . . . . . . 113

XIII Difference Between the Nisel and the Sansei

in Formal Ethnic Affiliation... . . 115

XIV Difference Between the Nisei and the Sansei

in Social Interaction . . . . . . . . 116

XV Correlations Between Nisei and Sansei's

Socioeconomic status and Their close

Frlends' Socioeconomic status . . . . 118

XVI Difference Between the $\mathrm{N}$ isei and the Sansei

in Opinion about Chlldren's Socialization

and about Marriage. . . . . . . . 119

XVII Difference Between the Nisei and the Sansei

In Ethnic Identity . . . . . . . . . 123

XVIII Correlations Between Age Factors and

Societal Hostility and Identity

in the Sansei Sample... . . . . . 126

XIX The Nisei and Sansei's

Socioeconomic status... . . . . . 151 
CHAP TER I

\section{INTRODUCT I ON}

\section{STATEMENT OF THE PROBLEM}

It has been over two hundred years since the United states of America became independent, and now she is one of the most influential countries in the world. Although the United states was established under the spirit of freedom and equality, there still exist gender, class, ethnic, and racial stratifications. Race relations is one of the crucial issues in studying the power balance between the minority groups and majority in political, economic, and other dimensions of society. The United States experienced a massive flow of immigrants a century or so ago. A second massive flow of immigrants, from Latin America and Southeast Asia, is currently in progress. On the one hand, these immigrants from both flows, and other immigrants as well, may have had difficulty in adapting themselves to the new culture. On the other hand, the dynamics of their assimilation has a continuously great impact on American society.

There are several different perspectives on the ethnicity of this country. Israel zangwill (1914) called 
this country a "melting pot" in his play. In the early 1920's, Chicago School sociologists, led by Robert E. Park, first sociologically analyzed the process of assimilation. Park and his colleagues apparently were influenced neither by European theories of race relations nor by social Darwinism (Omi and winant 1986:1-6). Milton Gordon (1964) described the mixture of races of this country as "ethclass," "which is based on race, religion and national origins, criss-crossed by class stratification" (pp.51-54). George stewart (1954) explained the assimilation process using the concept of "transmuting pot," in which "the foreign elements were not merely melted but vere largely transmuted..." (pp.23-25). However, there are counter arguments to these theories; Ruby Jo Reeves Kennedy (1952) posited the notion of "triple melting pot" based upon religious divisions (pp.56-59), and Gordon (1964) also argued the possibility of "cultural and structural pluralism" (p.75). Although the melting pot has been the main theme of assimilation theory in sociology, it is significant to reconsider this concept by studying the assimilation process of different ethnic groups.

Park (1950) predicted minority groups will be assimilated into the dominant culture of the host society over time through accommodation. However, the speed and degree of assimilation among ethnic groups have varied because of their different physical and cultural traits. 
Furthernore, conflict in varying degree between the minority groups and majority has been recurrent. Makoto Tsuruki (1976), identifying American society as a "mosaic" which consists of different colors, argued that although different colors find their own niches in the picture, it has been whites who have decided the location of each color in constructing the whole image of American society. He also argued that there has existed historically a communication gap between the minorities and majority because the latter takes its power over the minority groups for granted (pp. 212-215) .

This thesis is a case study of the assimilation process of minority groups; it focuses on the degree and process of assimilation of Japanese Americans, who have been identified as one of the most successful minority groups in this country. Many studies of the assimilation of Japanese Americans are based upon "middleman-minority" theory which emphaslzed high achievement of socioeconomic status (Blalock 1967; Bonacich 1973; Kitano 1976; Light 1972). There are some other studies based on the data collected by J.A.R.P. (the Japanese American Research Project) at UCLA in 19641966 (Bonacich 1980; Montero 1980; Woodrum 1978, 1987). They mainly focused on socioeconomic status, exogamous marriage rate, and geographical dispersion, and concluded that emphasis on education and departure from ethnic communities led to upward mobility, and as a consequence, 
to further assimilation (Bonacich 1980:255-259; Montero $1980: 85-88)$.

My major concerns in this study are: 1) the extent to which both the second and third generation of Japanese Americans are assimilated into American society; 2) how far the third generation are assimilated compared to the second generation; and 3 ) what the identity of the second and third generation are. I exclude the first generation because most of them are very old, and it is difficult to obtain empirical data from them. I also exclude the fourth and fifth generations because these cohorts are not mature enough to measure the socioeconomic achievement and the attitude toward interracial marriage. Hereafter, I will frequently use Japanese terms "Isse $i, "$ "Nisel," and "Sansel" which are equivalent to the first, second, and third generation immigrants respectively.

\section{RECONSIDERATION OF ASSIMILATION THEORY}

The race relations cycle which takes the form, to state it abstractly, of contacts, competition, accommodation and eventual assimilation, is apparently progressive and irreversible. Customs regulations, immigration restrictions and racial barriers may slacken the tempo of the movement; may perhaps halt it altogether for a time; but cannot change its direction; cannot at any rate, reverse it (Park 1950:150; emphasis applied).

It is typical to predict that when different cultures encounter each other, there emerge conflicts among them. 
Culture includes not only behavioral patterns of the people within the community but also philosophy, art, morals, and formal laws. Park (1950) argued that all these different cultural patterns will be accommodated and, as a final product, minority cultures will be totally assimilated into a host culture. The speed and degree of assimilation vary among races because of the difference of visibility and cultural traits (pp.740-762). However, does Park's assimilation cycle explain all the race relation patterns of this country? For example, although blacks and Asians are both visible, the latter are less suborainated and are in the higher stratum in the society in spite of the shorter period of stay. In contrast, Hispanics are in a lower position along the socioeconomic hierarchy than Asians even though the former are less visible than the latter. Therefore, it may be argued that one cannot employ only one theory to analyze the assimilation process of different races.

Lyman (1968) criticized Park's cycle because "Park did not carry out any full-scale study of ethnic groups to see whether his cycle approximated reality." Lyman argued that "Although often regarded as a theory, Park's cycle is most fruitful if regarded as a model. It fails as a theory because of its built-in unfalsifiability. ... It has been the fate of Park's cycle to be treated as a theory and, as such, to be regarded as empirically unvalidated and 
theoretically unsound" (Lyman 1968:16-18). Lyman cited several arguments about Park's cycle; either isolation, subordination, or fusion were final outcomes (Brown 1934). An often advanced hypothesis is that it takes three generations for immigrants to complete the cycle (Matsuoka 1946). Groups are either in conflict or accommodation or assimilation (Etzioni 1959). However, Lyman sees the usefulness of the cycle, identifying it as Weber's "ideal type," in its ability to provide a basis for constructing hypotheses (Lyman $1968: 20-22$ ).

Park's cycle of contact, competition, accommodation, and assimilation does provide a guideline to analyze the past history and present status of Japanese Americans. Kitano stressed that the adaptation of Japanese Americans to this country conforms to Park's cycle (Kitano 1976:200). For example, Japanese first came to this country as sojourners. They were faced with immigration restrictions and racial barriers including the subsequent internment during World War II. However, when two successive generations are compared, Nisei are more assimilated than Issei in that $N$ isei's behavioral patterns, value system, and socioeconomic status are closer to those of the members of the host society (Bonacich 1980:157-161, 224-226; Kiefer 1974:95-129; Kitano 1976:122-137). Shall one, then, conclude that Japanese Americans are at the final stage of Park's cycle: total assimilation? 
Gordon (1964:68-72)) set the hypothetical situation in which immigrants come to a host society, which is homogeneous in race, culture, and religion, and analyzed the assimilation process using seven variables: 1) cultural or behavioral assimilation (change of cultural patterns to those of host society), 2) structural assimilation (largescale entrance into cliques, clubs, and institutions of host society, on primary group level), 3) marital assimilation (large-scale intermarriage), 4) identificational assimilation (development of sense of peoplehood based exclusively on host society), 5) attitude receptional assimilation (absence of prejudicet, 6) behavior receptional assimilation (absence of discrimination), 7) civic assimilation (absence of value and power conflict). In doing so, he made a distinction between "acculturation" (change of cultural behavior) and "structural assimilation." For him, final assimilation is the stage in which "the immigrant is able to function in the host community without encountering prejudiced attitudes or discriminatory behavior" (Gordon 1964:63). Neither do these seven stages of assimilation take place continuously, nor is the degree of achieving assimilative parity in each of the seven categories the same for different groups of people. For example, blacks have achieved cultural and civic assimilation with some conditions but have not achieved the five other variables. Jews have achieved cultural, behavioral, and civic assimilation with some 
conditions but have not achieved the four other variables $(\mathrm{pp} .76)$

If one applies Gordon's assimilation process to the study of Japanese Americans, what variables have they achieved? As many studies show, Japanese Americans have achieved cultural ar behavioral assimilation and structural assimilation as well (Bonacich 1980; Connor 1977; Kitano 1976; Petersen 1971; Tsuruk1 1976). Civic assimilation has mostly been achieved except for the issue of "war reparation" which has been a concern for the group for more than four decades. Marital assimilation has partly been achieved; the rate of interracial marriage of sansei Japanese Americans is about 40 percent (Lee and Yamanaka 1987; Montero 1980). As to the three remaining variables -identificational, attitude receptional, and behavior receptional -- there are very few empirical data.

Since Gordon's assimilation theory is also based upon an "ideal type," one cannot be dependent on this theory without any reservations. However, the theory is useful to study the assimilation process of Japanese Americans when the objective of study is to get a thorough knowledge of the degree of assimilation of the group.

Based upon the theoretical assumptions of Park's assimilation cycle and Gordon's assimilation processes and the empirical data which dealt with assimilation of different races, one may conclude that minority groups are 
assimilating into a larger society over time even though the speed and degree vary because of internal variables (visibility, cultural traits, or aspiration to assimilate) and external variables (acceptance of host society, immigration law, or international circumstances). The question remains; assimilation to what? To answer this question, it is worth mentioning that Gordon made an effort to relate his seven variables to two, possibly three, sets of outcomes:

We now have a model of assimilation with seven variables which can be used to analyze the assimilation process with reference to either of two variant goal-systems: 1)nadaptation to the core society and culture," and 2)the "melting pot." Theoretically, it would be possible to apply the goal-system of "cultural pluralism" as well (Gordon 1964:75).

"Adaptation to the core society and culturen by leaving ethnic culture is called the "Anglo-conformity" theory. All the ethnic groups would renounce their ancestral culture and merge into the main stream of American culture which is basically English-oriented. Although the Idea of Angloconformity is sometimes related to racism, not all supporters of the idea are racists. Therefore, "regardless of superiority or inferiority, since English culture has constituted the dominant framework for the development of American institutions, newcomers should expect to adjust accordingly" (Gordon 1964:103-104). 
On the one hand acculturation is an important variable for Anglo-conformity; on the other hand it does not necessarily lead to further assimilation of ethnic groups. Although interethnic contacts often take place in secondary groups which include both employment and political involvement in a larger society, such contacts are impeded at primary socialization. Therefore, if "structural assimilation," which is the key variable to bridge acculturation and interethnic contacts, does not take place, the assimilation through Anglo-conformity is not likely to occur. Similarly, interracial marriage would seldom take place (Gordon 1964:110-114).

If the Idea of Anglo-conformity is expressed in the formula $A+B+C=A$, where $A, B$, and $C$ represent different ethnic groups and $A$ the majority group, the idea of melting pot is expressed in the formula $A+B+C=D$, where $A, B$, and $C$ represent different ethnic groups and $D$ the new culture which is the result of amalgamation of all the ethnic groups (Newman 1973:53-66). The melting pot theory assumes that all the different ethnic groups influence each other depending upon the size or power of each group, and there emerges a new culture which incorporates segments from all the ethnic groups; English, Italian, German, Norwegian, Mexican, Chinese, Japanese, and other ethnic groups are totally amalgamated through interracial marriage over time, and these different groups have neither prejudice nor 
discrimination toward each other. Although the melting pot theory was dominant until early this century, the idea has stirred controversy among scholars (Glazer and Moynihan 1963; Hirschman 1983; Kennedy 1952; Lyman 1968; Morgan 1981; Newman 1973; stewart 1954). Gordon also criticized the idea because it is hardly distinguishable from Angloconformity at one extreme of interpretation (Gordon 1964:125). One of the recent caustic remarks on this theory comes from Hirschman (1983). He reassessed the state of the assimilation paradigm and argued that the concept of melting pot was used to legitimize the ideology of American society as a land of opportunity:

The melting pot was also a central element in the development of the assimilation school of race and ethnic studies in American sociology. The progressive social view of some scholars coincides with the theory positing that race/ethnic divisions would eventually disappear, or at least be minimized, in industrial society. More than ideology, this was an attempt to develop a scientific thesis that would guide empirical research. The coincidence of the effort to reject the ideological hegemony of social Darwinism and the early emphasis on the empirical study of assimilation was not accidental, but it would be a mistake to judge the origins of assimilation theory as a simple product of liberal sentiment (Hirschman 1983:398).

Both Anglo-conformity and melting pot theory can be applied to explain the assimilation of immigrants from Europe, but these theories have left out other ethnic groups identified as "racial minorities" such as Negroes, Indians, 
Hispanics, and Asians. For example, the prediction of Marx and Engels, which argued the decline of racial and ethnic division in modern industrial society, is inadequate (Beck, E.M., Horan, Patrick M., and Tolbert II, Charles M. 1980: 113-130; Omi and winant 1986:9-24; Willhelm, sidney $M$. $1980: 98-112)$.

In challenging "Anglo-conformity," Kallen (1924) reexamined American democracy and used the term "cultural pluralism." He stressed the importance of equality which is an ideology of this country and argued the freedom to preserve cultural identity of each ethnic group. While he was opposed to the segregation of minority groups, he was also opposed to the dissolution of ethnic ties. The idea of cultural pluralism is expressed in the formula $A+B+C=A$ $+B+C$, where $A, B$, and C represent different ethnic groups (Newman 1973:67). Blacks, Indians, Hispanics, and Asians, this theory suggests, all contribute to the American society while preserving their own cultural traits and ethnic identities. Therefore, if one sees American society as culturally pluralistic, some ethnic groups which maintain their own cultural traits as well as ethnic identity should not be identified as unassimilable. Lyman argued:

One specific error, committed by friends and foes of Park alike, is to equate assimilation with fusion, or a "melting pot" and to regard the continuing existence of identifiable ethnic groups in America as a sign of non-assimilation. ... if maintenance of ethnic group identity is a 
culturally permissible alternative, then a people who persist in endogamy and who maintain or establish those ancillary institutions necessary to insure endogamy are not necessarily unassimilated by those practices (Lyman 1968:21).

Cultural pluralism has also received criticism (Glazer and Moynihan 1963; Gordon 1964; Morgan 1981; Newman 1973). Gordon, applying the seven varlables of assimilation, questioned the feasibility of such a pluralistic society in which identificational and attitude receptional assimilation take place without cultural and structural assimilation. He further argued that American society manifests "structural pluralism" rather than "cultural pluralism," because "the structurally separate subsocieties of the three major religious and the racial and quasi-racial groups" are still salient (Gordon 1964:157-159). Mannheim called the idea of cultural pluralism "conservative utopia" because the idea sees the present and future through the distant past; "Kallen put too much emphasis on ethnic origin, and he is bound by the spirit of American democracy" (Mannheim 1929:206-215). Morgan argued that pluralists, by using the word "culture," separate minority people from majority in order to "extend inequalities already present" (Morgan $1981: 54)$.

The advocates of pluralism may be considered ideological shotgun riders in that they are providing cover for the separatist position by assuring theoretical and ideological justification for separation (Morgan 1981:54). 
Other arguments on the assimilation theory come from "subordination theorists" (Blauner 1972; Bonacich 1972; Hirschman 1980; Woodrum 1978). Blauner (1972), using the term "third world groups," argued that ethnically diverse societies develop through either colonialism, immigration, or combination of both. There are three assumptions upon which the concept of colonialism rests. First, racial minority groups in the United states are colonized people. Second, all these groups share the same experience of oppression. Third, "there is a historical connection between third world abroad and the third world within" (pp.51-52). For example, native Americans, Chicanos, and blacks best fit the colonial model. Chinese and Japanese, although their entry to this country was voluntary, were faced with the exclusion of Asians and the restriction acts which limited their numbers and potential power. Therefore, they fit the model of combination of colonialism and immigration (pp.53-56). Similarly, Japan's economic success and the high socioeconomic achievement of Japanese Americans support the third assumption of colonialism (p.73).

So far, I have compared several different perspectives on the assimilation of ethnic groups. The assimilation theories are still paradigmatic, and none of them can generalize the dynamics of race relations of all the ethnic groups. "Contact" between two different groups is followed by "competition" over scarce resources, and the competition 
in industrial society becomes the issue of racial differentiation in the labor market. Consequently, there arises a question about whether racial inequality, if it still exists, is the "cause" of differentiation in the political, economic, and educational arena, or whether it is the "outcome" of exploitation of the subordinates by the people in power.

In this study, the writer takes the perspective of subordination theorists in order to inquire how Japanese Americans are treated in this society, whether they are one of the minority groups only because of their small population or whether they remain subordinated, especially to whites. In addition, there is curiosity about how Japanese Americans relate their ethnic background to the status of Japan, where their ancestors came from.

DEFINITIONS OF ASSIMILATION ADOPTED FOR THIS STUDY

The term "assimilation" is defined in many ways by different schools of thought. There are other terms that explain the process or stage of race relations: acculturation and accommodation. Some use assimilation and accommodation synonymously. Others talk of assimilation and refer to acculturation. It is worth noting here the definition of these terms by Park and Burgess (1921:138, 735): 
Assimilation is a process of interpenetration and fusion in which persons and groups acquire the memories, sentiments, and attitudes of other persons or groups, and, by sharing their experience and history, are incorporated with them in a common cultural life.

Accommodation has been described as a process of adjustment, that is, an organization of social relations and attitudes to prevent or to reduce conflict, to control competition, and to maintain a basis of security in the social order for persons and groups of divergent interests and types to carry on together their varied lifeactivities.

Acculturation is the process by which one group or people learns from another, whether the culture or civilization be gotten by imitation or by inculcation.

Johnston (1969) criticized some previous definitions of the term because the children of immigrants had been treated only instrumentally to show the slow assimilation rate of their parents (pp.1-4). In his study of the second generation Polish immigrants in Western Australia, Johnston (1965, 1969) made a distinction between "external assimilation" and "subjective assimilation."

Assimilation is defined here in terms of external and subjective assimilation. External assimilation implies the immigrant's lesser distinguishability from members of the host group. ... subjective assimilation denotes the immigrant's psychological identification with Australians in areas which initially set them apart. ... There may therefore be immigrants who are only subjectively assimilated, those who are only externally assimilated, those who are both subjectively and externally assimilated and those who are not assimilated in either respect (Johnston 1969:5). 
Parenti (1970) distinguished "cultural system," which includes beliefs, values, norms, symbols, and ideas, from "social system," which includes interrelations and associations among individuals and groups. He also argued the importance of "identity assimilation" because implanted ethnic awareness through kinship persists even if social assimilation at primary and secondary level progresses (PP. $66-78)$.

Kitano (1976) argued that, in the case of Japanese Americans, the strategies to adapt in this society "followed the lines of least resistance, avoided direct confrontation. It is basically a strategy of accommodation." He further raised a question as to whether the consequence of accommodation is a total assimilation (PP.2-3).

Kiefer (1974) made a distinction between acculturation and assimilation in the study of Japanese Americans, arguing that while assimilation emphasizes behavioral changes of both minority groups and the members of the host society, acculturation emphasizes the learning process, by minority groups, of skills and values of the host culture (P.86).

Others define acculturation as one of the subprocesses of assimilation (Cain 1962; Gordon 1964; Kitano 1967). Cain noted :

... although a number of studies confirm the idea that the second, and surely the third, generation Japanese-Americans have become acculturated, it is also quite apparent that they, at least from the 
perspective presented by Broom and Kitsuse, have not become fully assimilated (p.115).

In this study, the writer defines assimilation of Japanese Americans in the United States as:

A state in which both Japanese Americans and whites share the sense of "oneness" without having any prejudice, discrimination, or antagonism because of racial differences, and as $a$ consequence, members of both historically distinctive groups perceive themselves to be equally members of a single, united in-group which strives for the same goals and exhibits common interests. 
CHAPTER I I

STUDY OF JAPANESE AMERICANS

CONVENIENCES OF STUDY

For social scientists, the study of Japanese Americans provides two major conveniences; 1$)$ a generational perspective is applied to analyze different stages of assimilation, and 2) a chronological perspective divides the group of Japanese Americans into four categorles: the immigration period (1890-1924), the prewar period (19251941), the evacuation period (1942-1945), and the post war period (1946 to present) (Kitano 1976:9). What is distinctive, in American history, about the Japanese immigration is that Issei came during a short and distinctive span of time, then immigration was blocked. Nisei were born during a rather distinctive span of time, and even Sansei can be fairly well defined by span of years of birth. So the three generations are also rather discrete birth cohorts, and provide a special "convenience" for researchers; Issei were born in Japan between approximately 1870 and 1890 , Nise 1 were born in the United states between approximately 1910 and 1930, and Sansei between 1940 and 1970. There are also distinctive differences among 
three generations, Issei, Nisei, and Sansei, in the achievement of socioeconomic status, the integration with whites, the change of cultural and behavioral patterns, and intermarriage with whites. Therefore, the group of Japanese Americans becomes a model to study Gordon's seven variables of assimilation process (Kitano 1976:8-10).

In his study of Japanese Americans, Kitano (1976) used this generational analysis as the third variable, in addition to Gordon's "ethclass" concept which consists of two variables, ethnicity and class. Kitano termed his analytical framework "eth-gen-class":

Eth-gen-class terms have overlapping functions. Each refers to an identity: an ethnic identity -"I am Japanese"; a generational identity -- "I am an Issei (first generation)"; and a social-class identity -- "I am middle-class." ... Thus, the variables of identity, social structure, and culture interact with those of eth-gen-class. ... By looking at the interaction among these three variables, it may be possible to analyze Japanese behavior more precisely than would be possible by using these variables independently (Kitano 1976:51.

Japanese Americans comprise the only minority group which has experienced collective internment in the United states, during World War II. The only remotely similar experience of a minority group is the sporadic effort to relocate Native Americans on to reservations, mainly during the nineteenth century. Japanese Americans have also experienced the civil rights movement, and their communities 
have gone through distinctive political and economic, as well as social changes in the adaptation to capitalism of American society. In the meantime, Japan, which had been destroyed in the war, has achieved remarkable recovery and has emerged as an economic power in the world. Resurrection of "anti-Japanese sentiment" of recent years, caused by trade frictions between the United States and Japan, reminds many of aggravated relations of these two countries during the war time. Therefore, it is also meaningful to study how these historical and cyclical incidents influence the assimilation process of Japanese Americans and the establishment of their identity.

\section{HISTORICAL BACKGROUND}

In the mid $1850^{\prime} s$, the state of California was faced with the problem of Chinese immigrants which occurred after the discovery of gold. The governor of California was afraid that they would overrun the state by providing cheap labor in railroad construction, small businesses, or agriculture; because their main purpose of immigration was Eor money; and because they were deemed to be unassimilable. The problem of Chinese innigrants was solved by the Chinese Exclusion Act in 1882, which was designed to exclude Chinese from immigrating to this country. After this legislation, the Japanese immigrants were substituted as employees, mainly for the purpose of the continuation of the 
development along the West Coast (K1tano 1976:15-16).

The Immigration of Japanese started around 1885. The number of Japanese who came to this country during the first five years or so was about 2,000 . Between 1890 and 1900 , almost 22,000 Japanese came to the American mainland. For white Americans, however, the Japanese, like the Chinese earlier, presented a potential problem of interference in their living. In 1913, the California Alien Land Law was established "to prevent aliens who were ineligible to citizenship from owning land in California." Hosokawa (1969) mentioned that Issei were made the target of the euphemism "aliens ineligible to citizenship" (p.99). However, many Issei were married by this time, and they could place farm ownership under the name of their children (Kitano 1976:18). Finally, immigration from Japan was totally banned in 1924 with the enactment of the "Anti-Asian Immigration Act" (Hosokawa 1969:19-113; Kitano 1976:11-24; Tsuruk1 1976:69-75). Thus, Issei were faced with not only language and cultural barriers but also legislative restrictions, which labeled them "aliens" and hindered their aspiration to assimilate. It was not until Nisel were born within the United States that Japanese Americans began to become full-fledged members of society.

Issel are called "Bamboo" which patiently waits under snow for spring to come, because they were obedient to whites due to political poverlessness. In contrast, Nisei 
are identified as "Banana," because their cultural traits are similar to those of whites even though they have yellow skin color (Tsuruki 1976:118). There are two main points to be discussed in the study of Nisei: 1) achievement of high socioeconomic status, and 2) internment when most Nisei were in their formative, early adult years in 1942-1945. As to socioeconomic status, Nisei Japanese Americans have been successful, compared to other minority groups, in climbing up the social ladder. For example, schmid and Nobbe (1965:909-922), analyzing the Nam scores for socioeconomic status of different ethnic groups (Charles B. Nam 1963), reported that Japanese and whites had achieved the highest scores in income among all the ethnic groups and that Japanese had achieved higher scores in education and occupation than other ethnic groups including whites, Chinese, and blacks. This socioeconomic achievement is attributed to the value system and patience which Issei had implanted in their children. While Issei were bound within their ethnic community, running small businesses, they had encouraged Nisei to get higher education (Bonacich 1980:127130; Kitano 1976:101; Montero 1980:85-88; Petersen 1971:113121). Montero wrote:

The value system of the Japanese encouraged economic success, which is one reason why they came to the United states in the first place. solidly entrenched within the ethnic community, those who did not find suitable employment within the ethnic economy were ready to branch out into 
the larger Anglo society in the search of Einancial success. ... Through hard work and perseverance, alded as well by their value system, which was compatible with that of the American middle class, they soon achieved a measure of financial security. This allowed them to send their children, the Nisei, to universities and other institutions of higher education (Montero $1980: 851$.

The other issue which has impacted heavily on Nisei is the internment during Forld par II. Shortly after Japan attacked Pearl Harbor on December 7, 1941, large scale relocation of Japanese Americans was ordered. About 110,000 Japanese Americans in California, Oregon, and Washington -about two-thirds were United states citizens by birth -were forced to move to ten different concentration camps: Manzanar, Tule Lake (California); Poston, Gila River (Arlzona); Minidoka (Idaho); Heart Mountain (Wyoming); Granada (Colorado); Topaz (Utah); Rohwer, Jerome (Arkansas). Because of political and economic powerlessness, they could not take the risk of moving, through their own initiative, to another part of the country, thereby resisting the order of the American government (Hosokawa 1969:303-336; Kitano 1976:69-78). Kitano analyzes the behavior of Isse1 and Nisei who were obedient to the evacuation order:

The emphasis on norms -- the "how to behave in situations" direction of the Japanese culture -also contributed to their docility. Norms and values emphasizing conformity and obedience meant that those in power (e.g., the U.S. Army) were able to use this position to gain the cooperation of the evacuated population (K1tano 1976:84-86). 
After the war ended, Japanese Americans dispersed; some of them returned to their original residence, and others went to the East coast to start new 1ives. Regardless of the places of settlement after the war, hovever, Japanese Americans continued to meet racial discrimination, in varying degree, until the mid 1960's and beyond.

The issue of war reparations to those who were interned became controversial in recent years. an evacuation claims bill finally passed both the senate and the House in 1988, and the past president of the United states, Ronald Reagan, signed the bill the same year. About 60,000 Japanese Americans, those who were interned and are still alive, are to receive $\$ 20,000$ each (information provided by past president of Portland Chapter, Japanese American Citizens League).

\section{GEOGRAPHICAL DISTRIBUTION}

It is increasingly difficult to determine the population of Japanese Americans living in the United states, because interracial marriage occurs frequently among Sansei, and there are many mixed-blood children. There are also some Japanese, especially so called "war brides," who came to the United states after World War II. According to the U.S. Census of the Population (1980), it is estimated that about 701,000 Japanese americans are living in this country. 
A large number of Japanese Americans were concentrated in Hawail and California until 1920. Although they spread across the country after World War II, there are five core areas where large populations of Japanese Americans are living: Hawail, California, Pacific Northwest, Illinois, and New York. Among those five areas, Hawail, California, and New York contrast in behavioral patterns, cultural traits, and latent conflicts (K1tano 1976:164; Tsuruki 1976:86-113). For example, Tsuruki reported that there is antagonism between Japanese Americans in Hawail and California, and he attributes this group consciousness to participation of the 442nd Regimental Combat Team during World War II. Although Japanese Americans in Hawail experienced the attack on Pearl Harbor, they vere exempted from incarceration. A larger number of Japanese Hawailans were willing to join the American Army. However, Japanese Hawailans had difficulties in communicating with American officers because of their "pidgin" English. As a result, most of the leadership roles in the Combat Team vere given to Japanese Americans from the mainland, which generated antagonism between the two geographical groups (Kitano 1976:165; Tsuruki 1976:83). Another contrast is between Japanese Americans in New York and those in California. Japanese Americans in New York experienced less discrimination, because whites did not see them as poor farmers or gardeners which was the image tovard Japanese Americans in California. Furthermore, there is a 
larger number of Japanese businessmen and diplomats from Japan who are temporarily living in New York than in California. Those Japanese belong to the upper class, and they used to be seen as sojourners who do not cause any trouble to Americans (Kitano 1976:91-93; Tsuruk1 1976:135137). However, the situation has changed in this decade, with an increasing U.S. trade deficit and restrictions Imposed on the U.S. exports to Japan. Japanese, regardless of their residence, have become a source of irritation.

\section{HETEROGENEITY OF JAPANESE AMERICANS}

Although the study of Japanese Americans becomes the model of generational analysis of assimilation, it embraces the complexity of heterogeneity. This is not only because of interracial marriage, which is concomitant with the assimilation process, but also because of the influx of Japanese war brides and other Japanese who immigrated after World War II (Kitano 1976:9-10).

The other aspect of heterogeneity is the differences among Nisei. Basically, there are two different groups: Kibei and Non-Kibel. Kibei are those who were born in the United States and were educated in Japan (Kitano 1976:77-78; Tsuruki 1976:75 130-131). Bill Hosokawa wrote:

They (the Kibei) lived in native Japanese homes and went to Japanese schools. They were reared like Japanese children and were Nisel only in a technical sense. Yet, because they possessed 
American citizenship, they were permitted to return to the United States. ... Unable to find a niche in Nisei society, unable in some cases even to develop warm relationships with Americaneducated siblings because of their completely different interests, they tended to congregate in their own groups. These were the Kibei, a term that has a place along with Issei and Nisei, and they found themselves in a peculiar predicament as World War II approached (Hosokawa 1969:178).

Kibei had difficulties in swearing their "loyalty" to the U.S. government. Some of them were called "No No Boys" because when the Army called on all male Nisei of draft age to fill out questionnaires asking their allegiance to the United states of America, their answers were all "no." Therefore, Kibei, as a group, were seen as the most likely to be disloyal to the U.S. government (Hosokawa 1969:397; Thomas and Nishimoto 1946:84-112). This sense of disloyalty, and the education they received in Japan as well as cultural experience, greatly influenced their values, attitudes, and behaviors (Kiefer 1974:97; Kitano 1976:109; Petersen 1971: 204).

According to Tsuruki, Nisei are divided into four groups; 1) those who have been adjusted to both Japanese and American cultures, 2) those who have been assimilated into American society to a great degree, 3) those who still have Japanese values (most of whom are Kibei), and 4) those who cannot forget the disgraces they experienced during the wartime evacuation and still have an anti-american sentiment (Tsuruk1 1976:130-131). 
It is assumed that Nisei's heterogeneity has, to some extent, been transmitted to Sansei, which may be reflected in differences in the degree of assimilation among the individuals in the third generation. While many sansei are well acculturated and tend to identify themselves as Americans, some Sansei still hold Japanese identity and are susceptible to prefudicial attitudes toward whites.

\section{INTERPRETATION OF "MIDDLEMAN-MINORITY THEORY"}

Japanese Amerleans are called the most successful minority group in the United states because of their higher achlevement of socioeconomic status compared to other minority groups. Several studies of Japanese Americans apply a middleman-minority theory to analyze the assimilation process of the group (Bonacich 1980; Kitano 1974, 1976; Light 1972; Tsuruki 1976). The concept of "middleman minorities" was developed by Blalock (1967:79-84) who argued that although ethnic minority groups usually fill the lower status positions in society, some minority groups find their niches between the higher class and the lower class, and they serve as a buffer between a ruling group and the subordinates. These middleman minority groups play an important economic role; they concentrate in certain occupations such as trading, self-employed small business, and money lender, and they become mediators between producers and consumers, or between employers and employees 
(Bonacich 1973:583-584; Shibutani and Kwan 1965:190-193).

There are several interpretations about middlemanminority theory. Those who focus on economic achievement emphasize success of Japanese Americans in climbing up the soclal ladder (Bonaclch 1980; Montero 1980). Some studies indicate that Japanese Americans occupy more white collar Jobs and less manual work, earn the highest income, with the achievement of highest education next to Chinese among all the minority groups (Schmid and Nobbe 1965:909-922; Tienda and Lil 1987:141-165). The higher achievement along the income and occupational hlerarchy is often explained by Japanese Americans' cultural traits and value system Issei brought at the time of immigration (Bonacich 1980:61; Kiefer 1976:209; Kitano 1976:131-135; Tsuruk1 1976:50, 61). Some of the characteristics of the traditional Japanese value system are thriftiness, hard work, and perseverance, which are compatible with the American value system characterized by the protestant ethio. Therefore, the attitude of Japanese Americans who worked hard for the betterment of their future was accepted by the host culture with little conflict (Klefer 1974:209; Montero 1980:85). Klefer mentioned:

These values, known as the protestant ethic syndrome, were material success, education, cleanliness, honesty, hard work, sobriety, and politeness. The current developmental tasks of the Nisei must be understood in the light of this set of goals, chosen early in their lives and 
gradually dignified by the passage of time $(1974: 209)$.

Another aspect of higher socioeconomic status is educational achievement. On the one hand, Issei strove for the accumulation of wealth within the ethnic communities; on the other hand, they sent their children to colleges outside the ethnic boundaries, which accrued more alternatives for Nisei to choose their occupations (Kitano 1974:512, 1976:101; Montero 1980:85-86). Petersen, analyzing the study by Schmid and Nobbe on "Socio-economic Differentials among Non-white Races" (1965), argued that the main key to material success of Japanese Americans is education (Petersen 1971:113-114).

Considering the original aspiration to assimilate, the length of stay in this country, and the deprivation of property because of the internment during the war, it is remarkable that Japanese Americans have so rapidly achieved higher socioeconomic status. Therefore, they are a very successful minority group in the United states in that context.

In contrast, others emphasize that Japanese Americans are still racially differentiated from the majority of whites (Kitano 1974, 1976; Tsuruki 1976; Woodrum 1981) Although Japanese Americans have risen above the status of other minority groups because of high adaptive capacity, they have never got out of the stratum of middleman in the 
larger society (Kitano 1974:503-504, 1976:199; Tsuruki 1976:46-51). The middleman position, which some minority groups achieve, is attributable not only to their adaptability but also to scarce occupational alternatives; there is "no choice" except finding their niches in middleman's position. Therefore, after achieving the status between the lower class and the upper class, they soon reach a ceiling. Kitano argued:

The barrlers may be self imposed (for example, the group is reluctant to assimilate); but, more often, mobility is limited by a combination of the ethnic group culture and dominant group discrimination. ... Therefore, the minority finds that, although it has arisen above the lower levels, it has been prevented from rising to the top, and has become a iddleman minority (1974:502).

another counter argument comes from racial conflict and subordination theorists, who have stressed economic and political interests and the institutional context of group adaptation (Blauner 1972; Woodrum 1981). Woodrum, analyzing U.S. Census Data, argued that although Japanese Americans' income and occupational mobility have increasingly approximated those of whites, statistics themselves do not suggest an accurate measurement of upward mobility. First, Japanese Americans' median family income is above that of whites according to the Census Data. However, Japanese Americans are concentrated in urban areas such as California, Washington, and New York where the wage 
structure and cost of living are higher than the national average. Second, the proportion of families with multiple wage earners is high among Japanese Americans. Third, when their socioeconomic achievement is compared with that of whites, Japanese Americans receive lower "rates of return" for their education and occupation in the labor market; the index of differentials of Japanese Americans from whites in occupational returns on education, income returns on education, and income returns on occupation are all negative (Woodrum 1981:162-166). Therefore, to acquire the same occupation and the same amount of income as whites, Japanese Americans have to achieve longer education than whites.

other studies emphasize the relationship between socioeconomic achievement and racial composition in the U.S. labor market. While a rise in proportion of minorities in the total population increases minorities' political and economic power, it threatens the majority and leads to the subordination of minorities in the labor market (Bonacich 1980:9-23). Tienda and Lii argued that competition and discrimination in the labor market are more severe among the well educated non-whites than the less educated non-whites, because the former pose greater threat to occupations which were traditionally dominated by whites (Tienda and Lii $1981: 141-1641$.

Finally, some other studies stress political Involvement of middleman minority groups (Chandras 1978:47; 
Kitano 1974:515-516). Citing Gary Hamilton's notion of middleman-minority, Kitano argued that because of their political powerlessness, middleman minorities are restricted to playing certain limited roles in the economic structure (Kitano 1974:502, 513).

For minority groups, one of the conditions to achieve a middleman position in a larger society is "sojourning"; with willingness to endure hard work for a certain period and hope to go back to their homeland after accumulating wealth, some minority groups fit into the middleman class (Bonacich 1973:584-85). When Nisei were born, Japanese Americans were no longer sojourners. Nisei have achieved higher socioeconomic status than Issei, and Sansei are going to find themselves in a higher position in a larger society than Nisei (Montero 1980:86-87).

Looking at the concept of middleman-minority theory from an international perspective, if one employs Blauner's colonization model (1972), both Japan as a nation and Japanese Americans are still in the middleman position. As mentioned in Chapter $I$, the third assumption of the colonization model is the historical connection between minority groups and their mother countries. On the one hand, Blauner argued "... Japanese-Americans are the most successful nonwhite group by conventional criteria, and Japan has been the most economically developed and politically potent non-Western nation during most of the 
twentieth century" (Blauner 1972:73). On the other hand, Kitano (1974), citing the speech by Paul Ehrlich in Tokyo in 1973, warned that "its highly industrialized capacity, coupled with its lack of natural resources, has forced Japan to play the role of economic middleman." similarly, no matter how Japanese Americans have achieved high upward mobility, middlemen are middlemen, unless they get into the upper stratum in a society. The writer then wonders whether this middleman position is a process, for Japanese Americans, to be assimilated into a larger society or a perpetual state in which Japanese Americans are subordinated to whites.

\section{DYNAMICS OF ETHNIC IDENTITY}

There are some theories which explain dynamics of ethnic identity of minority groups (Bennett 1986; Glaser 1958; Hansen 1953; Park 1950; Shibutani 1961; stonequist 19351 .

Glaser (1958) categorized a person's ethnic identity into four patterns: segregating, marginal, desegregating, and assimilated. He argued that social interactions, reference groups, and economic and other rewards, which are key variables in establishing ethnic identity, often lead the second and the third generation of immigrants to marginality (Glaser 1958:31-40). Glaser further mentioned: 
... a person cannot change from a segregating to an assimilated identification pattern without first becoming marginal and then desegregating. However, change can occur in either direction on the continuum. Change from desegregating to marginal to segregating is common (1958:35).

Glaser's proposition is analogous to the "non-linear model" which was employed by Klefer (1974), Kitano (1976) Lebra (1972) in their studies of acculturation of Japanese Americans. Kiefer wrote that most studies of Japanese Americans employ linear model (Hiranouchi 1976; Matsumoto 1970; Maykovich 1972) in the analysis of the process of acculturation (Kiefer 1974:84-85). It is worth citing Lebra's explanation of the differences between linear model and non-linear model:

First, the non-linear model assumes that acculturation generates biculturality, that is the addition of a new culture to the old one, whereas the linear model involves replacement of the old culture by a new one. Second, biculturality in the non-linear model gives freedon of cholce or bicultural repertoire in action; whereas the linear model, bound to the idea of replacement, implies the opposite of freedom, namely, conflict. ... Third, the non-linear model stresses that acculturation processes are contingent upon social environment and therefore should be seen as a Eunction of social relationship, roles, audiences; or as Berreman (1964) perceives, of reference groups. The linear model, on the other hand, seems to take for granted the direct and entire embracement of the individual by a culture (Lebra $1972: 6)$.

According to the linear model, while each generation of Japanese Americans discards old cultural traits, they adopt 
the host's culture, and the successive generations are moving along the continuum from Japanese culture to American culture. In contrast, the non-linear model emphasizes that Japanese Americans have cultural alternatives and shift their own references according to time, place, and situation (Kitano 1976:201-202).

... the coexistence between the Japanese and the American cultures has been successful. Education, productivity, and "Americanism" have been high, and crime, delinquency, and other forms of soclal deviance have been low (Kitano 1976:203).

Although the non-linear model explains the process of acculturation of Japanese Americans, the model is also useful in studying dynamics of ethnic identity, because acculturation is one of the subprocesses of assimilation of minority groups (Gordon 1964:61-83).

Greeley (1974:296-315) and Woodrum (1978:19-22) used the notion of "ethnogenesis" to explain the process of acculturation and establishment of identity of ethnic groups; acculturation is dependent upon the education, experience, and primary and secondary structural relationships of ethnic groups; therefore, although newer generations of immigrants discard some ethnic traits and adopt American culture, they develop distinctive cultural traits which are different not only from the host culture but also from the ancestral culture. Greeley argued that "identification, heritage, and culture apparently 
interrelate in different ways at different times in the natural history of an ethnic group" (Greeley 1974:310).

Certain immigrant characteristics persist, but in addition, under the impact of the experience of American life, some traits become more rather than less distinctive. ... For the ethnics, then, the mix of traits and the emphasis within the cultural system are different from those of their immigrant predecessors. They share more with the common culture than they did to begin with, but in some respects they also may be more different from the descendants of the hosts than their ancestors vere from their hosts. ... For example, if one considers the variable of ethnic consciousness as part of the original immigrant system of traits, that consciousness may well have waxed and waned through the years, moving away from the common culture, then toward it, and away again in zigzag fashion (Greeley 1974:308-309).

If there is a connection between the status of an ethnic group and the advancement of their home country, as Blauner (1972) argued (see p.14 in this thesis), Greeley's ethnogenesis theory well explains how Japanese Americans' ethnic identity changes in the course of historical evolution. 
CHAPTER I I I

STUDY HYPOTHESES

MAJOR DOMAINS IN THIS STUDY

This study is based upon the following assumptions which are derived from the literature review: 1) American society consists of multiple hierarchies (Gordon 1964); 2) members of the third generation of ethnic groups often seek after their ancestral roots, revitalizing ethnic consciousness (Greeley 1974; Hansen 1953); 3 ) there is a historical connection between minority groups and their home countries (Blauner 1972); and 4) the Japanese Americans communities have experienced ethnic homogamy in combination with religious heterogamy (Cain 1962).

Although it is important to study the interactions between Japanese Americans and other minority groups, the emphasis of this study is on the relations between Japanese Americans and the majority of whites. Whites, in this study, are defined as representatives of the host society because of their large population, longer period of stay in this country than any other ethnic groups except for American Indians, and their greater wealth and power.

As the title of this study indicates, assimilation 
embraces several subprocesses as well as different levels (Gordon 1964:61-83). I define five domains in order to posit hypotheses to study the degree of assimilation:

Ethnic identity: this measures self-perception of Japanese Americans, regarding whether they perceive themselves as Japanese or as Americans, and shows the degree of "identificational assimilation."

Socioeconomic status: this indicates the achievement of upward mobility of two successive generations. It also illustrates where Japanese Americans locate themselves along the occupational hierarchy in American society.

Exogamous marriage with whites: this measures "marital assimilation," which accelerates further assimilation because, through interracial marriage, Japanese Americans lose physical visibility.

Ethnic ties: this indicates the degree of "structural assimilation," which is most important for exogamous marriage to occur.

Societal hostility: this includes prejudice, discrimination, and historlcal incidents which impede smooth assimilation of Japanese Americans.

Ethnic identity is defined as the key domain for two reasons: 1) if Japanese Americans perceive themselves as Japanese and feel social distance from the majority of whites, they are not fully assimilated notwithstanding high socioeconomic status and high rate of exogamous marriage with whites, 2) findings from J.A.R.P. data indicated no distinctive differences between Nisei and Sansei in the occupational, cultural, and family structural merger with the host soclety (Woodrum 1978:170-172); therefore, if there 
is a difference between successive generations, it is the identity that each generation estabilshes.

\section{HYPOTHESES}

1) Those who have achieved horizontal mobility are more likely to perceive themselves as Americans than those who have not achieved horizontal mobility.

Horizontal mobility refers to Japanese Americans' social interaction patterns at the primary level. Through large-scale entrance into cliques, clubs, and institutions of the host soclety, on a primary group level, "structural assimilation" takes place (Gordon 1964:71). Although many studies argue that the achievenent of upward mobility with the combination of geographical mobility has led to further assimilation of Japanese Americans into a larger society (Bonacich 1980; Light 1972; Montero 1977; Petersen 1971), upward mobility by achieving higher socioeconomic status and the horizontal mobility by interacting with whites are not always concomitant. Gordon (1964) sees American society as consisting of multiple hierarchies rather than as one vast hierarchical continuum. He noted that although the variables, including economic power, political power, and social status, vary together, "there is always some overlapping or lack of synchronization when large numbers of people are being considered" (p.41). He further stated: 
The precise number of hierarchical status groups on the American scene has been a matter of dispute among sociologists,... My own view is that the idea of broadly conceived status groups gives a better fit to the realities of the American status system than the unbroken continuum theory. These groups do not have hard and fixed boundaries but shade off imperceptibly into each other (pp.41-42).

Gordon (1964) used the term "ethclass," which consists of race, class, and religion; in order to describe the interactions of various subcultures in the United states (pp.50-53). Therefore, what counts in constructing one's image in this country is where he/she locates himself/herself among these three dimensions.

Parenti (1970) also argued that "assimilation involves much more than occupational, educational and geographic mobility" (P.75). Adaptation to the middle-class with increase in income does not necessarily lead ethnic groups to inter-group contacts. Similarly, such inter-group contacts, if they may occur, do not necessarily diminish ethnic consciousness. Therefore, ethnic groups may experience 1) cultural assimilation which includes beliefs, values, norms, and practices, 2) social assimilation which includes soclalization on both primary and secondary level, and 3) identificational assimilation (pp.75-76).

Pavlak (1976) studied "ethnic identification and political behavior" and concluded that even among upwardly mobile ethnic groups, ethnic identification persists (pp. 29-36). Supporting Parenti's three-stage process (1967) of 
cultural, social, and identificational assimilation, Pavlak argued that what has been called assimilation is really acculturation.

Consequently, there arises a question about the difference between "because of" motivation and "In order to" motivation. Did higher education of Japanese Americans lead to the better occupation and higher income which provided more opportunities for contacts with whites? Or did Japanese Americans have no choice except getting better occupation, which was available only by achieving higher education, in order to get out of a lower stratum of society? In other words, was further assimilation of Nisei and Sansei, compared to Issei, a natural consequence of upward mobility ("because of" motivation) or an objective for the group to survive in this country ("in order to" motivation)?

2) Those who feel societal hostility are likely to have stronger ethnic ties and are also more likely to perceive themselves as Japanese than those who do not feel societal hostility.

Prejudice against minority groups is reduced by intimate interethnic contacts between a majority group and minority groups (Allport 1954:261-282; Gordon 1964:235-239). Gordon (1964) argued that even when interethnic contacts take place at the secondary level of socialization, intimate contacts between minority groups and the majority at the 
primary level are held at a minimum (pp.111-112). He also noted that one of the conditions of assimilation is "development of sense of peoplehood based exclusively on host society" (p.71).

Nisei have experienced societal hostility not only because of their physical visibility, cultural traits, or conflict with local labor but also historical incident of the attack on Pearl Harbor and the following mass evacuation (see p. 20 in this thesis). Immediately after the war, Japanese Americans were labeled "dirty Japs," and were placed at the bottom of society. This susceptibility to societal hostility led to communal solidarity among the members of the group (Bonacich and Modell 1980:65-82). Based upon the analysis of J.A.R.P. data, Bonacich and Modell further noted that there is a relation between occupational pattern and ethnic bonds of both formal and informal organizations.

..ethnicity is not an eternal verity but a variable that is responsive to societal conditions, and that one very important condition is the economic position of the group in question. ... Those who moved into the corporate economy had less material reason for retaining close ethnic ties than did those who ran small businesses, and they behaved accordingly (Bonacich and Modell $1980: 257$ ).

Almost all Nisei are now retired after having gone through dynamics of social change of the country. How are their experiences of societal hostility related with their 
social interaction and identity establishment?

Sansei have not experienced severe discrimination as Nisei have. However, there is a resurrection of "antiJapanese sentiment" caused by trade frictions between the United states and Japan. Does this historical incident in this decade have an influence on smooth assimilation of Sansei?

3) Those who perceive themselves as Americans are more likely to choose-exogamous marriage with whites than those who perceive themselves as Japanese.

The major objective of this hypothesis is to study the correlation between self-identity and exogamous marriage and the pattern of mate-selection, rather than to explain causality of a Japanese American's marrying a white.

The outmarriage rate of Japanese Americans has been gradually increasing since the end of World War II. For example, Tinker (1973:55) reported a 49 percent outmarriage rate of Japanese Americans in Fresno County in 1971. Kikumura and Kitano (1973:69) also studied the data from the Marrlage License Bureau, Los Angeles County, and reported a 47 percent outmarriage rate in 1971. Montero (1980:54-55), analyzing J.A.R.P. data, concluded that while the outmarriage rate among $N i s e i$ is about 10 percent, it is almost 40 percent among Sansei.

Intermarriage between whites and Asians was 
proscriptive until antimiscegenation laws were nullified in 1948, through a U.S. Supreme Court decision. Prohibition of intermarriage had kept the racial group boundaries distinct; therefore, the increasing rate of outmarriage with whites indicates that Japanese Americans have achieved horizontal mobility (Tinker 1973:50-51, 64).

a general principle of outmarrlage is that the males of a minority group outmarry more frequently than the females (Barnett, 1963:107). In the case of Japanese Americans, females were more likely to outmarry than the males until the 1960's, but this tendency has disappeared since then (Tinker 1973:60). The pattern of mate selection is governed by the norms of each group which are derived from their distinctive cultures, and these norms are subject to change over time. However, mate selection is also influenced by certain conditions: size of groups, sex composition, and opportunity for contact with other racial groups. Therefore, the actual marriage practices are the result of the combination of norms of each group and some conditions under which a specific group is situated (Blau, Blum, and Schwarts 1982:45-61; Kikumura and Kitano 1973:72-75; Merton $1941: 361-364)$

When, with a changing social structure, the functional significance of certain norms governing choice of a spouse diminishes, the antagonism toward violation and finally the norms themselves will tend to disappear. When the in-and outgroups are in fact progressing toward social and 
cultural assimilation; when pathways for group consolidation are established; when a considerable part of the population is alienated from traditional group distinctions; when social mobility is notably high; when physical and cultural marks of group distinction have largely disappeared and group "differences" persist merely as a matter of purely technical definition ... (Merton 1941:363-364).

In testing this hypothesis, it is also significant to gain thorough knowledge of mate selection, because if this hypothesis is tested, those who perceive themselves as Japanese have a difficulty in finding a spouse because of limited alternatives. They might marry Japanese born in Japan, non-Japanese Orientals, or they marry whites simply because of no cholce.

Cain (1962) raised a question of religious intermarriage among Japanese Americans; Japanese American communities have experienced ethnic homogamy in combination with religious heterogamy.

...there is considerable intermarriage between Christians and Buddhists. The Japanese-American Methodist minister mentioned above suggested that at least half the male memers of Christian churches marry Buddhist women. ... Also there are often religious mixtures within kinship groups. Although the Issei are prone to be Buddhist, they often send their children and grandchildren to Christian sunday schools. A third complicating factor is that a person may hold, in a sense, a double loyalty. He may, for example, be a member of a protestant church but be an active participant in Buddhist social and recreational organizations (Cain 1962:117). 
Americans relate marrlage and religion?

4) There is a difference between the second and the third generations in achieving upward mobility and horizontal mobility, and in perceiving themselves elther as Japanese or as Americans.

A generational analysis is important in order to study differences in the degree and processes of assimilation between two successive generations.

Flrst, it is assumed that the third generation, compared to the second generation, has achieved higher education, and as a consequence, higher occupation and income. In the course of industrial modernization, the newer generation becomes upwardly mobile. Most Issei people were farmers, laborers, or the owners of small grocery stores. In contrast, Nisei had more opportunities to get professional work in the larger soclety (Bonacich and Modell 1980:157-172), and this trend is more salient among sanse 1 (Montero $1980: 79-88$ ).

Second, it is assumed that Nisei and Sansei have different social interaction patterns. Barnett (1963:106) argued that people living in urban areas are more likely to have contacts with members of other racial groups. Japanese Americans are heavily concentrated in big cities. How is this geographical location intertwined with generation and ethnic ties?

Finally, this hypothesis is posited to test the 
adequacy of Hansen's theory (1953) and Greeley's ethnogenesis theory (1974) which argued the possibility of reverse assimilation as opposed to Park's cycle (1950), which argued the eventual assimilation of minority groups. Hansen noted:

The theory is derived from the almost universal phenomenon that what the son wishes to forget the grandson wishes to remember (Hansen 1953:495).

Lyman also examined the verification of Park's cycle and argued:

... If $P$, then $Q$; if $Q$, then $R$; if $R$, then $S$. Should empirical research reveal a result contrary to the prediction of the hypothesis, the hypothesis could be abandoned as incorrect, or the principle of ceteris paribus introduced to account for the discrepancy (Lyman 1968:22).

As Blauner (1972) argued, if there is a connection between minority groups and their home countries, how do Sansei perceive themselves in connection with the emergence of Japan as an economic power in the world? 
CHAPTER IV

METHODOLOGY

OPERATIONAL DEFINITION OF THE VARIABLES

In this section, variables which were used to test each hypothesis are explained. Data were collected through faceto-Eace interviews for the Nisei sample and mailed questionnaires for the sansei sample. The interview schedule and questionnaire consisted of some questions from J.A.R.P. and some original questions which the writer constructed. These questions were basically closed-ended, and coded at the nominal or ordinal level. However, open-ended questions were also asked in order to inguire why interviewees/respondents made their particular decisions and to obtain further information (see the Interview schedule and the Questionnaire in Appendix B).

Four Japanese Americans participated in a pilot study: 1) male Nisei, age 70; 2) female Nisei, age 61; 3) male Sansei, age 35; and 4) female Sanse 1 , age 32 .

\section{Ethnic Identity}

The variables to measure ethnic identity include one's pride in being Japanese, an identity scale, the country to support in competition between Japan and the U.S., opinion 
about the preservation of Japanese culture, consciousness about one's ethnic roots etc. Ethnic identity is a difficult domain to measure. The following questions were constructed :

If you won a free trip abroad, which country would you like to visit?

Suppose that you are watching a volleyball game of the olympics, the U.S. vs. Japan. Which team do you support?

1 Absolutely Japan

2 Probably Japan

3 Hard to decide

4 Probably the U.S.

5 Absolutely the U.S.

Given a scale of 1 (a complete Japanese identity) to 10 (a complete American identity), please indicate the number which, in your judgment, most closely describes your identity.

Japanese

American

$$
\begin{aligned}
& \begin{array}{llllllllll}
1 & 2 & 3 & 4 & 5 & 6 & 7 & 8 & 9 & 10
\end{array} \\
& 1---1---1---1---1---1---1---1---1---1---1
\end{aligned}
$$

\section{Socioeconomic status}

This includes educational background, occupation, and income. Educational background was measured by the quality of education rather than by the years of formal schooling: some high school, completed high school, technical school, some college, completed college, post-baccalaureate study, and one or more graduate degrees.

As to occupational information, Nisei were asked to 
report the last occupation if retired. Title, position, routine works etc. were also asked in order to study how Japanese Americans are treated at the work place. Occupations were ranked 7 to 1 , where 7 represents highly ranked occupations including lawyers, doctors, or certified public accountants, and 1 represents occupations such as heavy laborers, miners, or fanitors. The Warner, Meeker, Eells' Revised Scale for Rating Occupation, from Handbook of Research Design and Social Measurement (Miller 1983:310311), was utilized for ranking.

The questions about income consisted of two parts: each sample's own income and his/her family income before taxes. Although each individual's income is more important in this study, information on family income is also necessary, especially when the respondent has no income. In the case of Nisei, four different figures were obtained: one's own income before retirement, family total income before his retirement, one's own income after retirement, and family total income after retirement. When a Nisei interviewee was retired, the year of retirement was also asked. The income before retlrement was adjusted to 1988 dollar value by using consumer price indexes from Economic Report of the president $(1989: 373)$.

Exogamous Marrlage

Exogamous marriage rate was measured by spouse's 
ethnicity: Japanese American, non-Japanese oriental, Japanese born in Japan, Caucasian, and other. When the Nisei sample was interviewed, ethnicity of his siblings' spouses as well as his children's spouses was also obtalned. This information, which includes a larger number of cases than the original Nisel sample, is useful to study the difference in exogamous marriage rate between $\mathrm{Nise} i$ and Sanse 1 .

Not only the actual ethnicity of one's spouse but also one's ethnic preference in marriage and one's opinion about his/her children's marriage are also necessary to investigate the pattern of mate-selection. Issei's opinion about marriage was also obtained through the Nisei interviewees' responses. In order to study one's aspiration to maintain endogamy, his/her perception about the importance of ethnic/religious background in marriage is a useful variable. The following question was constructed to measure these variables.

Please tell me about your ethnic preference of your children's spouse. Write in the ranking ( 1 , $2,3, \ldots)$ of your preference.

Japanese American

- Japanese born in Japan
Non-Japanese oriental
Caucasian
Other(specify) 
In marriage, do you think that ethnic background is more important than religious background?

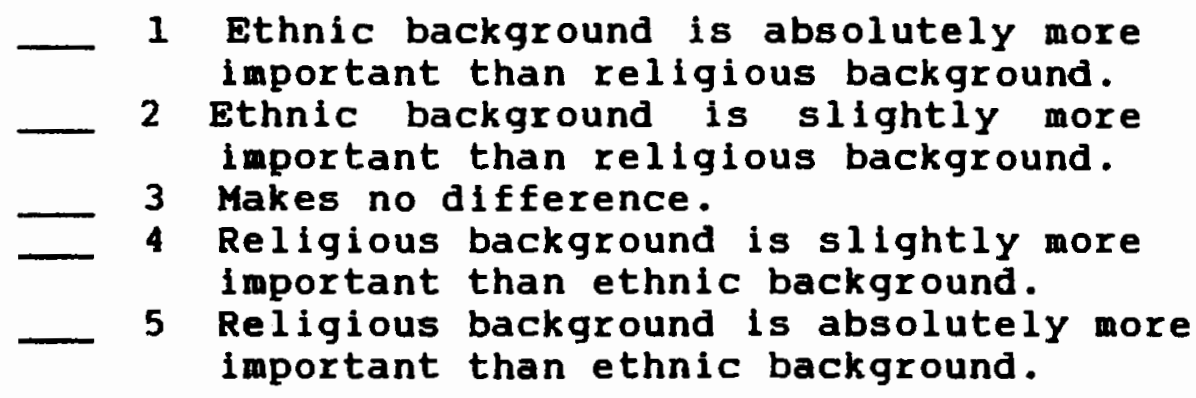

The comparison between one's religion and his/her spouse's religion and, in the case of the Nisei, the comparison between his religion and his parents' religion were used in order to test the assumption of religious heterogamy in the Japanese American community.

\section{Ethnic Ties}

Variables of ethnic ties consisted of one's past and present social interaction as well as his/her behavioral patterns. Past social interaction was measured by ethnicity of one's friends in grade school and high school, and present social interaction was measured by proportion of Japanese American friends. Information about two of one's closest friends was obtained to study how ethnicity, age, sex, and socioeconomic status are correlated in social interaction.

Behavioral patterns, which reflect ethnic bond, were measured by variables including visiting patterns of friends as well as relatives, ethnic organizational affiliation, 
participation in the church activities of different religions, frequency of reading ethnic newspapers, etc. The proportion of Japanese American organizations to the total number of organizations that one belongs to was used as a variable to measure the degree of ethnic organizational affiliation.

\section{Socletal Hostility}

Although it is significant to collect data on perception of whites toward Japanese Americans, "societal hostility" that Japanese Americans feel from the host society was defined as an indicator of prejudice and discrimination in this study. There are several variables: the frequency of experiences and feeling of being discriminated against in housing, at schools, on jobs, or other places; degree of hindrance of advancement because of being a Japanese American; intensity of susceptibility to anti-Japanese sentiment, etc. The intensity of these variables was coded at the ordinal level. Open-ended questions were also asked to obtain speciflc examples of discrimination.

\section{SAMPLES}

As noted in Chapter II, the Pacific Northwest, including seattle and Portland, is one of the core areas of high population density of Japanese Americans. According to the report made by the Economic Development Department of 
the state of oregon in 1984, there are about 8,580 Japanese living in Oregon, and 4,655 (54 percent of the entire Japanese population in Oregon) reside in the Portland area. However, 1,500 among the 4,655 are temporary residents from Japan such as businessmen, their families, and students. Therefore, Japanese Americans, including Issei, Nisei, Sansei, and the next generations, who have Japanese ancestral roots as well as American citizenship, are approximately 3,000 .

Since this study is a generational analysis, the sample consisted of two successive generations: Nisei and Sansei. The sampling method was basically the same as that of J.A.R.P.; the Nisei group was chosen as the first sample from the membership lists of Japanese American organizations, then their children conveniently became the second sample. To be included in the first sample, persons had to fulfill the following conditions: 1) they are male Japanese Americans; 2) they were born in the United States and possess American citizenship; 3) their father entered this country before the Anti-Asian Immigration Act in 1924 (in most of the cases, a male Japanese first came to the United states, then he got a wife from Japan by picture marriage); 4) their parents practiced endogamous marriage; 5) they currently live in the Portland area; and 6) they have one or more children.

The first condition was set because a female sample was 
unobtainable; 1) most of the major member lists, including the Japanese American Citizens League and the Japanese Ancestral soclety, usually contain only husbands' names even 1f their wives are members; 2) the Japanese Ancestral Women's Club is the only one large scale organization for women, and a great number of them are Kibel which would have skewed the analysis (see pp.27-29 in this thesis).

The third condition, which follows the paternal family lineage, includes some whose father is Issei and mother is Nisei. Although there may be a difference between those who have a Isse 1 mother and those who have a Nisei mother, this should not critically affect the validity of the study because they are all classified in the same historical cohort.

The second sample, the Sansei group, was composed of the children of the first sample. No control was conducted for this group; regardless of their sex, age, birth place, current residence or marital status, all the children of the first sample were defined as the second sample.

There arises a question of representativeness of the sample, which was selected only from the membership lists of Japanese American organizations. There likely are some Nisei who do not belong to any ethnic organization, and those people were excluded from the sample. Although the samples are not technically perfect, they are comprehensive enough to draw a tentative conclusion on the assimilation 
processes of $\mathrm{N}$ isei and Sansei.

The membership lists of the organizations were collected in November, 1988. All the names of Japanese American organizations, associations, and clubs, as well as the names of leaders of each organization, were obtained through one of the prominent persons among the Japanese American community in Portland, with whom the writer made an acquaintance in June, 1987.

There are about thirty organizations including small clubs: JACL (Japanese American Citizens League, Portland Chapter), Gresham-Troutdale Chapter JACL, Japanese Ancestral Soclety of Portland, Japanese Ancestral Women's Club (Nikkei Fujinkal), Oregon Nisei Veterans, Oregon Nisel Golf Club, Epvorth United Methodist Church, Oregon Buddhist Church, Buddhist Dalhonzan Henjyojl Temple, Portland Bowling Club, Gresham Bowling Club, Ikoi-so Terrace (Nikkei Community Project), Chano-yu Benkyo-kai, Oregon Judo Obukan, Fujinamikai (Classical Japanese Dancing), Hood Ginsha (Poetry), Ikebana Saga School (Flower Arranging), Sogetsu School (Flower Arranging), Urasenke Portland Dokokai (Tea Ceremony), Hiroshima Doshi Kai, Okayama Club, Shiga Club, Yamaguchi Club, Seiha Miyabi Kai (Koto), Veleda club, etc.

From these, six major non-religious organizations which have large memberships were chosen. These were Portland Chapter JACL, Gresham-Troutdale Chapter JACL, Oregon Nisei Veterans, Japanese Ancestral Society of Portland, Oregon 
Nisei Golf Club, and Portland Bowling Club. Then, the leaders of each organization were reached by telephone and informed of the purpose of the study. They were all willing to provide the membership lists with the condition that the lists were to be used only for this research profect. They were also asked to nark "N" for Nisei and "g" for Sansei -this is not a violation of privacy because Japanese Americans usually identify themselves by publicly telling others which generation they belong to.

The Oregon Nisei Veterans consists of 136 members with 8 Sansel included. The members fought in World War II, the Korean War, the Vietnam War, and so forth. ${ }^{1}$

The Oregon Nisei Golf Club and Portland Bowling Club are recreational organizations, which have the memberships of 76 male Nisei and 78 male Sanse 1 , and 65 male Nisei and 48 male Sansei, respectively.

The Japanese Ancestral Society consists of 216 members, including Issei, Nisei, and a few more recent immigrants fron Japan. The aim of the group is to promote cultural activities and exchange between the United states and Japan. It sponsors various cultural festivals with the cooperation of the Japanese Consulate in Portland.

The Gresham-Troutdale Chapter JACL has a total membership of 112 ( 3 male Issei, 2 female Issei, 92 male Nisei, 7 female Nisei, 7 male Sansei, and 1 female Sansei). The Portland Chapter JACL lists 16 clubs, shops, or 
companies, and approximately 200 individual names including 131 male Nisei, 30 female Nisei, 18 male Sansei, and 6 Eemale Sansel. 2

From these six membership lists, names of 642 male Nisei were extracted. They were all randomly numbered 1 through 642, and every tenth person was selected to be included in the first sample. When names were duplicated, the next number was chosen. These efforts resulted in the 64 different male Nisel names.

Among these 64 , the phone numbers of three people were unobtainable from the membership lists or the telephone directory. Of the remaining 61 persons, 46 live in Portland and 15 live in the suburbs of Portland such as Hillsboro, Beaverton, Newberg, Gresham, Milwaukie, Clackamas, Tigard, and Lake Oswego. All 61 Nisei people were reached by telephone between December 10 and December 13, 1988, and the purpose of the study was explained. Among the 61, there were 2 Issei and 3 Sansei by mistake. One person had no children. Six people refused to cooperate with the project. Four people preferred a mailed questionnaire. Four people could not be reached during the period when the telephone interviews were conducted. One person was excluded because his children, age 16 and 10 , were too young to become part of the second sample. Finally, 40 male Nisei were selected as the first sample for this study. Although five of them received their education in Japan for more than two years at 
either high school or grade school, they were included in the sample. All 40 people satisfied the conditions above mentioned.

\section{DATA COLLECTION}

The data from the first sample were collected by faceto-face interviews. Prior to the interview, some general information on those included in the sample was obtained when the writer made an appointment; age, parents' home towns in Japan, current occupation (last occupation if retired), and number of children. All of the 40 in the sample were interviewed between January 5 and January 19, 1989. The interview lasted for about two hours for each person. Thirty-six people were interviewed at their home and 4 others at their offices.

Although the first sample consisted of male Nisei, they were treated as a family unit rather than as individuals; information about their wives' opinions, including retention of Japanese culture, discipline of their children, or church attendance, was also obtained. Whenever possible, the wives were asked to foin the interview for the purpose of exploring crucial differences between males and females, if they existed at all. Seventeen wives joined the face-toface interview (only the information from males was coded for actual quantitative data analysis).

The names and addresses of children of the first sample 
were obtained when the interview was conducted. The size of the second sample, the sansei group, turned out to be 106 . Data from the second sample were collected through mailed questionnaires in order to reach all of the sample members regardless of their present residence. The questionnaires were mailed out on five occasions within a few days after the interviews with the first sample had been conducted. The last questionnaires were mailed out on January $23,1989$. After follow-up letters, when called for, were sent, a total of 60 completed questionnaires had been returned by February 27, 1989. Among the 60, seven people expressed their interest in reading the final copy.

\section{DATA ANALYSIS PROCEDURE}

The data obtained by face-to-face interview and mailed questionnaires were coded according to the coding guide which the writer constructed (see the Coding Guide in Appendix C). All the variables that describe ethnic ties, exogamous marriage, and ethnic identity were coded concordantly so that the smallest number represents low degree of assimilation, and the largest number high degree of assimilation. The proportion of Japanese American organizations (V50), one's desire to visit Japan (v63), pride in Japan's eminence (V64), and pride in being a descendant of Japanese (V67) were coded discordantly so that the largest number represents low degree of assimilation, 
and the smallest number represents high degree of assimilation. The variables of societal hostility (V56, V58, V59, and $V 60$ ) were coded so that the largest number indicates the highest intensity of hostility.

In order to measure the associations among various variables, Pearson's correlation coefficient was utilized. 3 The sets of data obtained from the first and second samples were treated separately.

\section{CHARACTERISTICS OF THE SAMPLES}

Where Did Isse i Come Fron?

Some information regarding Issei was obtained at the time of interviewing $N$ ise $1(N=40)$. Elghteen males (458) came from Chugoku region, mainly Yamaguchi, Hiroshima, and Okayama. Nine males (22.5\%) came from Kyushu region, 7 males (17.58) from Chubu region, 6 others (158) from Kinki region. The wives of these Issei, in most cases, came from the same reglons.$^{4}$

When they came to this country in the early 1900's, they were typically only 17 to 23 years old. They started to work at a railroad, a sawmill, a logging camp, or a cannery. After saving some money, they became self-employed and ran their own businesses such as fruit stands, grocery stores, laundries, restaurants, or small hotels. 
Description of the Nisel sample

There no longer exists, in Portland, a so-called Japan town, where people have face-to-face contacts in everyday life. Of the total $40 \mathrm{Nisei}$ interviewees in this study, 15 people (37.58) live in the southeast, 16 people (408) in the north and the northeast, 4 people $(108)$ in the southwest, 2 people (5\%) in the northwest, and the remaining 3 people (7.58) In the Portland area (SMSA) in Tigard, Beaverton, and Gresham.

The mean age was 65.3, with the youngest, age 55, and the oldest, age 80 . Twenty-two people (55\%) were born in the Portland area, 6 people (158) elsewhere in the state of Oregon, 9 people (22.58) either in the state of Washington or in the state of Idaho, and 3 others in other states. Eighteen people (458) were still working, 6 people (158) were semi-retired, and 16 others (40\%) were completely retired. occupation varies from barbers, gardeners, auto repairmen, and postal clerks to school teachers, accountants, lawyers, and doctors. As to the employent pattern, 19 people (47.58) were self-employed in the hotel business, in an auto repair shop, as a farmer, in a grocery store, as physicians, dentists, etc.

The average educational level of this sample was "some college education," with the lowest, "completed high school," and the highest, "one or more graduate degrees." As to the last income before retrrement, the average income 
was $\$ 30,000-\$ 39,999$, and the average family total income before the interviewees' retirement was $\$ 40,000-\$ 49,999$ (see Appendix A for more information).

Looking at the marital status, 39 people were married, and one person was divorced. of the 39 interviewees who were married, 2 people got divorced in the past. As to the ethnicity of a spouse, 34 people (858) married Japanese Americans, and 6 people (158) married Japanese born in Japan. One person had a Caucasian ex-spouse, which could be said to have produced exogamous marriage rate for this sample of 2.5 percent. However, there were cases in which the interviewees' siblings married Caucasians (see the section on "Verification of the fourth hypothesis" in Chapter $v)$. of the 34 interviewees who married Japanese Americans, 30 people (88.28) married Nisei, and 4 people (11.88) married Sansei.

A large proportion of the sample, 33 people (82.58) still have contacts with relatives 1 iving in Japan, and 32 people (80\%) have visited Japan. Thirty people, regardless of having visited Japan, answered that Japan would be the Eirst country to travel. 5

Description of the sansel sample

One hundred and six names and addresses of sanse 1 , which includes 50 males and 56 females, accrued from the interviews with the Nisei sample. 6 of the total number of 
106 people, 60 respondents mailed back a completed questionnaire, which resulted in a return rate of 56.6 percent. Among 60 sansei respondents, there were 21 male respondents and 39 female respondents. In other words, the return rate by sex was 42 percent for males and 69.6 percent for females.

of the total of 60 respondents, 31 people (51.7\%) live in the Portland area, 6 people (108) in other places in Oregon, 9 people (15\%) in the Northwest outside the state of Oregon, 6 people (108) in the state of California, 7 people (11.78) in other states, and one person (1.78) temporarily in Japan.

The mean age of this sample was 31.7 , with the standard deviation 7.67 . In other words, 41 people were between age 25 and 39 (this sample showed a normal distribution). Ten people were 24 years old or under, with the youngest, age 17, and 9 people vere 40 years old or over, with the oldest, age 52. The age of the Nisel sample and the Sansei sample did not overlap in this study.

As to socioeconomic status, the average educational level was "completed college" (two people are still going to a high school, and some of the respondents are going to finish college education in the next few years). No one was self-employed except one physician who was in private practice. Occupational pattern of this sample revealed the variety of available jobs in modern soclety: registered 
nurses, managers of import and export business, a disc jockey, a newspaper reporter, a flight attendant, dental hygienists, pharmacists, etc. Only 3 people were working for a Japanese-affiliated company. The average individual income of last year (1988) was $\$ 20,000-\$ 29,999$ (some parttime workers were included). The average family total income of last year (1988) was $\$ 40,000-\$ 49,999$ (see Appendix A for more information).

The data regarding marital status $(N=60)$ showed that 33 people (55\%) were married, 24 people (40\%) were single, and 3 others (5\%) were divorced. Among those who were married, there were 4 people who got divorced in the past. Interestingly enough, the ex-spouses of those 7 people who have experienced divorce were all Caucasians, and the second spouses of the 4 were either Japanese Americans or nonwhites. As to the ethnicity of a spouse $(N=36), 12$ people (33.38) married Japanese Americans, 2 people (5.6\%) Japanese born in Japan, 18 people (50\%) Caucasians, and 4 people (11.18) married persons from other ethnic group such as Hispanic, Filipino, and black. The data revealed that the exogamous marriage rate of this sample was 61.1 percent, which is higher than the findings of the study by Montero (1980) who analyzed J.A.R.P. data and reported a 40 percent rate of exogamous marriage of the third generation of Japanese Americans (see the section on "Verification of the fourth hypothesis" in Chapter V). 
Although 47 people (79.78) do not have contacts with relatives in Japan, 32 people (54.28) know what part of Japan their ancestors came from $(N=59)$. of 59 respondents, 24 people (40.78) have visited Japan; 17 people traveled Japan for sightseeing and visiting relatives, for studying, or for cultural awareness, and 7 others on business. 
CHAPTER $V$

FINDINGS

VARIABLES TO MEASURE ETHNIC IDENTITY

As mentioned in the section on "Operational definition of the variables" (pp.50-55), there are several variables to measure ethnic identity. In defining the variables to actually test the hypotheses, I selected four key variables.

\section{Variables}

[V64]: Pride in Japan's eminence

v65 : The country to support in competition

V66 : Identity scale

[V67) : Pride in being a descendant of Japanese

Variables indicated by "[ ]" were coded discordantly so that the largest value represents a low degree of assimilation, and the smallest value a high degree of assimilation.

TABLE I-(1) shows correlations of those variables in the Nisei sample. Pride in Japan's eminence (V64) showed strong negative correlations $\left(-.4164^{*}\right.$ and -.3372$)$ with the country to support in competition (V65) and identity scale (v66); those who are proud of the economic development of Japan are likely to have Japanese-leaning identity and are likely to support Japan in competition and vice versa. The 
TABLE I

CORRELATION AMONG VARIABLES TO MEASURE

ETHNIC IDENTITY

$\begin{array}{ll}\text { (1) THE NISEI SAMPLE } & \mathrm{N}=40\end{array}$

\begin{tabular}{|c|c|c|c|c|}
\hline & $V_{64}$ & $V 65$ & V66 & V67 \\
\hline $\begin{array}{l}\text { Pride in Japan's eninence (V64) } \\
\text { The cantry to suppont in competition (V65) } \\
\text { Identity scale (V66) } \\
\text { Pride in being a descendant of Japanese (V67) } \\
\text { * Significant at the } .01 \text { level } \\
\text { ** Significant at the .001 level }\end{array}$ & $\begin{array}{l}1.0000 \\
-.4164^{*} \\
-.3372 \\
.0719\end{array}$ & $\begin{array}{c}1.0000 \\
.5223^{*} \\
.0605\end{array}$ & $\begin{array}{r}1.0000 \\
-.0162\end{array}$ & 1.0000 \\
\hline (2) THE SANSEI SAMPLE & & & & $\mathrm{J}=57$ \\
\hline & $V_{64}$ & V65 & V66 & V67 \\
\hline $\begin{array}{l}\text { Pride in Japan's eninenoe (V64) } \\
\text { The cantry to suppont in ompetition (V65) } \\
\text { Identity scale (V66) } \\
\text { Pride in being a descendant of Japanese (V67) }\end{array}$ & $\begin{array}{l}1.0000 \\
-.2131 \\
-.4039 \star \star \\
.2245\end{array}$ & $\begin{array}{l}1.0000 \\
.2656 \\
0.0\end{array}$ & $\begin{array}{l}1.0000 \\
-.2022\end{array}$ & 1.0000 \\
\hline
\end{tabular}


country to support in competition (V65) and identity scale (v66) showed a strong positive correlation (.5223*). However, pride in being a descendant of Japanese (V67) did not show strong correlations with any other variable. It may be explained by the fact that 36 people $(908 \mathrm{~N}=40)$ said that they are "very much" proud of being Japanese (see TABLE XVII-(4) on P.124).

In the Sansei sample, TABLE I-(2), the directions of correlations of those variables were almost the same as the Nisei sample. Pride in Japan's eminence (V64), the country to support in competition (V65), and identity scale (V66) showed negative correlations, and the country to support in competitions (V65) and identity scale (V66) showed a moderate positive correlation. Especially, the correlation between pride in Japan's eminence (V64) and identity scale (v66) was significant $(-.4039 * *)$. Noticeable correlations of this sample, which were different from the Nisei sample, were the correlations between pride in being a descendant of Japanese (V67) and two other variables (V64 and V66); directions were the same but the correlations were stronger $(.2245$ and -.2022$)$ than the Nisei sample.

These correlations, in both TABLE $I-(1)$ and $I-(2)$, imply that those who are proud of Japan's eminence in the world economy are likely to support Japan in competition, and also are likely to have Japanese-leaning identity, and vice versa. Based upon these observations, I am going to 
utilize the country to support in competition (v65) and identity scale (V66) as major variables, while using pride in Japan's eminence (V64) and pride in being a descendant of Japanese (V67) as minor variables, in order to test the hypotheses .

\section{VERIFICATION OF THE FIRST HYPOTHESIS}

Hyoothes ls

Those who have achieved horizontal mobility are more likely to perceive themselves as Americans than those who have not achieved horizontal mobility.

\section{Variables}

V27 : The proportion of Japanese American friends

V29 : Visiting pattern of friends

[V50]: The proportion of Japanese American organizations

V11: Occupation

V12 : Education

V68 : Income

V65 : The country to support in competition

V66 : Identity scale

Variables indicated by "[ ]" were coded discordantly so that the largest value represents a low degree of assimilation, and the smallest value a high degree of assimilation.

The Nisei and Sansei samples were treated separately, because those two samples showed different social interaction patterns and ethnic affiliation (see TABLE XIII on p.115 and TABLE XIV on p.116).

Hypothesis Testing

In both TABLE II-(1) and II-(2), the proportions of 


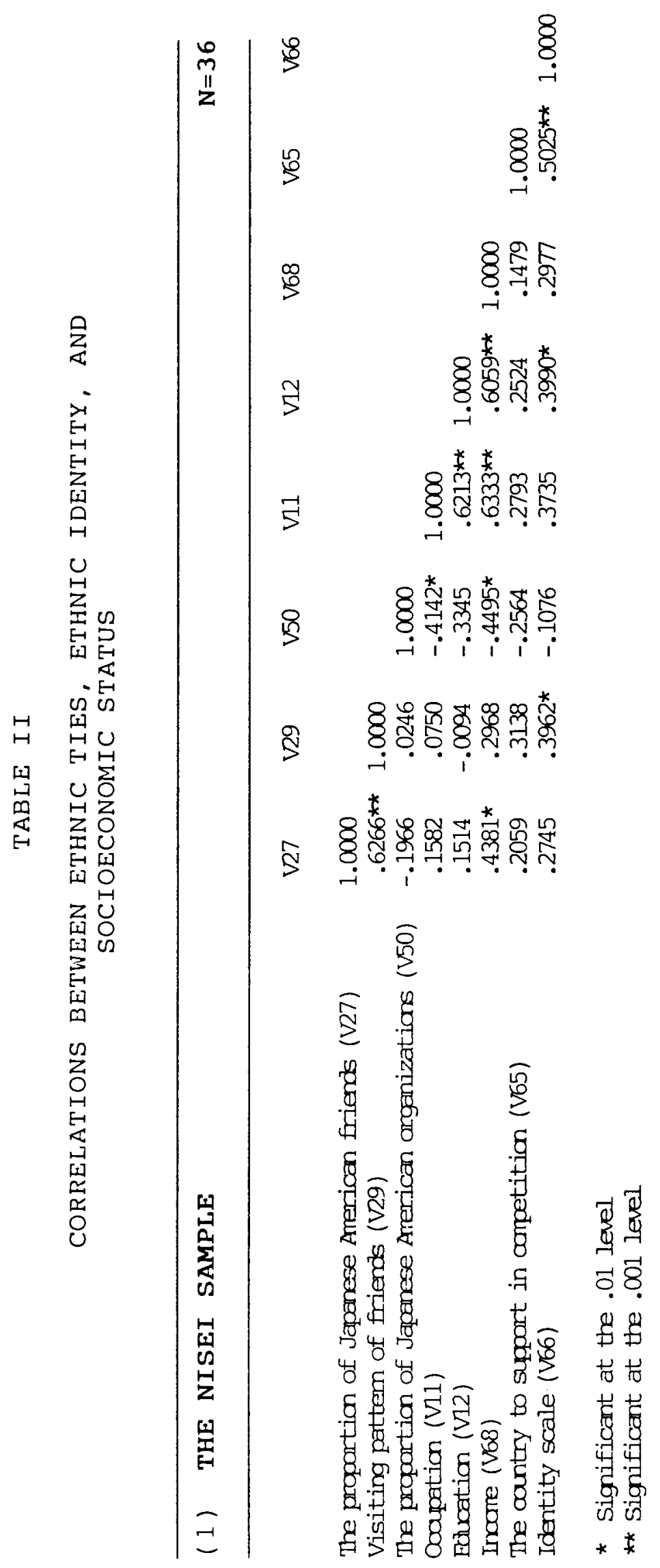




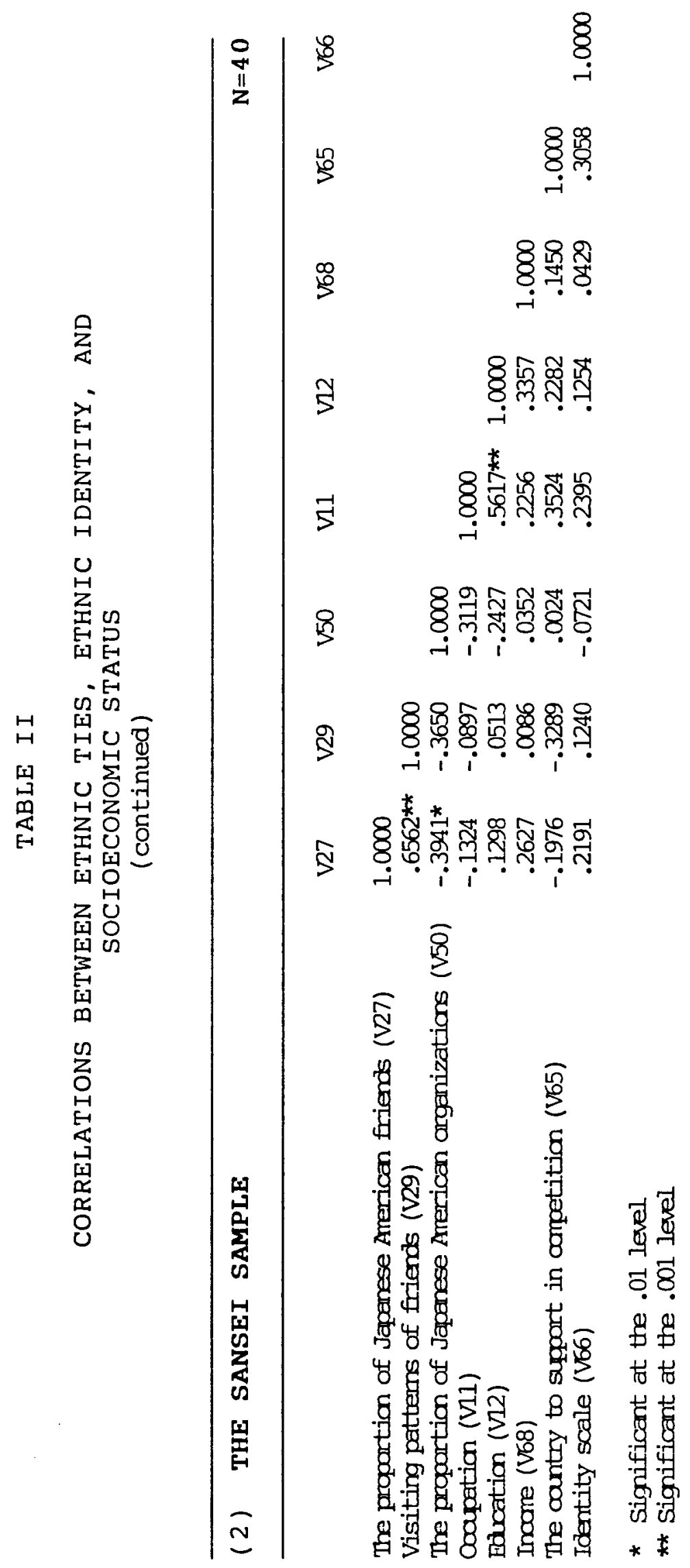


Japanese American friends (V27) and the visiting pattern (v29) showed significant strong positive correlations (.6266** and .6562** respectively); those who have more Caucasian friends than Japanese American friends tend to socialize with Caucasian friends more often than Japanese American friends, and vice versa. This is acceptable because social interaction patterns are contingent upon the actual interpersonal contacts. In TABLE II-(1), the variables of social interaction patterns (V27 and V29) and the proportion of Japanese American organizations (V50) did not show high correlations (-.1966 and .0246); this may be explained by the fact that almost all the Nisei people belong to multiple Japanese American organizations (see TABLE XIII-(1) on p.115). In TABLE II-(2), the proportion of Japanese American organizations (V50) showed strong negative correlations $\left(-.3941^{*}\right.$ and -.3650$)$ with the proportion of Japanese American friends (V27) and visiting pattern (V29); those who have more Japanese American friends and socialize with them more often than Caucasian friends are likely to be affiliated with Japanese American organizations, and vice versa. However, these correlations in the Sansei sample do not explain causality among these variables. Therefore, there still remains a question regarding whether Japanese Americans have more chances to make Japanese American friends through the participation in ethnic organizations, and as a consequence, socialize with 
them more frequently, or whether they choose ethnic organization simply because their friends are the members of Japanese American organizations.

In the Nisei sample, TABLE II-(1), the social interaction patterns (V27 and v29) and the ethnic identity (V65 and V66) showed positive correlations. Especially, the correlation between visiting pattern (V29) and identity scale (v66) was significant $(.3962 *)$. The proportion of Japanese American organizations (v50) showed a moderate negative correlation $(-.2564)$ with the country to support in competition (V65). All these correlations mean that those who have more frequent social interactions with Caucasians and who are less affiliated with ethnic organizations are likely to have American-leaning identity and are likely to support the U.S. in competition, and vice versa.

In the sansei sample, TABLE II-(2), identity scale (v66) showed moderate positive correlations 1.2191 and .1240 ) with social interaction patterns (V27 and V29), and a very weak negative correlation $(-.0721)$ with the proportion of Japanese American organizations (V50). The correlations between these variables were the same as TABLE II-(1), though not as strong as the wisei sample, and the same inference can be made as to the relation between one's horizontal mobility and self-perception. However, the social interaction patterns (V27 and V29) showed negative correlations $(-.1976$ and -.3289$)$ with the country to support 
in competition ( $\mathrm{V} 65$ ), of which directions were different from the Nisei sample; those who have more Caucasian friends and socialize with them more often than Japanese American friends are likely to support Japan in competition. What kind of assumptions can be made from this proposition? One of the plausible explanations is that sansei who have more frequent social interactions with Caucasians are able to contrast their ancestral roots (Japan) with their native country (the U.S.), and as a consequence, tend to support Japan in competition. Although it is questionable whether or not Sansei Japanese Americans actually support a Japanese team when they are watching a game, the U.S. vs. Japan, they may have a hard time in deciding which team they should support .

From above mentioned observations of the correlations in TABLE II-(1), it is concluded that in the Nisei sample those who have achieved horizontal mobility, by cutting off ethnic pulls and by getting into the larger society of whites, are more likely to percelve themselves as Americans than those who have not achieved horizontal mobility, and vice versa. The first hypothesis was verifled in the Nisei sample. However, it is still questionable whether the first hypothesis is verifiable in the sansei sample, because the correlations in TABLE II-(2) vere not strong enough to come to a conclusion. 


\section{Discussion}

Questions remain; how about the relation between upward mobility and ethnic identity, and between upward mobility and horizontal mobility? Upward mobility and ethnic identity were positively correlated in this study. In the Nisei sample, TABLE II-(1), occupation (V11), education (V12), and income (V68) were all positively correlated with the country to support (V65) and identity scale (v66). Especially, education (V12) and identity scale (V66) showed a significant correlation $(.3990 *)$. In the Sansei sample, TABLE II-(2), these variables showed almost the same correlations as the Nisei sample. Therefore, it is concluded that those who have achieved higher socioeconomic status are likely to perceive themselves as Americans.

Upward mobility and horizontal mobility revealed different correlations in the two samples. In the Nisei sample, the proportion of Japanese American organizations (V50) showed negative correlations $(-.4142 *,-3345$, and $-4495 *$ ) with the variables of socioeconomic status. This may be explained by the fact that those who were highly ranked along the occupational scale -- doctors, lawyers, or large scale business owners -- also belonged to many nonethnic occupational associations, which lowered the proportion of Japanese American organizations. Social interaction patterns (V27 and V29) and income (v68) were strongly correlated $(.4381 *$ and .2968 respectively). It is 
assumed that as a Japanese American achieves a living standard comparable to that of the Caucasian middle class, he starts to associate with whites. In contrast, social interaction patterns (V27, V29) and occupation (V11) and education (V12) did not show strong correlations. Especially, the actual visiting patterns (V29) and occupation (V11) and education (V12) were not strongly correlated $(.0750$ and -.0094$)$. Considering the fact that 30 people of this sample interact with Japanese American friends more often than Caucasian friends (see TABLE XIV on p.116) it is safe to say that Nisei's education and occupation do not have any significant relation to their social interaction patterns.

In the Sansei sample, while the proportion of Japanese American friends (V27) and education (V12) and income (V68) showed moderate positive correlations (.1298 and .2627), actual visiting pattern (V29) and socioeconomic status (V11, v12, and V68) did not show meaningful correlations. Does this mean that social interaction patterns have no relation with upward mobility? It is also interesting that social interaction patterns (V27 and V29) and occupation (v11) showed weak negative correlations. Does this mean that those who are in the lower stratum along the occupational hierarchy are more likely to socialize with Caucaslans than those who are in the higher stratum? 


\section{Summary}

In both Nisei and Sansel samples, there are positive relations between horizontal mobility and American identity, and between upward mobility and American identity; those who have more frequent contacts with whites or those who have achieved higher socioeconomic status are likely to perceive themselves as Americans. However, horizontal mobility and upward mobility do not necessarily synchronize. The notion of multiple hierarchy, which Gordon (1964) argued, may explain this outcome (see pp.41-42 in this thesis). It is assumed that Japanese Americans, especially Nisel, are clustered along a status hierarchy within their own ethnic group.

If the assumption of multiple hierarchy is adequate, what makes Japanese Americans who have achieved higher socioeconomic status also have American-leaning identity? Does the difference between "because of" and "in order ton motivation (see p.43 in this thesis), which resulted in the Nisei high socioeconomic status, explain the relation between upward mobility and identity? or is there any other factor, for example societal hostility, which affected Japanese Americans in establishing their identity? The second hypothesis may shed light upon this question. 
VERIFICATION OF THE SECOND HYPOTHESIS

Hypothesis

Those who feel societal hostility are likely to have stronger ethnic ties and are also more likely to perceive themselves as Japanese than those who

do not feel societal hostility.

\section{Variables}

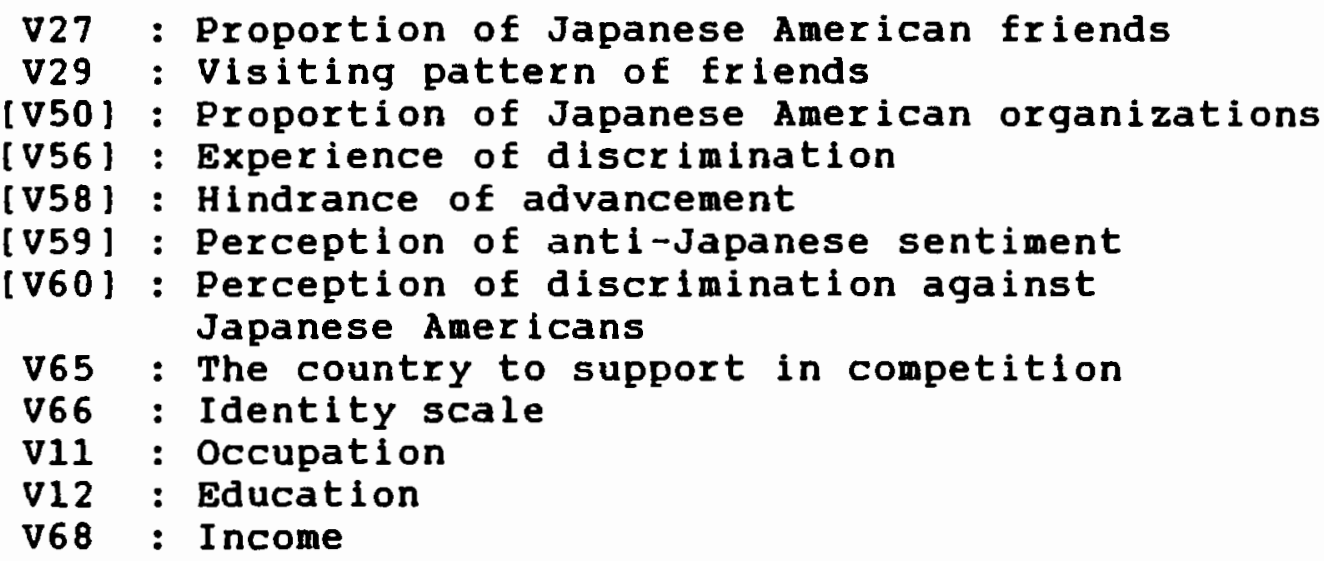

Variables indicated by "[ ]" were coded discordantly so that the largest value represents a low degree of assimilation, and the smallest value a high degree of assimilation.

In testing the second hypothesis, the Nisei sample and the Sansei sample were treated separately, because those two successive generations have experienced completely different encounters with discriminatory laws and societal practices (see TABLES XII-(1) through XII-(4) on p.113).

Hypothesis Testing

In the Nisei sample, TABLE III-(1), no consistent correlation was indicated between ethnic ties (V27, V29 and v50) and societal hostility (V56, V58, V59, and V60), and 


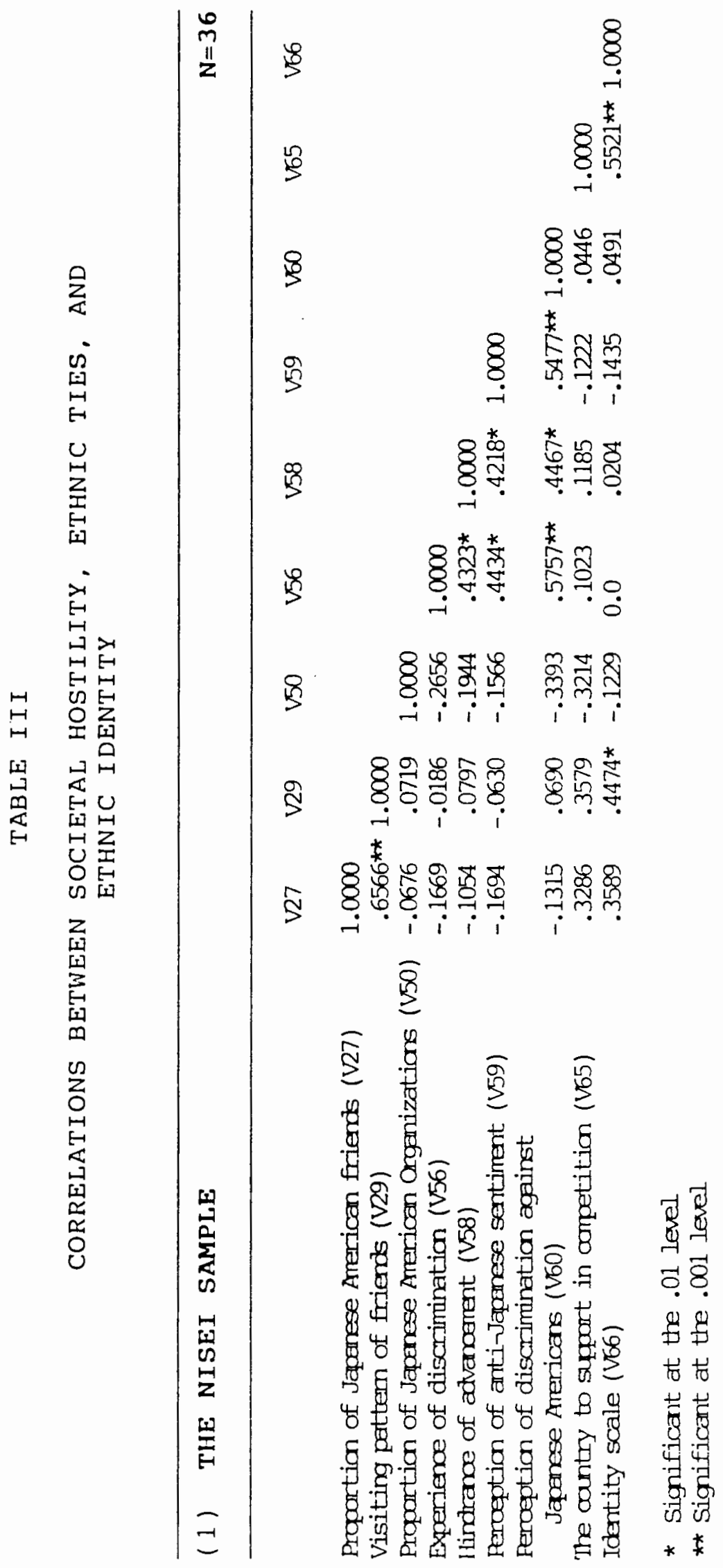




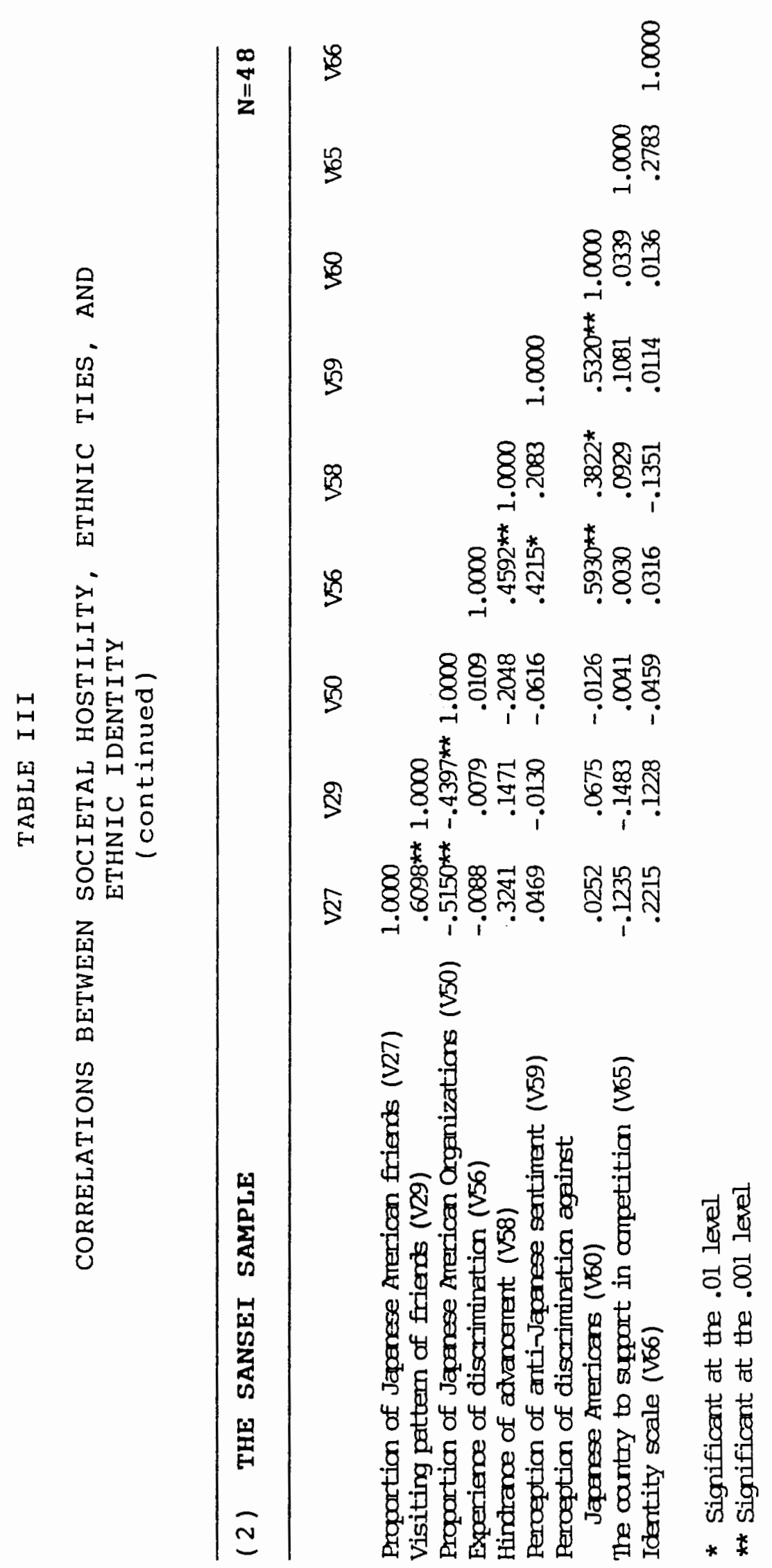


between societal hostility and identity (V65 and v66). For example, the proportion of Japanese American friends (V27) showed very weak negative correlations with societal hostility $(-.1669,-.1054,-1694$, and -.1315$)$; those who have experienced higher intensity of societal hostility are likely to have more Japanese American friends, while actual social interaction patterns (V29) and societal hostility were not strongly correlated. Although the proportion of Japanese American organizations (V50) showed moderate negative correlations with societal hostility, these correlations do not necessarily indicate a relation between the feeling or experience of societal hostility and the strength of ethnic ties because the proportion itself did not indicate the strength of ethnic ties (see p.78 in this thesis).

In the Sansei sample, TABLE III-(2), no significant correlation was indicated among the variables mentioned above. A noticeable relation was a positive correlation (.3241) between the proportion of Japanese American friends (V27) and hindrance of advancement (V58); those who have more Caucasian friends are likely to think that being a Japanese American has hindered his/her advancement. What explanation can be made from this correlation? It may be explained that those who have more Caucasian friends see the as a "reference group," and regardless of their (Japanese Americans') actual hindrance of advancement, are 
likely to think that they are disadvantaged by being a Japanese American.

From those observations of the variables in TABLE III(1) and III-(2), it is concluded that there is no correlation between societal hostility, ethnic ties, and identity. The second hypothesis was nullified.

\section{Discussion}

The rejection of this hypothesis may be explained by the fact that the members of each generation have felt/experienced the same intensity of societal hostility (see the standard deviation of discrimination in TABLE XII on p.113).

Although the second hypothesis was nullified, there were very significant strong positive correlations among the variables of societal hostility (V56, V58, V59, and V60) in both TABLE III-(1) and III-(2); those who have felt/experienced discrimination and who think Japanese Americans are still being discriminated against, perceive that being a Japanese American has hindered his/her advancement in society.

In TABLE IV-(1) and IV-(2), relations between societal hostility and socioeconomic status are shown. In the Nisei sample, there were positive correlations between experience of discrimination (V56) and occupation (V11), and between hindrance of advancement (V58) and occupation 1.2427 and 


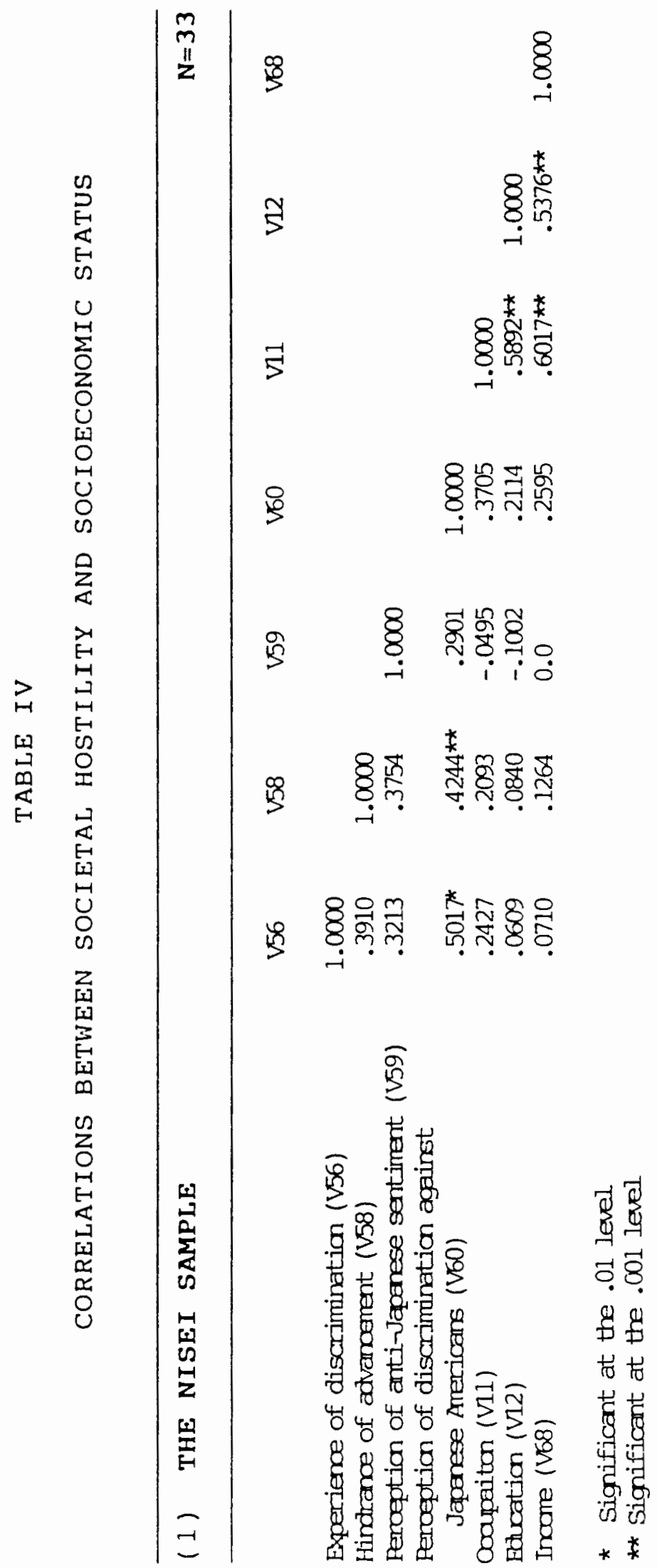




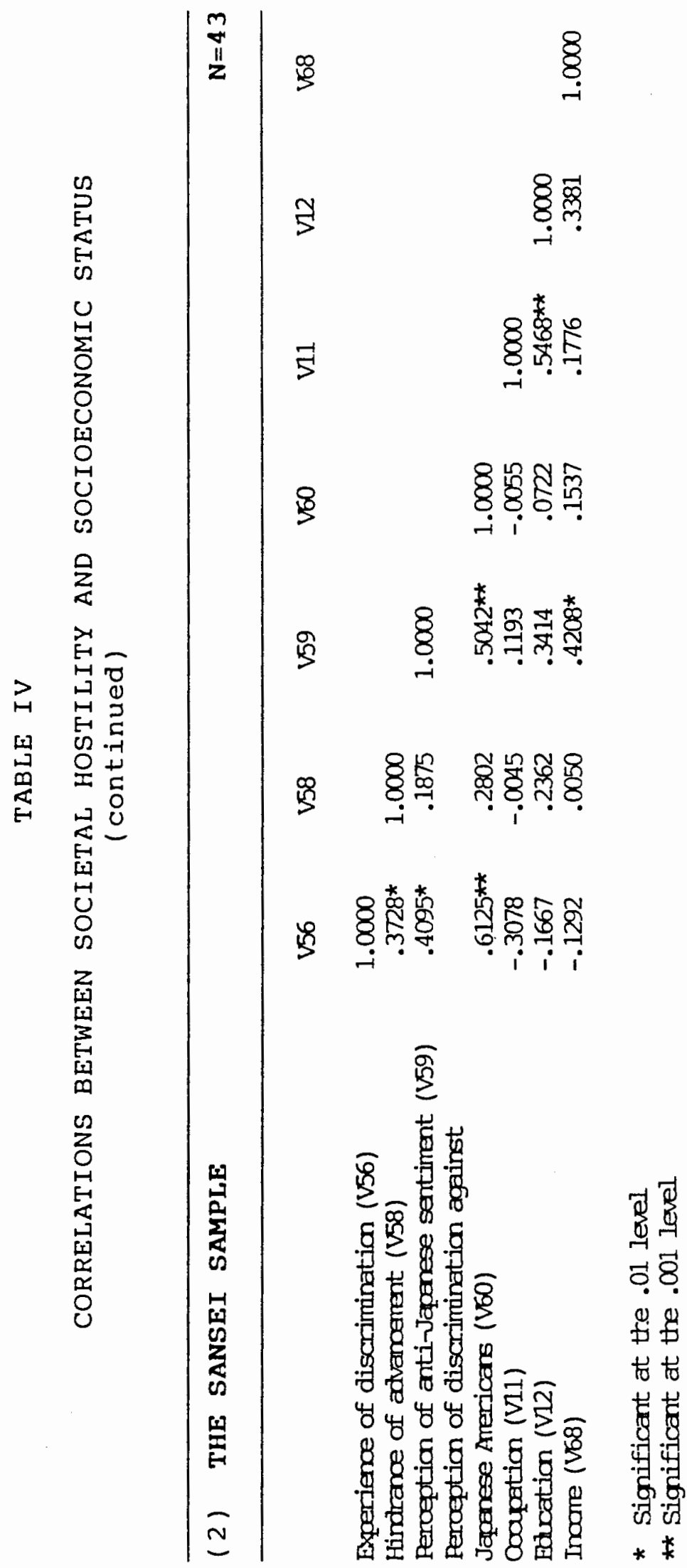


.2093 respectively). Occupation (V11), education (V12), and income (V68) showed positive correlations $(.3705, .2114$, and .2595) with perception of discrimination against Japanese Americans $(\nabla 60)$. In the Sansei sample, education (V12) showed positive correlations (.2362 and .3414 respectively) with hindrance of advancement (V58) and perception of antiJapanese sentiment (V59). The correlation between income (V68) and perception of anti-Japanese sentiment showed a significant positive correlation (.4208*). From these observations, it is interpreted that as a Japanese American achieves higher socioeconomic status, he/she feels a greater intensity of hostility from society. To support this assumption, it is worth noting here some comments from the interviewees and respondents regarding how Japanese Americans feel about the issue of discrimination.

Comments from Nisei:

"After all this is a white majority society. They are the ones who make laws and rules. I'm involved with political movement, and $I$ know it (discrimination) is there."

"I think there is antl-Japanese sentiment especially among those who lost jobs. They always need a scapegoat. The whole cycle started again (emphas is applied)."

"We are treated much better now, but discrimination won't disappear ever as long as we are visible."

"Whites do not show prejudice, but they look down upon us. They just don't show it because of the law." 
"I got promotion in salary, but I couldn't get promotion in management. They don't trust me."

"I don't think being a Japanese American has hindered my advancement. I have met all the challenges by working hard three times as much (as whites). Training, exams, I never failed."

"They are fealous. They think orientals should be the second."

Comments from Sansei:

"Within the industry, "Japs" are a constant source of irritation. Occasionally, it is directed toward me."

"Due to the tremendous rush of orientals applying to universities, many admission offices tend to put limits on how many orientals are admitted, otherwise the school would be dominated by orientals."

"There is subtle discrimination such as sales people in stores not helping unless asked. Discrimination is well hidden."

"I feel discrimination very often. It is usually non verbal."

"Japanese Americans have done well economically which at time poses a threat to others."

"It is more of a stereotype. Teachers expect too much, because they think Japanese students are all intelligent."

\section{Summary}

In both Nisei and Sansei samples, societal hostility has relation with neither social interaction patterns nor identity. However, there is a positive relation between socioeconomic status and societal hostility. Those who have achieved higher education, who are ranked high along the 
occupational hierarchy, and who receive more income, are likely to feel societal hostility. This positive relation between socioeconomic status and societal hostility reflects studies by Bonacich (1980) and Tienda and Lii (1981), which found competition and subordination of minority groups in the U.S. labor market (see p.33 in this thesis).

The question which I had raised in the summary of the first hypothesis remains unanswered. The question was what has led these Japanese Americans who have achieved higher socioeconomic status to establish American-leaning identity? There may be a relation between ethnic identity and aspiration to maintain endogamy.

VERIFICATION OF THE THIRD HYPOTHESIS

Hyoothesis

Those who percelve themselves as Americans are more likely to choose exogamous marriage with whites than those who perceive themselves as Japanese.

\section{Varlables}

$\checkmark 9$ : spouse's ethnicity

V21 : Opinion about children's socialization

V22 : Opinion about the ethnicity and religion in marriage

(v64) : Pride in Japan's eminence

v65 : Country to support

V66 : Identity scale

v15-V20: Ethnic preference in children's marriage

(Asked to give a ranking)

V15 Japanese American

V16 Japanese born in Japan

V17 Non-Japanese oriental

V18 Caucasian

v19 Other 
V20 Does not matter

s1-s6 : Ethnic preference in one's own marriage

(Asked to give a ranking)

s1 Japanese American

S2 Japanese born in Japan

S3 Non-Japanese oriental

S4 Caucasian

55 other

S6 Does not matter

Variable indicated by "[ ]" was coded discordantly so that the largest value represents a low degree of assimilation and the smallest value a high degree of assimilation. Variables of ethnic preference in marriage (V15-V20 and s1-S6) were coded by ranking.

The Nisei sample and the Sansei sample were treated separately to test the second hypothesis, because the exogamous marriage rate of these two samples showed a distinctive difference (see the exogamous marriage rates in the section on "Verification of the fourth hypothesis" on pp. 120-121).

The Nisei Sample

Twenty-five $\mathrm{Nisei}$ interviewees $(71.48, \mathrm{~N}=35)$ said that their fathers had strong preference for a Japanese American, and 27 interviewees $(67.5 \%, N=40)$ said that their mothers had strong preference for a Japanese American. As to the ethnic preference in Nisei's own children's marriage, of the total of 40 interviewees, while 12 people (308) said that it does not matter what ethnic people their children marry, 26 interviewees (65\%) selected a Japanese American as the first choice. It is also worth noting that 13 interviewees 
(32.58) expressed bias against blacks and Hispanics. 8

The Sansel Sample

As to ethnic preference in sansei respondents' children's marriage, two-thirds of the sansei respondents said that it is the chlldren's own decision. However, of the total of 60 respondents, whlle 13 people (21.78) selected a Japanese American as the first choice, 20 people (33.38) said that they have no ethnic preference. In contrast, asked about ethnic preference in their own marriage, 14 people (23.38) answered that they have no preference, and 14 people (23.38) selected a Japanese American as the first choice, though 24 people (40\%) selected a Caucasian as the flrst choice. No distinctive difference was observed between males and females.

Hypothesis Testing

In the Nisei sample, the analysis of correlations between ethnic preference in their children's marriage and their own identity did not reveal strong relations, which may be explained by the fact that the majority of interviewees prefer a Japanese American. In TABLE $V-(1)$, there are three variable pairs which showed meaningful correlations. The correlations between preference for Japanese born in Japan (V16) and pride in Japan's eminence (V64), and between preference for Japanese born in Japan (V16) and identity scale (V66) were quite strong $(-.4082$ and 
TABLE V

CORRELATIONS BETWEEN ETHNIC PEEFERENCE

IN MARRIAGE AND ETHNIC IDENTITY

\section{(1) THE NISEI SAMPLE}

Japanese born in Japan (V16)

With N (12)

Pride in Japan's eminence (v64)

Japanese born in Japan (V16)

With $\mathrm{N}$ (12)

Identity scale (V66)

Does not matter (V20)

With N (27)

Country to support (V65)
$-.4082$

SIG $\quad .094$

.5359

SIG $\quad .036$

$-.3147$

SIG .055

\section{(2) THE SANSEI SAMPLE}

Japanese American (V15)

$-.3742$

With N (16)

Pride in Japan's eminence (V64)

SIG .077

Japanese born in Japan (V16)

$-.5465$

With N (13)

Pride in Japan's eminence (V64)

SIG $\quad .027$

Japanese born in Japan (V16)

.4672

With N (13)

Identity scale (V66)

SIG $\quad .054$

\section{(3) THE SANSEI SAMPLE}

Japanese American (S1)

With N (29)

Pride in Japan!'s eminence (V64)

Japanese born in Japan (S2)

With $N(22)$

Identity scale (V66)

Caucasian (V18)

With N (32)

Pride in Japan's eminence (V64)
$-.2689$

SIG .079

.4018

SIG $\quad .032$

.2528

SIG $\quad .081$ 
.5359 respectively); those who have pride in Japan's eminence are likely to prefer Japanese born in Japan, and vice versa, while those who have American-leaning identity are likely to give a low ranking to preference for Japanese born in Japan and vice versa. The last variable pair between no ethnic preference (V20) and the country to support in competition (V65) also showed a meaningful correlation (-.3147), which means that those who support the U.S. in competition are likely to think ethnicity does not matter in marriage.

In the sansei sample, TABLE $V-(2)$, the correlation between preference for a Japanese American in children's marriage (V15) and pride in Japan's eminence (V64) is quite strong (-.3742); those who are proud of the economic development of Japan are likely to prefer a Japanese American in their children's marriage, and vice versa. The correlations between preference for Japanese born in Japan (V16) and pride in Japan's eminence (V64), and between preference for Japanese born in Japan (V16) and identity scale (v66) are also strong (-.5465 and .4672); those who are proud of Japan's eminence are likely to give a high ranking to preference for Japanese born in Japan and vice versa, while those who have American-leaning identity are likely to give a low ranking to preference for Japanese born in Japan, and vice versa.

The correlation between ethnic preference in Sansei's 
own marriage and ethnic identity also showed the same pattern as the correlations in TABLE $\mathrm{V}-(2)$. In TABLE $\mathrm{V}-(3)$, preference for a Japanese American (S1) and pride in Japan's eminence (V64) showed a moderate negative correlation (-.2689); those who have pride in the economic development of Japan are likely to give a high ranking to preference for a Japanese American and vice versa. Preference for Japanese born in Japan (S2) and identity scale (V66) showed a strong positive correlation (.4018); those who have Americanleaning identity are likely to give a low ranking to preference for Japanese born in Japan and vice versa. Preference for a Caucasian (S4) and pride in Japan's eminence (V64) showed a moderate positive correlation $(.2528)$; those who are proud of the economic development of Japan are likely to give a low ranking to preference for a Caucasian .

The analysis of TABLE $V-(1), V-(2)$, and $V-(3)$ revealed that there are correlations between one's ethnic preference in marriage and his/her ethnic identity. In both Nisei and Sansei samples, those who have American-leaning identity are likely to prefer a Caucasian or are likely to have no preference in marriage and vice versa.

In order to support these observations, it is meaningful to refer to TABLE $V I-(1)$ and $V I-(2)$. In the Nisei sample, TABLE VI-(1), the country to support (V65) and identity scale ( 866 ) showed moderate positive correlations 


\author{
TABLE VI \\ CORRELATIONS BETWEEN ETHNIC IDENTITY, \\ OPINIONS ABOUT CHILDREN'S SOCIALIZATION, \\ AND OPINION ABOUT MARRIAGE
}

\title{
(1) THE NISEI SAMPLE
}

$\mathbf{N}=38$

\begin{tabular}{llllllll}
\hline & $V 21$ & $V 22$ & $V 64$ & $V 65$ & $V 66$
\end{tabular}

Qpinion abait children's socialization (V21) 1.0000

Opinion abat the ethnicity and religion

in manciage (V22)

Pride in Japan's eminence (V64)

country to support (V65)

Identity scale (V66)

$\begin{array}{rrlll}.0376 & 1.0000 & & \\ -.3694 & .0783 & 1.0000 & \\ .1258 & .3273 & -.4616^{\star} & 1.0000 \\ .0251 & .3487 & .3663 & .4902 * & 1.0000\end{array}$

* Significant at the .01 level

** Significant at the .001 level

\section{(2) THE SANSEI SAMPLE}

$\begin{array}{lllll}V 21 & V 22 & V 64 & V 65 & V 66\end{array}$

Opinion about children's socialization (V21) 1.0000

qoinion about the ettnicity and religion

in maniage (V22)

Pride in Japan's eminence (V64)

Cantry to support (V65)

Identity scale (V66)

* Significant at the .01. level

** Significant at the :001 level
.08521 .0000

$\begin{array}{lll}-.2614 & .0323 & 1.0000\end{array}$

$\begin{array}{llllll}-.1732 & .1080 & -. .1530 & 1.0000\end{array}$

$\begin{array}{lllll}.1194 & .2400 & -. .3400 & .2786 & 1.0000\end{array}$ 
$(.3273$ and .3487$)$ with opinion about the ethnicity and religion in marriage (V22); those who have Americanleaning identity and who support the U.S. in competition are likely to see religion, rather than ethnicity, as a more important factor in marriage and vice versa. Pride in Japan's eminence (V64) and opinion about children's socialization (V21) showed a moderate negative correlation (-.3694); those who do not have much pride in the economic development of Japan are likely to prefer that their children take an active part with Caucasians rather than Japanese Americans and vice versa. In the Sansei sample, TABLE VI-(2), the analysis of the variables above mentioned revealed almost the same correlations as the Nisei sample (see TABLE XVI-(1) and XVI-(2) on p.119).

From the analysis of TABLE $V$ and TABLE VI, it is concluded that those who perceive themselves as Americans are more likely to choose exogamous marriage with whites than those who perceive themselves as Japanese. The third hypothesis was verified.

\section{Discussion}

Questions remain regarding the relations between ethnic preference in marriage and other domains: ethnic ties, socioeconomic status, and societal hostility, and regarding the issue of mate selection and religious heterogamy. 
TABLE VII

CORRELATIONS BETWEEN ETHNIC PREFERENCE

IN MARRIAGE AND ETHNIC TIES

(THE SANSEI SAMPLE)

The proportion of Japanese American friends (V27) .6999 With $\mathrm{N}(12)$

Non-Japanese Oriental (V17)

SIG .006

The proportion of Japanese American friends (V27) $-.4933$ With $\mathrm{N}$ (15)

Caucasian (V18)

SIG .031

Visiting pattern of friends (V29)

.5070

With $\mathrm{N}$ (1I)

Non-Japanese Oriental (V17)

SIG .056

Visiting pattern of friends (V29)

$-.6867$

With $\mathrm{N}$ (13)

Caucasian (V18)

SIG .005

The proportion of Japanese American friends (V27)

.4184

With $\mathrm{N}(31)$

Japanese American (S1)

SIG .010

The proportion of Japanese American friends (V27)

.4025

With N (22)

Non-Japanese Oriental (S3)

SIG .032

The proportion of Japanese American friends (V27)

$-.5883$

With N (34)

Caucasian (S4)

SIG .000

Visiting pattern of friends (V29)

.4595

With $N(26)$

Japanese American (S1)

SIG .009

Visiting pattern of friends (V29)

.4783

With $N(20)$

Japanese born in Japan (S2)

SIG .016

Visiting pattern of friends (V29)

.3855

With N (19)

Non-Japanese Oriental(S3)

SIG .052

Visiting pattern of friends (V29)

$-.6384$

With $N$ (28)

Caucasian (S4)

SIG .000 
Ethnic Preference in Marriage and Ethnic Ties. In the Sansei sample, TABLE VII, the proportion of Japanese American friends (V27) and visiting pattern (V29) showed strong negative correlations $(-.4933$ and -.6867$)$ with preference for a Caucasian (v18), while those two variables (V27 and V29) showed strong positive correlations 1.6999 and .5070 ) with preference for a non-Japanese oriental (v17); those who have more Japanese American friends and socialize with them more often than Caucasian friends are likely to give a low ranking to preference for a Caucasian, and a high ranking for a non-Japanese oriental. Social interaction patterns (V27 and V29) and ethnic preference in Sansei's own marriage ( $S 1$ to $S 4$ ) showed the same patterns of correlations as ethnic preference in children's marriage. It is assumed that those who have strong ethnic ties also have strong aspiration for endogamy. In the Nisei sample, a noticeable correlation was not observed, which may be explained by the fact that 26 interviewees gave the highest ranking to preference for a Japanese American.

Ethnic Preference in Marriage and socioeconomic status. In the Nisei sample, TABLE VIII-(1), socioeconomic status (V11, V12, and V68) showed moderate negative correlations with preference for Japanese born in Japan (-.1111, -.1680, and -.1690$)$ and strong positive correlations with preference for a Caucasian $(.6741, .3912$, and .4243); those who have achieved higher socioeconomic 
TABLE VIII

CORRELATIONS BETWEEN ETHNIC PREFERENCE IN MARRIAGE AND SOCIOECONOMIC STATUS

\begin{tabular}{|c|c|}
\hline (1) THE NISEI SAMPLE & \\
\hline $\begin{array}{l}\text { Japanese born in Japan (V16) } \\
\text { With } N(12)\end{array}$ & -.1111 \\
\hline Occupation (V11) & SIG .366 \\
\hline $\begin{array}{l}\text { Japanese born in Japan (V16) } \\
\text { With } N(12)\end{array}$ & -.1680 \\
\hline Education (V12) & SIG .301 \\
\hline $\begin{array}{l}\text { Japanese born in Japan (V16) } \\
\text { With } N(12)\end{array}$ & -.1690 \\
\hline Income (V68) & SIG .300 \\
\hline $\begin{array}{l}\text { Caucasian (V18) } \\
\text { With N (12) }\end{array}$ & .6741 \\
\hline Occupation (V11) & SIG .008 \\
\hline $\begin{array}{l}\text { Caucasian (V18) } \\
\text { With } N(12)\end{array}$ & .3912 \\
\hline Education (V12) & SIG . 104 \\
\hline $\begin{array}{l}\text { Caucasian (V18) } \\
\text { With } N(12)\end{array}$ & .4243 \\
\hline Income (V68) & SIG .085 \\
\hline (2) THE SANSEI SAMPLE & \\
\hline $\begin{array}{l}\text { Japanese born in Japan (V16) } \\
\text { With N ( } 9 \text { ) }\end{array}$ & $\begin{array}{l}-.3213 \\
\text { STG } .102\end{array}$ \\
\hline Occupation (VII) & SIG $\cdot 102$ \\
\hline $\begin{array}{l}\text { Japanese born in Japan (V16) } \\
\text { With } N(13)\end{array}$ & -.4257 \\
\hline Education (V12) & SIG .073 \\
\hline $\begin{array}{l}\text { Japanese born in Japan (V16) } \\
\text { With N (12) }\end{array}$ & .0318 \\
\hline Income (V68) & SIG . .461 \\
\hline $\begin{array}{l}\text { Caucasian (V18) } \\
\text { With } N(11)\end{array}$ & .1718 \\
\hline Occupation (V11) & SIG .307 \\
\hline
\end{tabular}


TABLE VIII

CORRELATIONS BETWEEN ETHNIC PREFERENCE IN MARRIAGE AND SOCIOECONOMIC STATUS

(continued)

\begin{tabular}{ll}
\hline (2) THE SANSEI SAMPLE (Continued) & \\
\hline Caucasian (V18) & .1899 \\
With N (15) & SIG .249 \\
Education (V12) & .3945 \\
Caucasian (V18) & SIG .081 \\
With N (14) & \\
Income (V68) & \\
\hline (3) THE SANSEI SAMPLE & -.3269 \\
\hline Japanese American (S1) & SIG .055 \\
With N (25) & \\
Occupation (V11) & -.2483 \\
Japanese American (S1) & SIG .089 \\
With N (31) & \\
Education (V12) & .0076 \\
Japanese American (S1) & SIG .485 \\
With N (27) & .0706 \\
Income (V68) & SIG .355 \\
Caucasian (S4) & SIG .001 \\
With N (31) & .1368 \\
Occupation (V11) & SIG .220 \\
Caucasian (S4) & With N (34) \\
Education (VI2) & Caucasian (S4) \\
With N (30) \\
Income (V68)
\end{tabular}


TABLE IX

CORRELATIONS BETWEEN ETHNIC PREFERENCE IN MARRIAGE AND SOCIETAL HOSTILITY

\section{(I) THE NISEI SAMPLE}

Japanese born in Japan (V16)

$-.3333$

With N (12)

Perception of discrimination against Japanese Americans (V60) SIG .145

Caucasian (V18)

.6667

With $\mathrm{N}(10)$

Hindrance of advancement (V58)

SIG .018

Caucasian (V18)

.5106

With $\mathrm{N}$ (12)

Perception of discrimination against Japanese Americans (V60) SIG .045

(2) THE SANSEI SAMPLE

Japanese born in Japan (V16)

$-.5071$

With $\mathrm{N}$ (13)

Hindrance of advancement (V58)

SIG .038

Japanese born in Japan (V16)

$-.4842$

With $N(13)$

Perception of discrimination against Japanese Americans (V60) SIG .047

Caucasian (V18)

.4901

With N (15)

Perception of anti-Japanese sentiment (V59)

SIG .032

\section{(3) THE SANSEI SAMPLE}

Japanese American (S1)

$-.2836$

With N (29)

Perception of anti-Japanese sentiments (V59)

SIG .068

Japanese born in Japan (S2)

$-.5329$

With N (20)

Perception of anti Japanese sentiments (V59)

SIG .008

Japanese born in Japan (S2)

$-.4634$

With $N(20)$

Peroeption of discrimination against Japanese Americans (V60) SIG .020

Caucasian (S4)

.2846

With $N(31)$

Perception of anti-Japanese sentiment (V59)

SIG .060 
status are likely to give a high ranking to preference for Japanese born in Japan and a low ranking to preference for a Caucasian.

In the Sansei sample, TABLE VIII-(2) and VIII-(3), the variables of ethnic preference in their children's marriage and in their own marriage and socioeconomic status showed the same pattern of correlations as TABLE VIII-(1).

Ethnic Preference in Marrlage and Societal Hostility. In the Nisei sample, TABLE IX-(1), perception of discrimination against Japanese Americans (V60) showed a moderate negative correlation (-.3333) with preference for Japanese born in Japan (V16), while hindrance in advancement (V58) and perception of discrimination (V60) showed strong positive correlations $(.6667$ and .5106$)$ with preference for a Caucasian (V18); those who feel societal hostility are likely to give a high ranking to Japanese born in Japan, and a low ranking to a Caucasian.

In the Sansei sample, TABLE $I X-(2)$ and $I X-(3)$, the variables of societal hostility and ethnic preference in their children's marriage and in their own marriage showed the same pattern of correlations as TABLE IX-(1).

Mate Selection. Ethnic preference in marriage and actual mate selection were consistent in this sample except for two cases who expressed preference for Japanese Americans and married Caucasians. There were 6 single people (five females and one male, with mean age 29.3) who 
selected a Japanese American as the first choice. However, no inference can be made from these data, because the sample size was small and qualitative data were not obtained with regard to this issue.

Religious Heterogamy. The data regarding the issue of racial homogamy in combination with religious heterogamy revealed complicated marriage patterns. In the $\mathrm{Nise}$ sample, of 36 interviewees who have religion, 2 people said that their wives are non-believers, and 3 people answered that their spouses believe in different religions. Examining the interviewees', their spouses', and their parents' religion, there were 18 Christians who have Christian wives and Buddhist parents, 2 Christians who have Christian wives and Christian parents, 2 Buddhists who have Buddhist wives and Christian parents, and 9 Buddhists who have Buddhist wives and Buddhist parents. Among those who have the same religion as their spouses' and who have different religion from their parents' (eighteen Christians and 2 Buddhists), 8 people became Christians and 2 people became Buddhists when they got married. This means that 10 people changed their religion at the time of marriage. The analysis implies that, of the total 40 interviewees, 13 people (32.58) practiced religious heterogamy.

In the Sansei sample, 14 respondents (23.38) claimed to be non-believers, 6 respondents (10\%) Buddhists, 32 (53.3\%) Christians, and $8(13.38)$ believers in other religions. of 
the 36 respondents who are married, 27 people said that their spouses either have the same religion or they have no religion. In this sample, 12 respondents have Japanese American spouses. Among those 12 people, there were 5 people whose spouses have different religions. Therefore, of 36 marriages, the proportion of those who practiced racial homogamy with religious heterogamy was 13.9 percent.

\section{Summary}

Although it is difficult to make a conclusion with variable pairs, which do not include enough cases, the patterns of correlations lead to tentative assumptions.

In both Nisei and Sansei samples, Japanese Americans who have American-leaning identity are likely to prefer exogamous marriage with whites. Yet, those who have stronger ethnic ties prefer marriage with Japanese Americans. In the sansei sample, the relation between ethnic ties and ethnic preference in marriage implies that Sansei Japanese Americans who have stronger ethnic ties tend to give a higher ranking to a non-Japanese orlental than a Caucasian. However, it is still questionable whether or not some Sansei perceive other Orientals as members of the same kind.

Positive relations between preference for a Japanese American or Japanese, societal hostility, and socioeconomic status may be explained by positive relation between 
societal hostility and socioeconomic status, which was tested in the second hypothesis (see pp.85-89). Negative relation between socioeconomic status and exogamous marriage negates the assumption, which was made in the second hypothesis that ethnic preference in marriage explains positive relation between socioeconomic status and ethnic identity. The relation between socioeconomic status and exogamous marriage also negates the assumption made by Montero (1980) who argued that "if we find that socioeconomic status is positively related to outmarriage, the substantial educational and occupational gains the Nisei and the Sansei are making would lead us to predict an accelerating rate of outmarriage among Japanese Americans in the future" (Montero, 1980:55). Further study is needed to examine how exogamous marriage is related to socioeconomic status .

In this study, relations between exogamous marriage and other domains were tested using the variables of ethnic "preference," therefore they do not necessarily explain the actual marriage practice among Japanese Americans. As Merton (1941) argued (see pp.46-47 in this thesis), the high rate of exogamous marriage in the sansei sample is assumed to be a function of opportunity for contacts with whites in the same age cohort.

The empirical data regarding a religion revealed that as Cain (1962) hypothesized (see p.47 in this thesis), 
Japanese communities have experienced racial homogamy in combination with religious heterogamy in the second generation, and this phenomenon still takes place in the third generation. 9

\section{VERIFICATION OF THE FOURTH HYPOTHESIS}

\section{Hypothesis}

There is a difference between the second and the third generations in achieving upward mobility and horizontal mobility, and in perceiving themselves either as Japanese or as Americans.

The test of the fourth hypothesis consists of three subsections: upward moblilty (socioeconomic status), horizontal mobility ("structural" and "marital assimilation"), and ethnic identity ("identificational assimilation").

\section{Upward Mobility}

In order to analyze differences of socioeconomic status between the Nisei sample and the Sansei sample, I selected those who fit in one standard deviation from the mean age which was 65.3 for the Nisei and 31.7 for the Sansei. In the Nisei sample, there were 28 people who were between 60 and 71 years of age, and in the sansei sample, there were 41 people who were between 25 and 39 years of age. The mean of income of the Sansei sample reflects only full-time workers. TABLE $X$ shows the achievement of socioeconomic status 
TABLE X

DIFFERENCE BETWEEN THE NISEI AND THE SANSEI IN EDUCATION, OCCUPATION, AND INCOME

Value

Percentage

Nisei

Sansei

\section{(1) EDUCATION}

Completed high school

Technical or vocational

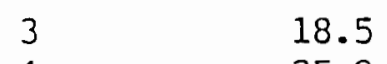

25.9

0.0

0.0

$\left(\frac{\circ}{0}\right)$

school

Some college

25.9

22.0

Completed college

5
6
7
8

18.5

3.7

51.2

Post-baccalaureate study

7.4

17.1

One or more graduate

8

9.8

degrees

Mean

4.852

$\mathrm{N}=27$

6.146

$\mathrm{N}=41$

\section{(2) OCCUPATION}

Lowest status

Highest status

Mean

\section{3 \\ 4 \\ 5 \\ 6 \\ 7}

3.6

17.9

50.0

3.6

25.0

5.286

$\mathrm{N}=28$
2.8

8.3

30.6

47.2

11.1

5.556

$\mathrm{N}=36$

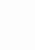

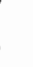

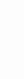

(응) 
of two samples. First of all, the mean of education on the scale was 4.852 (between "technical or vocational school" and "some college") for the Nisei sample, and 6.146 ("completed college") for the Sansei sample. Some Sansei are predicted to finish college education in a few years; therefore, over 90 percent of the sansei will have completed college education. The Sansei sample has already achieved a higher educational level than the Nisei sample.

Secondly, the mean rating of occupation on the scale was 5.286 for the Nisei sample, and 5.556 for the Sansei sample. The proportion of those who were categorized 5 or under were 71.5 percent in the Nisei sample, and 41.7 percent in the sansei sample. As mentioned in the section on "Characteristics of the samples" in Chapter IV, Sansei engage in a wide variety of occupations. Although it is difficult to judge the occupational mobility of sansei from these data, it is safe to say that sansei show a trend to climb up the occupational hierarchy.

Finally, the mean of income was $4.542(\$ 30,000-\$ 39,999)$ for the Nisei sample, and $3.727(\$ 20,000-\$ 29,999)$ for the Sansei sample. Considering the age factor, in which the mean age was 65.3 for the Nisei, and 31.7 for the Sanse 1 , it is assumed that within the span of time of 30 years, the Sansei would receive higher income than the Nisei.

From the analysis of the education, occupation, and income of the two successive generations, it is concluded 
that the Sansei sample has achieved a higher socioeconomic status than the Nisei sample. However, considering all the factors, such as educational level of the Sansei and contextual change of society including technological development, expectation for higher educational attainment, job opportunities and so forth, it is still questionable whether the Sansei have achieved a higher socioeconomic status in "white society" than the Nisei (see the section on "Interpretation of middleman-minority theory" on pp.29-35).

Horizontal Mobility

In this section, I am going to inquire into differences in "structural" and "marital assimilation" between the $\mathrm{Nise}$ sample and the Sansei sample, by dealing with the data on past and present social interaction, the experience and perception of discrimination, formal ethnic affiliation, outmarriage, and opinion about marriage and about children's socialization.

Friends in School Days. TABLE XI indicates horizontal mobility of the Sansei; for the Nisei, their good friends were Japanese Americans, while for most of the Sansei (more than four-fifths of the sample), their good friends were Caucasians. Some Nisei (two-fifths of the sample), who had more Caucasian friends than Japanese friends or equal number of both, grew up in Idaho where Japanese were less concentrated than in the Portland area. In open-ended 


\section{DIFFERENCE BETWEEN THE NISEI AND THE SANSEI IN SOCIALIZATION IN SCHOOL DAYS}

Ethnicity of friends

Nisei

\section{(1) GRADE SCHOOL}

Mostly Japanese Americans

Mostly Japanese Americans and non-Japanese Orientals

Mostly Caucasians

An equal number of all

40.0

5.7

42.9

11.4
Percentage

Sansei

( 8 )

1.7

(8)

3.4

86.4

8.5

$\mathbf{N}=35$

$N=59$

\section{(2) HITH SCHOOL}

Mostly Japanese Americans

42.9

(응

1.7

(은)

Mostly Japanese Americans

2.9

1.7

and non-Japanese Orientals

Mostly Caucasians

40.0

89.7

An equal number of all

14.3

6.9

$N=35$

$\mathrm{N}=58$ 
questions, many interviewees mentioned that Japanese American children were not welcome to join Caucasian groups. In addition to the social context, which did not allow Japanese American children to socialize with whites, Issei parents tried to keep Nisei within the Japanese American community. Fourteen interviewees (408) said that their parents (Issei) wanted them to stick only with Japanese Americans. In addition to this, almost all the Nisei interviewees mentioned that they had no time to play after school, because they went to a Japanese school every day and had to help their parents who were running restaurants, small hotels, or grocery stores. 10

Discrimination. TABLE XII shows differences in the experience and perception of discrimination between two successive generations. In the Nisei sample, 25 interviewees (62.5\%) were interned, mainly in Minidoka, Idaho, during World War II. Ninety-five percent of the Nisei interviewees said that they had experienced, in varying degree, racial discrimination at various places. 11 More than 90 percent of the interviewees said that Japanese Americans are discriminated against even today. The interviewees who said Japanese Americans are discriminated against "only a little" mentioned that they do not know whether Japanese Americans are still discriminated against, because they do not associate with whites.

In contrast, 19 respondents $(32.28 \mathrm{~N}=59)$ in the Sansei 
TABLE XII

DIFFERENCE BETWEEN THE NISEI AND THE SANSEI IN DISCRIMINATION

Value

Percentage

Nisei

$\underline{\text { Sansei }}$

(1) EXPERTENCE OF DISCRIMINATION

Very much

Sometimes

Seldom

Never
3
2
1
0

Mean

Std. Dev.
$62.5(\%)$
22.5
10.0

5.0

2.425

.874

$\mathrm{N}=40$
5.1 (\%)
27.1
35.6
32.2

1.051

$\mathrm{N}=59$

\section{(2) HINDRANCE OF ADVANCEMENT}

Very much

Somewhat

Only a little

Not at all
3

2

1

0
8.1 (응

35.1

29.7

27.0

1.243

.955

$\mathrm{N}=37$
$1.7(\%)$

5.1

20.3

72.9

.373

.740

$\mathrm{N}=59$

Mean

Std. Dev.

\section{(3) PERCEPTION OF ANIT-JAPANESE SENITIMENT}

very much

Somewhat

Oniy a little

Not at all
3
2
1
0

Mean

Std. Dev.
$23.1(\%)$

56.4

17.9

2.6

2.000

.725

$\mathrm{N}=39$ $5.4\left(\frac{9}{8}\right)$

41.1

35.7

17.9

1.339

.837

$\mathrm{N}=56$

\section{(4) PERCEPIION OF DISCRTMINATION AGATNST JAPANESE AMERICANS}

Very much

Somewhat

Only a little

Not at all
3

2

1

0
15.0 (ํ)
62.5
20.0
2.5

1.900

.672

$\mathrm{N}=40$
0.0

24.1

51.7

24.1

1.000

.701

$\mathrm{N}=58$ 
sample have never experienced discrimination. However, many Sansei perceive that there still exists prejudice and subtle discrimination against Japanese Americans.

Both Nisei and Sansei were concerned about the problems of "Skinheads" and "Asian Gangs," which have emerged as a new race issue in the past year. One sansei respondent made a comment on this issue:

"From my sons' experiences, I have to say there is some discrimination going on, and with all the gangs in the news now, it's easy for people to lump all Orientals in with Asian Gangs."

Formal Ethnic Affiliation. Organizational affiliation of successive generations revealed a significant difference. The Nisei belong to an average of 3.2 organizations or clubs (this figure includes not only ethnic organizations but also other organizations). The mean proportion of Japanese American organizations to one's entire organizational affiliation, TABLE XIII-(1), was 71.3 percent; that is, more than two-thirds of the organizations that one belongs to are Japanese American. Fifteen people (37.5\%) said that they belong only to Japanese American organizations. The most popular ethnic organization was JACL.

In contrast, the Sansei belong to an average of 1.4 organizations. Of the 60 respondents, 20 people $(33.38)$ do not belong to any organization. Only 7 people (11.78) belong to ethnic organizations. Among those 7 people, only 
TABLE XIII

DIFFERENCE BETWEEN THE NISEI AND THE SANSEI

IN FORMAL ETHNIC AFFILIATION

\section{Percentage}

Nisei

Sansei

( 1 ) PERCENTAGE OF ETHNIC ORGANIZATION IN

ONE'S ENTIRE ORGANTZATION (\%)

$0-24\left(\frac{\circ}{\circ}\right)$

$25-49\left(\frac{\circ}{\circ}\right)$

$59-74\left(\frac{\circ}{0}\right)$

$75(\%)$ or over

Mean $5.0\left(\frac{\circ}{0}\right)$

7.5

37.5

50.0

71.325

$\mathrm{N}=40$
$84.7(\%)$

0.0

11.9

3.4

10.322

$\mathrm{N}=59$

(2) FREQUENCY TO READ ETHNIC

NEWSPAPERS

Regularly

Occasionally

Infrequently

Never

$\begin{array}{ll}80.0\left(\frac{\circ}{\circ}\right) & 3.3\left(\frac{\circ}{\circ}\right) \\ 5.0 & 13.3 \\ 10.0 & 31.7 \\ 5.0 & 51.7 \\ \mathrm{~N}=40 & \mathrm{~N}=60\end{array}$


DIFFERENCE BETWEEN THE NISEI AND THE SANSEI IN SOCIAL INTERACTION

Percentage

$\underline{\text { Nisei }}$

$\underline{\text { Sansei }}$

\section{(1) PROPORITION OF JAPANESE AMERICAN FRIENDS}

Nearly all

About 3/4

About $1 / 2$

About $1 / 4$

Nearly none

$\begin{array}{rr}32.5\left(\frac{\circ}{6}\right) & 1.7\left(\frac{\circ}{6}\right) \\ 37.5 & 5.0 \\ 22.5 & 6.7 \\ 7.5 & 31.7 \\ 0.0 & 55.0 \\ \mathrm{~N}=40 & \mathrm{~N}=60\end{array}$

$75.0\left(\frac{0}{6}\right)$

$13.5(\%)$

See Japanese American friends
more often than Caucasian friends

See Japanese American friends

17.5

38.5

as often as Caucasian friends

See Japanese American friends

less often than Caucasian friends
$7.5 \quad 48.1$

$N=52$

(3) ETHNIC PEOPLE WITH WHOM ONE IS COMFORTABLE

Japanese Americans

$41.0(\%) \quad 10.2(\%)$

Orientals

0.0

1.7

Caucasians

2.6

15.3

Other

$$
0.0
$$

1.7

$=$ Does not Matter

56.4

71.2

$N=39$

$N=59$ 
4 people belong to JACL, and 3 others to recreational clubs. Frequency to read Japanese American newspapers, TABLE XIII-(2), also showed great differences between the two samples. Wile 80 percent of the Nisei interviewees read Japanese American newspapers regularly, 51.7 percent of the Sansei respondents have never read ethnic newspapers. In comparing the differences in formal ethnic affiliation between the Nisel sample and the Sansei sample, it is clear that ethnic ties are getting dissolved in the third generation.

Social Interaction. The analysis of social interaction patterns at the primary level, TABLE XIV-(1), XIV-(2), and XIV-(3) also indicated horizontal mobility of the newer generation. Ninety percent of the Nisei sample answered that the majority of their friends are Japanese Americans, while 55 percent of the sansei sample reported that they have no Japanese American friends. In both $\mathrm{Nisei}$ and Sansei samples, asked a question about the ethnicity of one's friends when not all of his/her friends are Japanese, majority of the interviewees/respondents said that the rest of the friends are Caucasians. No one reported nonJapanese orientals or other ethnic persons.

Close Friends. Regarding a question of two closest friends, in the Nisei sample, while 33 interviewees (89.28 $\mathrm{N}=371)$ chose a Japanese American as one of his close friends and 29 interviewees $(80.68 \mathrm{~N}=36)$ as the other close friend, 
TABLE XV

CORRELATIONS BEIWEEN NISEI AND SANSEI'S SOCIOECONOMIC STATUS AND THEIR CLOSE FRIENDS' SOCIOECONOMIC STATUS

\begin{tabular}{|c|c|c|c|c|c|c|}
\hline (1) THE NISEI SAMPLE & & & & & \multicolumn{2}{|c|}{$\mathrm{N}=16$} \\
\hline & V11 & $\mathrm{V} 12$ & V35 & V36 & V40 & V41 \\
\hline compation (VI1) & 1.0000 & & & & & \\
\hline Education (V12) & $.6999 *$ & 1.0000 & & & & \\
\hline Education of F1 (V35) & .1130 & .0731 & 1.0000 & & & \\
\hline Coapation of FI (V36) & .2978 & .2429 & $.7820^{\star \star *}$ & 1.0000 & & \\
\hline Education of F2 (V40) & .3826 & .3837 & .1658 & .1675 & 1.0000 & \\
\hline Coapation of F2 (V41) & .2779 & .2404 & .3291 & .2692 & $.7601 *$ & 1.0000 \\
\hline (2) THE SANSEI SAMPLE & & & & & & $\overline{33}$ \\
\hline & $\mathrm{V} 11$ & $\mathrm{~V} 2$ & V35 & V36 & V40 & V41 \\
\hline Coapation (VIl) & 1.0000 & & & & & \\
\hline Ebucation (V12) & $.5702 \star \star$ & 1.0000 & & & & \\
\hline Education of F1 (V35) & $.5473 * \star$ & .3568 & 1.0000 & & & \\
\hline Compatain of Fl (V36) & $.6713 * \star$ & .3066 & $.7025 * \star$ & 1.0000 & & \\
\hline Education of F2 (V40) & $.4511 *$ & $.4615^{\star}$ & $.6489 * x$ & $.5763 \star \star$ & 1.0000 & \\
\hline Coapation of F2 (V41) & 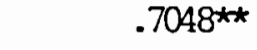 & $.5613^{\star \star}$ & $.4590^{\star}$ & $.6380 * \star$ & $.6008 * \star$ & 1.0000 \\
\hline $\begin{array}{ll}F 1: & \text { Close friend } 1 \\
F 2: & \text { Close friend } 2\end{array}$ & & & & & & \\
\hline $\begin{array}{l}\text { * Significant at the } \\
\text { * } \text { Significant at the }\end{array}$ & $\begin{array}{l}.01 \text { level } \\
.001 \text { level }\end{array}$ & & & & & \\
\hline
\end{tabular}




\section{DIFFERENCE BETWEEN THE NISEI AND THE SANSEI IN OPINION ABOUT CHILDREN'S SOCIALIZATION AND ABOUT MARRIAGE}

\section{Percentage}

$\underline{\text { Nisei }}$

$\underline{\text { Sansei }}$

\section{(1) OPINION ABOUT CHILDREN'S SOCIALIZATION}

Stick pretty much only with

Japanese Americans

$2.6\left(\frac{\circ}{0}\right)$

$0.0\left(\frac{\circ}{0}\right)$

Take an active part mainly with

Japanese Americans

43.6

14.9

Makes little difference

51.3

70.2

Take an active part mainly with

Caucasians

2.6

12.8

Stick pretty much only with Caucasians

0.0

2.1

$N=39$

$\mathrm{N}=47$

(2) IMPORTANCE IN MARRIAGE, EIHINIC BACKGROUND OR REILIGIOUS BACKGROUND

Ethnic background is absolutely

more important

Ethnic background is slightly

more important

Makes little difference

Religious background is slightly more important

Religious background is absolutely more important

0.0

7.1

$N=39$

$\mathrm{N}=56$ 
only 4 interviewees $(10.8 \% \mathrm{~N}=37)$ chose a Caucasian as one of his close friends and 6 interviewees $(16.78 \mathrm{~N}=36)$ as the other close friend. Interestingly, no one chose a nonJapanese Oriental as his close friend. In the Sansei sample, however, while 15 respondents $(26.38 \mathrm{~N}=57$ ) chose a Japanese American as one of his/her close friends and 8 respondents $(14.58 \mathrm{~N}=55)$ as the other close friend, 36 respondents $(63.28 \mathrm{~N}=57)$ chose a Caucasian as one of his/her close friends and 41 respondents $(74.5 \% \mathrm{~N}=55)$ as the other close friend.

Comparing the correlations between the sample's education and occupation and the two closest friends' education and occupation, these two successive generations showed an interesting difference. As indicated in TABLE XV(1) and $X V-(2)$, while, in the Nisei sample, the correlations were positive but not very significant, in the Sansei sample, all these variables (V11, V12, V35, V36, V40, and V41) showed very significant, strong, positive correlations. This is evidence that the Sansei's social interaction is more class oriented than the Nisei's.

Outmarriage and Opinion about Children's Socialization. As mentioned in the section on "Operational definition of variables" in Chapter IV, the data regarding marital status of the Nisei interviewees' siblings and children were also obtained. Among the Nisei, 106 such cases were usable to actually code the Nisei's spouse's ethnicity. Of the 
total number of 146 cases, which includes the original 40 Nisei interviewees, 2 people married non-Japanese orientals, and 12 people married Caucasians. Therefore, the exogamous marriage rate of the Nisei is 9.6 percent, which approximates the figure (10 percent) that Montero (1980) reported in his analysis of J.A.R.P. data.

Among the Sansei, of the 106 children, 59 people (55.68) are married; 36 to Caucasians, and 5 to persons from other ethnic groups. Therefore, the exogamous marriage rate of this group is 69.5 percent, which is very high in comparison with J.A.R.P. data.

TABLE XVI-(1) and XVI-(2) show differences in opinions about marriage and children's socialization. As many as 50 percent of Nisei, as their Issei parents wished, tried to malntain strong ethnic bond in children's socialization as well as in marriage.

The comments from the Nisei interviewees and the Sansei respondents, with regard to these issues, convey different perspectives in socialization and marriage for members of the two generations.

Comments from the Nisei:

"The most important thing in marriage is to have something to share. I think a husband and a wife should have the same cultural background."

"A husband and a wife have to have the same interest. They have to be able to share the same feeling. That is a feeling of being prejudiced." 
"Fortunately, all my daughters married Japanese Americans. I'm so happy."

"My wife and I used to take our children to Japanese church to meet other Japanese kids. But they ended up in marrying Caucasians."

"It is difficult for Japanese Americans to keep inmarriage. When my daughter was born, I thought I might be holding a blue-eyed grand child."

Comments from the sansei:

"My exposure to Japanese Americans was limited, and it never seemed important to specifically look for a Japanese American spouse."

"Children's marriage is their own decision, and it shouldn't be based on race, creed or color."

"I want my children to be happy. As long as their friends are good kids, I don't care their ethnicity."

"I want my children to understand Japanese heritage, but I want them to get along with majority of whites."

"I hope that my children will have an opportunity to socialize with others from all ethnic groups. They (my children) will know who they are, by meeting many people."

The analyses of data regarding "structural" and "marital assimilation" revealed that compared to the $\mathrm{Nisei}$ sample, the Sansei sample has left ethnic milieu and fully appreciates social interaction with the members of main stream Americans. The Sansei are also ready to welcome the further horizontal mobility in future generations.

\section{Ethnic Identity}


TABLE XVII

DIFFERENCE BETWEEN THE NISEI AND THE SANSEI

IN ETHNIC IDENTITY

\section{Percentage}

Nisei

Sansei

\section{(1) PRIDE IN JAPAN'S EMINENCE}

Very much

Somewhat

Makes little difference

Not at all

$\begin{array}{rr}80.0(\%) & 60.3(\%) \\ 17.5 & 24.1 \\ 2.5 & 13.8 \\ 0.0 & 1.7\end{array}$

$\mathrm{N}=40 \quad \mathrm{~N}=58$

\section{(2) COUNIRY TO SUPPORT IN COMPEIITION}

Absolutely Japan

Probably Japan

Hard to decide

Probably the U.S.

Absolutely the U.S.

$\begin{array}{lr}20.0(\%) & 0.0(\%) \\ 25.0 & 10.0 \\ 30.0 & 23.3 \\ 10.0 & 35.0 \\ 15.0 & 31.7 \\ \mathrm{~N}=40 & \mathrm{~N}=60\end{array}$

(3) IDENITTY SCALE

Japanese identity

Value
1
2
3
4
5
6
7
8
9

American Identity

10

Mean

$2.5(\%)$

0.0

$3.3(\%)$

15.0

10.0

25.0

12.5

7.5

1.7

1.7

0.0

13.3

3.3

18.3

20.0

2.5

5.0

35.0

18.3

5.0

4.725

6.217

2.136

2.001

$\mathrm{N}=40$

$N=59$ 


\section{TABLE XVII}

DIFFERENCE BETWEEN THE NISEI AND THE SANSEI

IN ETHNIC IDENTITY

(continued)

Percentage

Nisei

Sansei

(4) PRIDE IN BEING A DESCENDANT

\section{OF JAPANESE}

Very much

Somewhat

only a little

Not at all

$\begin{array}{rr}90.0(\%) & 71.2\left(\frac{\circ}{5}\right) \\ 5.0 & 23.7 \\ 5.0 & 5.1 \\ 0.0 & 0.0 \\ \mathrm{~N}=40 & \mathrm{~N}=59\end{array}$


identity between the Nisei sample and the sansei sample. The mean scores of identity scale of two samples, in XVII(3), indicate that the Nisei have Japanese-leaning identity (mean 4.725), while the Sansei have American-leaning identity (mean 6.217).

Although the quantitative data, regarding ethnic identity, revealed steady "identificational assimilation" from the Nisei to the Sansei, how Sansei perceive themselves in relation with Japan is still questionable. In TABLE XVII-(1) and XVII-(4), it is noticeable that a large proportion of the sansei respondents have pride both in Japan's eminence and in belng a descendant of Japanese. For the Nisei, pride comes from their Japanese background; many Nisei interviewees said, "It's my heritage," "It's my parents' country," or "Because I'm Japanese." For the Sansei, Japan's eminence is a wonderful "success story"; some Sansei respondents wrote that Japan's development showed what hard work and discipline can do. Yet, other Sansei see a connection between them and Japan where their ancestors came from; "Japan is part of my heritage. I'm very proud of being Japanese."

Opinion about cultural preservation also indicated interesting differences between the $\mathrm{Nisei}$ and the Sansei. In the Nisei sample $(N=40), 37$ people (92.5\%) answered that future generations should preserve a Japanese culture, but they have a pessimistic view that sansei and Yonsei (the 
TABLE XVIII

CORRELATIONS BETWEEN AGE FACTOR AND

SOCIETAL HOSTILITY AND IDENTITY

IN THE SANSEI SAMPLE

Age (V4)

Experience of discrimination (V56)

$-.3635$

Hindrance of advancement (V58)

$-.1703$

Perception of anti-Japanese sentiment (V59)

$-.2218$

Perception of discrimination (V60)

$-.1403$

Desire to visit Japan (V63)

$-.3440$

Pride in Japan's eminence (V64)

$-.4050 *$

Country to support in competition (V65)

.1828

Identity scale (V66)

Pride in being a descendant of Japanese (V67)

$-.0539$

$\mathrm{N}=37$

* Significant at the .01 level

All the variables in the table above, except $v 65$ and V66, were coded discordantly so that the largest value represents a low degree of assimilation and the smallest value a high degree of assimilation. 
fourth generation) are not interested in preserving such cultural flavor, including values and beliefs that Issei had brought at the time of immigration. Many Nisei are concerned about how deeply future generations will be able to keep their cultural heritage and will be able to keep identity as Japanese. In the Sansei sample $(\mathrm{N}=59), 14$ people (23.78) answered that a Japanese culture should be blended into the main stream of American culture. They commented that Japanese Americans have to face up to the reality that they are primarily in a Caucasian society where a lot of Japanese values and beliefs do not fit. However, 40 people $(67.8 \%)$ still support cultural preservation and commented that it is very important to be aware of one's cultural heritage so that future generations do not lose identity as Japanese.

TABLE XVIII shows the relations between age factor and the identity and perception of discrimination in the Sansei sample. These correlations imply that among the Sansei, younger people are more susceptible to societal hostility, and are more conscious of the country where their ancestors came from, than older people in the same generation. It is worth noting here some comments from the sansei respondents about how they see a connection between Japanese Americans and Japan:

"I believe there are varying amounts of bigotry everywhere whether it's against Japanese Americans 
or other ethnic groups."

"In general, the image of Japanese Americans is positive. But I'm sure there are still some people who hold a prejudice against us. With the increasing trade tension, those directly affected by it may show more prejudice toward Japanese Americans in the future."

"People are afraid that Japan is buying up the U.S. Their irritation is often directed toward us."

"There will always be some discrimination, either based on history or new topics. We will be always associated with what Japan does in the world."

\section{Summary}

The Sansei have achieved higher upward mobility than the Nisei in every indicator of socioeconomic status. Especially, the attainment of educational level was very high. However, this remarkable educational attainment leads to two questions; 1) whether Sansei Japanese Americans are getting a fair return on their investment (education), including job opportunity, promotion, occupational satisfaction, and interpersonal relations at their work place, and 2) what motivated Sansei to achieve higher education?

The first question should be examined with reference to the positive relation between societal hostility and upward mobility which was tested in the second hypothesis; Japanese Americans are still subordinated in the labor market. The second question may be explained by Nisei's values to discipline their children, which they have inherited from 
their Issei parents, and Nisei's high occupational and income achievement (see pp.30-31 in this thesis); many Nisei knew, through their experiences, the key to economic success was education, and they could also offer their Sansei children educational opportunity. 13

The Sansei have also achieved horizontal mobility by cutting off the ethnic ties and getting into the main stream of Caucasian society. In addition to their association with whites, the Sansei's social interaction pattern was more class oriented than the Nisei. In the test of the first hypothesis, it was assumed that $\mathrm{Nisei}$ were clustered along a hierarchy within their own ethnic boundary. Because of this ethnic boundary and small group size, Nisei were not differentiated by class. The data, which were obtained from open-ended questions, indicated that the sansei made friends at colleges or through jobs, while the Nisei made friends through their wives or ethnic organizations.

A question arises when Nisei's social interaction pattern and sansei's horizontal mobility are examined; how did both Nisei and Sansei perceive non-Japanese orientals as horizontal mobility progresses? In the test of the third hypothesis, in the sansei sample, there was a relation between ethnic ties and preference for non-Japanese Orientals. However, in the fourth hypothesis testing, in both Nisei and Sansei samples, nobody chose other orientals as his/her close friends, and almost none feel comfortable 
with non-Japanese orientals. The Sansei's exogamous marriage was also predominantly with Caucasians. It is assumed that other orientals did not function as a stepping stone for Japanese Americans to achieve structural assimilation.

Although further study is needed to inguire about the Nisei and Sansei's identity, the data which were obtained in this study indicate where Japanese Americans are heading; the Sansei have achieved further "identificational assimilation" by establishing American-leaning identity, while the Nisei have Japanese-leaning identity as well as strong attachment to Japan even though they are American citizens.14 Yet, the Sansei have not established 100 percent American identity.

From the analyses of socioeconomic status, social interaction, and ethnic identity, it is concluded that there is a difference between the Nisei and the sansei in achieving upward mobility and horizontal mobility, and in perceiving themselves either as Japanese or Americans. The fourth hypothesis was verified. 
CHAPTER VI

\section{CONCLUSION AND FURTHER STUDY}

This thesis focused on five domains to study the degree of assimilation of Japanese Americans. Those domains were 1) ethnic identity, 2) socioeconomic status, 3) exogamous marriage with whites, 4) ethnic ties, and 5) societal hostility. The key domain was ethnic identity. Four hypotheses were posited in order to examine relations of those domains. In this chapter, through the evaluation of all the domains, I shall seek to answer the three major concerns of this study; 1) the extent to which the second and third generation of Japanese Americans are assimilated into American society; 2) how far the third generation is assimilated compared to the second generation; and 3 ) what the identity of the second and third generation are.

Many classical assimilation theories of minority groups in the United States argued that as minority groups achieve high socioeconomic status, they start to socialize with whites, and as a consequence, they establish identity which is closer to the host country; upward (vertical) mobility leads to outward (horizontal) mobility, which results in further identificational assimilation. However, Japanese Americans do not fit into this assimilation process. As 
Gordon argued, American society consists of multiple hierarchies (1964:41-42); even when Japanese Americans achieved higher socioeconomic status, there existed a boundary between a Japanese American society and a white society, which was salient especially for the Nisei. Many Nisei people were not self-employed. They were postal clerks, school teachers, accountants, lawyers, and doctors. They had many opportunities for contacts with whites, because their work places were in a larger society where majority people were whites. Notwithstanding this social environment, Nisei social interaction at the primary level was mainly with other Japanese Americans. This pluralistic social structure of $N$ isei has dramatically changed when Sansei became outwardly mobile. The sansei are less affiliated with ethnic organizations and have more frequent interactions with Caucasians. Some Sansei have grown up in the surroundings where none of their friends were Japanese Americans. Therefore, "structural assimilation," which, according to Gordon (1964:81), is the keystone of the arch of assimilation, has taken place in the third generation. Ironically, when the Sansei have achieved structural assimilation, they hit the "point of no-return," because outward mobility was a trade off between "acceptance in the larger society" and "dissolution of ethnic ties."

How did structural assimilation occur, then? History would answer the question: World War II, mass evacuation, 
destruction of the Japanese American community, desegregation after the civil rights movement. When Issei and Nisei returned to their original places after internment, they did not reconstruct a so called Japan town -- unfortunately, the data regarding why Nisei, possibly Issei, did not rebuild their community were not obtained. After the civil rights movement, the Nisei were desegregated, which, in turn, isolated their children, the Sansei, from other Japanese Americans. A series of all those historical incidents, interwoven, contributed to Sansei's further assimilation. Therefore, Sansei structural assimilation was not an anticipated but an inevitable outcome.

Although the $\mathrm{Nisei}$ have lost face-to-face contacts with other Japanese Americans in everyday life, they have reestablished formal and informal organizations, including JACL and other recreational clubs. They have also maintained the same social interaction pattern as they had before the war; almost all of the Nisei's friends are other Japanese Americans, and they feel most comfortable with Japanese Americans rather than Caucasians. The impact of utter rejection and humiliation, reflected in internment, experienced in the formative years of young adulthood, still lingers in the memories of the Nisei, and forms a basis of identity even into old age. It is not questionable that the internment during the war has left scars upon Nisei; how can 
one share the sentiment of the people in the host society who have once rejected him?

The destruction of the Japanese Americans community, therefore, on the one hand, smoothed the way for the sansei to further assimilation; on the other hand, it impeded the Nisei's smooth assimilation, pulling back the Nisei to the lure of ethnic ties, which may be paradoxical, though. This paradox of the trick of history resulted in a generation gap between the Nisei and the Sansei in achieving "identificational assimilation."

When the sansei have achieved structural assimilation, they have also achieved "marital assimilation." Almost two-thirds of the sansei have outmarried, mainly with Caucasians, while only one-tenths of the Nisei outmarried. Analyzing the situational differences in marriage between successive generations, almost all Issei parents wanted Nisei to marry a Japanese American. In addition to this, marriage with whites was prohibited as a social fact and as a social context as well; for Japanese American men, dating Caucasian women was a taboo. In contrast, the sansei are no longer governed by the norms of marrying to the same kind, in spite of their parents' effort to take them to a church to meet other Japanese American chlldren. Furthermore, they had less opportunity to meet other Japanese Americans and had more opportunity to socialize with Caucasians because of a small group size, dissolution of ethnic ties, and 
concentration in a city. Although the Nisei wished that their children could socialize with other Japanese Americans, they did not build a Japanese school; it would have been costly to build their own school for such a small number of children and the city provided satisfactory educational facilities. In addition to this, the Nisei's living standard did not prevent the sansei from interacting with whites. The Sansei's marriage pattern well illustrates Merton's (1941) theory of "intermarriage and social structural fact"; intermarriage is likely to occur when there are factors such as social and cultural assimilation, group consolidation, high social mobility and so forth (Merton, 1941:361-374). The actual marriage practice of the Sansei was a function of new norms and opportunity to interact with whites.

Sansei, average 31 years old, fully enjoy "equal opportunities" which is a principle of the United stated of America. However, have they achieved "identificational assimilation?" How about other types of assimilation, such as "attitude receptional," "behavior receptional," and "civic assimilation," all of which Gordon (1964) posited as subprocesses of assimilation?

Although the third hypothesis was nullified, showing no consistent relation between societal hostility and identity and between societal hostility and ethnic ties, the data implied that there is a positive correlation between 
socioeconomic status and societal hostility. The comments which were obtained from both Nisei and Sansei also indicated that there still exists discrimination against Japanese Americans. They were concerned with anti-Japanese sentiment as well. Especially for Sansei, societal hostility is "fear of competition" which is often directed toward them whenever the relationship between the United states and Japan becomes a controversial issue. The empirical data in this study well support that sansei have not achieved attitude receptional, behavior receptional, and civic assimilation, yet.

Looking back at Japanese Americans' status transformation, Nisei were in the transitional period from "middleman-minority" to the members of a larger society; some of them were selfmemployed, and others were working at public places. In contrast, Sansei are no longer "middleman-minority"; almost none of them is self-employed. They have got out of the position of "middleman-minority" as an occupational status. Over three generations, Japanese Americans have demonstrated a remarkable "success story." However, it is questionable if they are getting fair return of education on occupation and on income in "white society." Promotion in management and interpersonal relations with other workers also have to be studied in order to investigate whether Japanese Americans are still restricted to playing as a buffer in the industrial relations. Further 
studies have to be done in order to examine whether or not the Sansei fully enjoy civil rights as American citizens.

Now, what are the identity of $N$ isei and Sansei? The Nisei, who have not achieved structural assimilation, have Japanese-leaning identity. They were caught between double loyalty, if I may call it, longing both for their ancestral roots and for full acceptance as Americans. In contrast, the Sansei, who have achieved both structural and marital assimilation, have American-leaning identity, and for most of them the United states is the country to which they have loyalty. Yet, they have not achieved complete "identificational assimilation." Is it the Yonsei, the fourth generation, who are going to achieve one hundred percent American identity, then?

Although it is unpredictable whether or not future generations will establish full identificational assimilation, there is a tendency, among younger sansei, to have more pride in their ancestral roots than older sansei. As Japan emerged as an economic power in the world, younger Sansei started to see the connection between them and the country where their grandparents came from; they have more desire to visit Japan, have more pride in the economic development of Japan, are more likely to support Japan in competition, and have more Japanese-leaning identity than older sansei. They are also faced with new societal hostility; they are aware of the fact that Japanese 
Americans sometimes become a target of irritation in the industry whenever mass media stir issues of an unfavorable relationship between the United states and Japan. I may well ask, then, if "identificational assimilation," which waxed in the third generation, is going to wane in the next generation?

Let us return to the previously advanced definition of assimilation:

A state in which both Japanese Americans and whites share the sense of "oneness" without having any prejudice, discrimination, or antagonism because of racial differences, and as a consequence, members of both historically distinctive groups perceive themselves to be equally members of a single, united in-group which strives for the same goals and exhibits common interests.

This is the definition of assimilation of Japanese Americans in this study. As long as Japanese Americans feel societal hostility, regardless of whether it is based upon history or new topics, and as long as Japanese Americans embrace a notion of "we" which refer to themselves, and "they" which refer to the white majority, they are not fully incorporated in this society. This study revealed that Japanese Americans are not at the final stage of Park's cycle: eventual assimilation. It may take a few more generations for them to complete the assimilation processes, if Japanese Americans are going to achieve full assimilation in this country at all. 
There is another flow of Japanese coming to the United states in recent years. Those new immigrants from Japan are called "New Issei." If those New Issei are included, as another variable, in the process of assimilation, Japanese Americans, as a group, will surely experience new, not fully predictable, struggles to retain ethnic identity and at the same time to achieve acceptance and validation by the host society. 


\section{ENDNOTES}

1. Twenty-two people in the Nisei sample have joined military service. Some of them were drafted for the Military Inteliigence service and served as interpreters. Eight people joined "442," a regimental combat team during world War II, and fought in Italy under the slogan of "Go for Broke." The team, which consisted of only Japanese Americans, was the most decorated team in that it was wounded most and got the most medals.

2. While the Japanese Ancestral society is involved with cultural exchange, the JACL deals with political issues. JACL became active in the late 1970's, centering on the issue of $\$ 20,000$ war reparation to each Japanese American who was interned during World War II. Although it has been a long-pending issue, war reparation became controversial in 1970's for two reasons. First, the civil rights movement raised the consciousness of Japanese Americans about their civil rights. Second, Sansei became mature, and sansei attorneys tried to push the issue. With the assistance of the NAACP (the National Association for the Advancement of Colored People), which consists mainly of blacks, the members of JACL occasionally met Senators, the Governor, and the leaders of each county, trying to claim the civil rights of American citizens who happened to be Japanese. Their aim is to protect the civil rights not only of Japanese Americans but also of all the American citizens (information was provided by the past president of the Portland Chapter, Japanese American Citizens League).

3. In order to calculate the correlation coefficient between variables, pairwise missing-value treatment was used in the third hypothesis testing (ethnic preference), and listwise treatment in the first and the second hypotheses testing. There were not significant differences between the correlations with pairwise treatment and those with listwise treatment in the first and the second hypotheses testing.

4. Each region includes the following prefectures. Chubu: Yamanashi, Shizuoka, Nagano, Niigata, Toyama, Ishikawa, GiEu, Aichi, Fukui 
Kinki: Osaka, Kyoto, Hyogo, Shiga, Nara, Wakayama, Mie Chugoku: Yamaguchi, Hiroshima, Shimane, Tottori, Okayama

Kyushu: Nagasaki, Fukuoka, Kumamoto, Oita, Saga, Miyazaki, Kagoshima

5. Some Nisei who joined "442" expressed a desire to visit Europe, especially Italy and France, where they fought during World War II.

6. The average number of children of each generation was coded by using the data which were obtained from the $N$ ise i interviewees. Isse $i$ had average 3 children, Nisei between 2 and 3 children, and sansei 0 or 1 child. In the Sansei sample, of 36 respondents who are married, 18 people had no children.

7. Of the total 40 Nisei interviewees, 5 lost their fathers when they were in childhood. About half of the interviewees said that their parents did not want them to marry even Chinese.

8. Those who have bias against blacks and Hispanics said that Japanese culture is quite different from blacks' and Hispanics' culture. They stressed a low crime rate in the Japanese American community because of strong family ties which is one of the characteristics of Japanese culture.

9. Cain (1962) argued that some Japanese Americans may hold a religious double loyalty; a person who is a member of a Protestant church may take part in activities at a Buddhist church (1962:117).

The data revealed that 5 Nisei interviewees (12.5\% $\mathrm{N}=40)$ and 4 sanse $i$ respondents $(7.48 \quad N=54)$ "often" take part in activities of different religious churches, and $25 \mathrm{Nisei}$ interviewees $(62.5 \% \mathrm{~N}=40)$ and 17 Sansei respondents $(31.5 \% \quad N=54)$ "sometimes" go to different religious churches to enjoy cultural festivals and so forth. In the Japanese American community, churches may function as a place for social rather than religious purposes.

10. In the Nisei sample, 5 interviewees went to a Japanese school less than one year, 6 interviewees 2 to 4 years, and 22 interviewees more than 5 years. Classes were held from 4:00 P.M. to 6:00 P.M., Monday through Friday, plus four hours on Saturdays. Of the total of 40 interviewees, 8 interviewees (20\%) can speak Japanese "very fluently," 12 interviewees (30\%) "pretty 
well," 18 interviewees (45\%) can understand spoken Japanese, and 2 people (5\%) know a few words.

11. A typical example of discrimination was name calling: "Jap." Many Nisei could not buy a house in "white" residential areas. Some Nisei mentioned that even at college they were treated improperly by professors. It was very difficult for Nisei to get a job in public places, and that is why they opened their own business. After the civil rights movement, being a Japanese American became a disadvantage and an advantage as well; the self-employed often lost customers, while sometimes it was easy to loan money from a bank because of the affirmative action.

12. A few respondents who are married to Caucasians stated that their spouses' parents were initially opposed to their engagement. Sansei think that as long as Japanese Americans are visible, prejudice and discrimination will never disappear.

13. Nisei's achievement along the income and occupational hierarchy is often explained by their Japanese values which is characterized by thriftiness, hard work, and perseverance. The data which were obtained in this study revealed that 22 interviewees went to technical schools or colleges on the GI Bill. Therefore, Nisei's achievement in socioeconomic status is attributed not only to a cultural factor but also a situational factor.

14. At the time of the interview, many $N$ isei mentioned that they did not know "who they were" for a long time. One of the interviewees said:

"When I was a kid, I didn't understand why I couldn't play with other kids (whites). I volunteered for the army when the war broke out. I fought in Europe. I felt all loyal. When I was wounded, I felt I am the same as anyone else. But, they put me in the camp..." 


\section{REFERENCES}

Abramson, Harold J. 1975. "The Religioethnic Factor and the American Experience: Another Look at the ThreeGenerations Hypothesis," Ethnicity, Vol.2, No.2, June, pp. 163-177

Adams, Romanzo 1937. Interracial Marriage in Hawail. New York: The Macmillan Co.

Allport, Gordon W. 1954. The Nature of Prejudice. Massachusetts: Addison-Wesley Publishing Co, Inc.

Barnett, Larry D. 1962. "Research in Interreligious Dating and Marriage," Marriage and Family, Vol.24, pp.191-194

- 1963. "Interracial Marriage in California," Marriage and Family, Vol.25, pp.425-427

Beck E. M., Horan, Patrick M. and Tolbert II, Charles M. 1980. "Industrial Segmentation and Labor Market Discrimination," Social Problems, Vol.28, No.2 December, pp.113-130

Berreman, Gerald D. 1964. "Aleut Reference Group Alienation, Mobility, and Acculturation," Anthropologist, No.66, pp. $231-250$

Blalock, Hubert M. Jr. 1967. Toward A Theory of MinorityGroup Relations. New York: John wiley \& Sons, Inc.

Blau, Peter M. 1977. "A Macrosociological Theory of Social Structure," American Journal of Sociology, Vol.83, June, pp. 26-54

Blau, Peter M., Blum, Terry C. and Schwartz, Joseph E. 1982. "Heterogeneity and Intermarriage," American sociological Review, Vol.47, February, pp.45-62

Blauner, Robert 1972. Racial Oppression in America. New York: Harper \& Row, Publishers

Bonacich, Edna 1972. "A Theory of Ethnic Antagonism: the Split Labor Market," American Sociological Review, vol.37, pp.547-559 
- 1973. "A Theory of Middleman Minorities." American Sociological Review, Vol.38, October, pp.583-594

Bonacich, Edna and Modell, John 1980. The Economic Bas is of Ethnic Solidarity: Small Business in the Japanese American Community. Berkeley: University of California Press

Broom, Leonard and Kitsuse, John I. 1955. "The Validation of Acculturation: A Condition to Ethnic Assimilation," American Anthropologist, Vol.57, No.1, February, pp. 44-48

Brown, W.0. 1934. "Culture Contact and Race Conflict," in Race and Culture Contacts. E.B. Reuter (Ed.), New York: McGraw-Hill

Cain, Leonard D. Jr. 1962. "Japanese-American Protestants: Acculturation and Assimilation," Review of Religious Research, Vol.3, No.3, winter, pp.113-121

Chandras, Kananur $v$. 1978. In Racial Discrimination Against Neither-white-nor-black American Minorities. San Francisco: R \& E Research Associates, Inc.

Chewning, Sister Mary, 1973. The Japanese Evacuation Claims From Oregon. Master's Thesis, Holy Names College, Oakland, California

Child, Irvin L. 1943. Italian or American?. New Haven: Yale University Press

Connor, John W. 1977. Tradition and Change in Three Generations of Japanese Americans. Chicago: Nelson-Hall Inc.

Dahrendorf, Ralf 1959. Class and Class Conflict in Industrial Society. Stanford, California: Stanford University Press

Duncan, Otis D. and Lieberson, Stanley 1959. "Ethnic Segregation and Assimilation," American Journal of sociology, vol.50, pp.364-374

Economic Report of the President 1989. Washington: United states Government Printing office

Etzioni, Amitai 1959. "The Ghetto-- a Re-Evaluation," Social Forces, Vol.37, pp.255-262 
Fujii, Toshimasa 1980. The Degree of Acculturation and Success Patterns in Three Generatioins of the Japanese Americans in the portland Area. Master's Thesis, Portland state University

Glaser, Daniel 1958. "Dynamics of Ethnic Identification," American Sociological Review, Vol.23, No.1, February, pp. $31-40$

Glazer, Nathan 1983. Ethnic Dilemmas 1964-1982. Massachusetts: Harvard University Press

Glazer, Nathan and Moynihan, Daniel Patrick 1963. Beyond the Melting Pot. Cambridge, Massachusetts: M.I.T. Press.

Gordon, Milton M. 1958. Social Class in American Sociology. Durham, North Carolina: Duke University Press

- 1964. Assimilation in American Life: The Role of Race, Religion, and National Origins. New York: Oxford University Press

- 1975. "Toward a General Theory of Racial and Ethnic Group Relations," Ethnicity, Vol.2, pp.84-110

Greeley, Andrew M. 1974. Ethnicity in the United states. New York: Wiley

Grodzins, Morton 1949. Americans Betrayed. Chicago: University of Chicago Press

Hansen, Marcus L. 1953. "The Third Generation in America," Commentary, Vol.14, pp.492-500

Hastings, Donald W., Clelland, Donald A. and Danielson, Robin L. 1982. "Gordon's Assimilation Paradigm Revisited: The Issue of Ethnic comunality, Insularity, and Return Migration," Research in Race and Ethnic Relations, Vol.3 Edited by Marrett, Cora Bagley and Liggon, Cherly, pp.189-206

Hirschman, Charles 1980. "Theory and Models of Ethnic Inequality," Research in Race and Ethnic Relations, Vol.2, pp.1-20, JAI Press Inc.: Greenwich, Connecticut

- 1983. "America's Melting Pot Reconsidered," Annual Review of Sociology, Vol.9 pp.397-423

Hosokawa, Bill 1969. Nisei: The Quiet Americans. New York: V1lliam Morrow and Company, Inc. 
- 1982. JACL in Quest of Justice. New York: William Morrow and Company, Inc.

Hosokawa, Fumiko 1978. The Sansel: Social Interaction and Ethnic Identification among the Third Generation Japanese. Doctoral Dissertation at UCLA

Hughes, Helen MacGill 1970. Racial and Ethnic Relations. New Jersey: Allyn and Bacon, Inc.

Ianni, Francis A.J. 1957. "Residential and Occupational Mobility as Indices of the Acculturation of an Ethnic Group," Social Forces, Vol.36, October, PP.65-72

Ichihashi, Yamato 1932. Japanese in the United states =A Critical study of the problems of the Japanese Imigrants and Their Children. California: Stanford University Press

Ichioka, Yuji 1988. The Issei =- The Forld of the First Generation Japanese Immiarants, 1885-1924. New York: The Free press

Jacobs, Paul and Landau, Saul with Pell, Eve 1971. To Serve the Devil. Vol.2, Colonials and Sojouners. New York: Random House

Johnston, Ruth 1969. The Assimilation Myth: A study of Second Generation polish Immigrants in Hestern Australia. The Hague: Martinus Nijhoff

Kallen, Horace 1924. Culture and Democracy in America. New York: Boni \& Liveright

Kennedy, Ruby Jo Reeves 1952. "Single or Triple MeltingPot?: Intermarriage Trends in New Haven, 1870-1950," american Journal ef Seclelegy, Vol.58, No.1, Ju1y, pp. 56-59

Klefer, Christie 1974 . Changing cultures, changing Lives, San Francisco: Jossey-Bass

K1kumura, Akemi and Kitano, Harry H. L. 1973. "Interracial Marriage: A Picture of the Japanese," Journal of soctal Issues, Vol.29, No.2, pp.67-81

Kim, Kwang Chung and Hurh, Won Moo 1988. "Korean Immigrants' Mental Health: A Sociological Analysis." Paper prepared for Annual Meeting of the Assoclation for Asian Studies, San Francisco, March 25-27, 1988 
Kitano, Harry H.L. 1974. "Japanese Americans: The Development of a Middleman Minority," Pacific Historical Review, Vol.43, No.4, November, pp.500-519

- 1976. Japanese Americans: The Evolution of a Subculture. Englewood Cliffs, New Jersey: Prentice-Hall, Inc.

Kramer, Judith R. 1970. The American Minority Community. New York: Thomas Y. Crowell Company

Kuo, Chia-Ling 1982. "Perceptions of Assimilation Among the Chinese in the United States," Research in Race and Ethnic Relations. Edited by Marrett, Cora Bagley and Leggon, Cheryl, Vol.3, pp.127-143

Lam, Franki 1986. "Suburban Residential segregation of Chinese and Japanese Americans: 1960, 1970 and 1980," Sociology and Social Research, Vol.70, No.4, July, pp. 263-265

Lavender, Abraham D. and Forsyth, John M. 1976. "The Sociological study of Minority Groups as Reflected by Leading Sociological Journals: Who Gets Studied and who Gets Neglected?," Ethnicity, Vol.3, No.4, December, pp. $388-398$

Lebra, Takie Sugiyame 1972. "Acculturation Dilemma: The Function of Japanese Moral Values for Americanization," Council on Anthropology and Education New Letter, Vol.3, No.1, pp.6-13

Lee, Sharon M. and Yamanaka, Keiko 1987. "Intermarriage in the Asian American Population." Paper prepared for presentation at the 82 nd Annual Meeting, American Sociological Association, August 17-21, 1987, Chicago.

Levine, Gene N. and Montero, Darrel 1973. "Socioeconomic Mobility Among Three Generations of Japanese Americans," Journal of Social Issue, Vol.29, No.2, pp.33-48

Lieberson, Stanley 1963. Ethnic Patterns in American Cities. New York: The Free Press

- 1980. A piece of the pie. Berkeley: University of California Press

Light, Ivan H. 1972. Ethnic Enterprise in America: Business and Welfare Among Chinese, Japanese, and Blacks. Berkeley: University of California Press 
Lyman, Stanford M. 1968. "The Race Rrlations Cycle of Robert E. Park," Pacific Sociological Review, Vol.2, Spring, pp. $16-22$

Mannheim, Karl 1929. Ideology and Utopia. London: Routledge \& Kegan Paul

Massey, Douglas S. and Denton, Nancy A. 1985. "Spatial Assimilation as a Socioeconomic Outcome," American Sociological Review, Vol.50, pp.94-106

Matusoka, Jitsuichi 1946. "Race Relations and Nisei Problems," Sociology and Social Research, Vol.30, pp. 452-459

Mc Call, George J. and Simmons, J. L. 1966. Identities and Interactions. New York: The Free Press

Merton, Robert $K$. 1941. "Intermarriage and Social Structural Fact and Theory," Psychiatry, Vol.4, August, pp.361-374

Miller, Delbert C. 1983. Handbook of Research Design and Social Measurement. New York: Longman Inc.

Min, Pyong Gap 1988. "Problem of Korean Immigrant Entrepreneurs." Paper prepared for presentation at the 1988 Annual Meeting of the Asian Studies Association, San Francisco, March 26, 1988

Montero, Darrel 1980. Japanese Americans: Changing Patterns of Ethnic Affiliation Over Three Generations. Colorado: Westview Press, Inc.

Montero, Darrel and Levine, Gene N. 1977. "Research Among Racial and Cultural Minorities: Problems, Prospects, and Pitfalls," Journal of Social Issues, Vol.33, No.4

Morgan, Gordon D.1981. America Without Ethnicity. New York: Kennikat Press Corp.

Myrdal, Gunnar 1964. An American Dilemma. New York: McGrawHill Book Company

Nam, B. Charles 1963. Methodology and Scores of Socioeconomic Status. Washington D.C.: U.S. Bureau of the Census

Newman, William M. 1973. American Pluralism: A study of Minority Groups and Social Theory. New York: Harper \& Row, Publishers 
Omi, Michael and Winant, Howard 1986. Racial Formation in the United States: From the 1960s to the 1980s. New York: Rlutledge \& Kegan Paul

Parenti, Michael 1970. "Ethnic Politics and the Persistence of Ethnic Identifications," in The Ethnic Factors in American Politics. Edited by Hawkins, Barrett $w$. Columbus, Ohio: Charles E. Merrill Publishing Co.

Park, Robert E. 1950. Race and Culture. Glencoe, I1l.: Free Press

Park, Robert E. and Burgess, Ernest W. 1921. Introduction to the Science of Sociology. Chicago: University of Chicago Press

Pavlak, Thomas J. 1976. Ethnic Identification and Political Behavior. San Francisco, Ca.: R and E Research Associates

Petersen, william 1971. Japanese Americans: Oppression and Success. New York: Random House

Rex, John 1970. Race Relations in Sociological Theory. New York: Schocken Books

Rose, Arnold and Rose, Caroline 1950. America Divided, Minority Group Relations in the United States. New York: Alfred A. Knopf

Rosenthal, Erich 1960. "Acculturation Without Assimilation?," American Journal of Sociology, Vol.66, November, pp.275288

Schmid, Calvin F. and Nobbe, Charles E. 1965. "Socioeconomic Differentials among Nonwhite Races," American Sociological Review, Vol.30, pp.909-922

Shibutani, Tamotsu and Kwan, Kian M. 1965. Ethnic Stratification: A Comparative Approach. New York: Macmillan

Sowell, Thomas 1975. Race and Economics. New York: David Mckay Company, Inc.

Stearns, Marjorie R. 1937. Japanese People in Oregon. Master's Thesis at University of oregon. Reprinted by $R$ and $\mathrm{E}$ Research Associates

Stewart, George R. 1954. American Hays of Life. New York: Doubleday and Co. 
Thomas, Dorothy Swaine and Nishimoto, Richard N. 1946. The Spoilage. Berkeley: University of California Press

Tienda, Marta and Lii, Ding-Tzann 1987. "Minority Concentration and Earnings Inequality: Blacks, Hispanics, and Asians Compared," American Journal of Sociology, Vol.93, No.1, July, pp.141-165

Tinker, John N. 1973. "Intermarriage and Ethnic Boundaries: The Japanese American Case," Journal of Social Issues, Vol.29, No.2, pp.49-66

Tsuruki, Makoto 1976. Japanese Americans. Tokyo, Japan: Kodansha Inc.

U.S. Department of Commerce, Bureau of Census 1980. "Japanese, Chinese, and Filipinos in the United States," 1980 Census of Population, Washington, D.C.: Government Printing office.

Van Den Berghe, Pierre L. 1976. Ethnic Pluralism in Industrial Societies: A Special Case?," Ethnicity. Vo1.3, No.3, September

Weber, Max 1930. The Protestant Ethic and the Spirit of Capitalism. New York: Charles Scribner's Sons

Willhelm, Sidney M. 1980. "Can Marxism Explain America's Racism?," Social Problems, Vol.28, pp.98-112

Williams, Robin M. Jr. 1970. American Society: Sociological Interpretation. New York: Alfred A. Knopf, Inc.

Woodrum, Eric 1978. Japanese American Social Adaptation over Three Generations. Doctoral Dissertation at the University of Texas, Austin

1981. "An Assessment of Japanese American Assimilation, Pluralism, and Subordination," American Journal of Sociology, Vol.87, pp.157-169

Zangwill, Israel 1914. The Melting pot. New York: The Macmillan Co. 
APPENDIX A

THE NISEI AND SANSEI'S SOCIOECONOMIC STATUS 
TABLE XIX

THE NISEI AND SANSEI'S SOCIOECONOMIC STATUS

Value

Percentage

Nisei

Sansei

\section{(1) EDUCATION}

Some high school

Completed high school

Technical or vocational school

Some college

Completed college

Post-baccalaureate study

one or more graduate degrees

Mean
2
3

0.0 (응)

17.9

25.6

23.1

17.9

2.6

12.8

5.000

$\mathrm{N}=39$
3.3 (\%)

1.7

1.7

23.3

45.0

11.7

13.3

5.933

$\mathrm{N}=60$

\section{(2) OCCUPATION}

Lowest status

Highest status

2

3

4

5

6

7
2.5 (응)

2.5

15.0

42.5

15.0

22.5

5.325

$\mathrm{N}=40$
$0.0(\%)$

2.0

16.0

28.0

36.0

18.0

Mean

5.520

$\mathrm{N}=50$

\section{(3) INDIVIDUAL INCOME}

$\$ 9,999$ or under $\$ 10,000-\$ 19,999$

$\$ 20,000-\$ 29,999$

$\$ 30,000-\$ 39,999$

$\$ 40,000-\$ 49,999$

$\$ 50,000-\$ 59,999$

$\$ 60,000$ or over
1

2

3

4

5

6

7
2.7 (음

16.2

18.9

21.6

10.8

10.8

18.9

4.297

3.604

Mean 
TABLE XIX

THE NISET AND SANSEI'S SOCIOECONOMIC STATUS (continued)

Value Percentage

Nisei Sansei

\section{(4) FAMILY TOTAL INCOME}

$\$ 9,999$ or under

$\$ 10,000-\$ 19,999$

$\$ 20,000-\$ 29,999$

$\$ 30,000-\$ 39,999$

$\$ 40,000-\$ 49,999$

$\$ 50,000-\$ 59,999$

$\$ 60,000$ or over

Mean

\begin{abstract}
1
3

4

5

6

7
\end{abstract}

0.0 (\%)

5.9

17.6

11.8

20.6

8.8

35.3

\subsection{7}

$\mathrm{N}=34$
2.3 ( 8 )

0.0

4.7

16.3

16.3

20.9

39.5

5.651

$\mathrm{N}=43$

Nisei's individual income and family total income in TABLE (3) and (4) reflect percentage of income distribution before interviewees' retirement. The value is not adjusted to 1988 . 


\section{APPENDIX B}

INTERVIEW SCHEDULE AND QUESTIONNAIRE 


\section{INFORMED CONSENT}

I, , hereby agree to serve as a subject in the research project on the assimilation of Japanese Americans in the Portland area.

I understand that the study involves face-to-face interview, telephone interview, and mailed questionnaire.

It has been explained to me that purpose of the study is to learn the present status of Japanese Americans living in the Portland area; 1)the extent to which Japanese Americans are assimilated in American society, 2) how far the third generation is assimilated compared to the second generation, and 3 ) what the identity of the second and third generation of Japanese Americans are.

I may not receive any direct benefit from participation in this study, but my participation may help to increase knowledge which may benefit others in the future.

I have been assured that all information I give will be kept confidential and that the identity of all subjects will remain anonymous. I have also been assured that I may refuse to answer specific questions or terminate the interview at any time.

I have read and understand the foregoing information.

Date

Signature

If you experience problems that are the result of your participation in this study, please contact the secretary of the Human Subjects Research and Review Committee, office of Grants and Contracts, 303 Cramer Hall, Portland state University, 464-3417. 
The Degree of Assimilation of the Second and Third Generation of Japanese Americans

As a part of the thesis project of Hisako Matsuo(a Candidate of the M.A. degree in Sociology), under the supervision of

$$
\begin{aligned}
& \text { Prof. Leonard Cain (Committee Chair), Ph.D } \\
& \text { Prof. Jan Hajda, Ph.D } \\
& \text { Prof. Robert Shotola, Ph.D }
\end{aligned}
$$

of Sociology Department at Portland State University.

Explanations and Instructions

1. There are no right or wrong answers to the questions.

2. The only appropriate answer to each question is the one that best applies to you if not given specific instructions.

3. Your participation in this study is completely voluntary.

4. Your response will be kept strictly confidential.

5. If you have any questions regarding this study, call or write to

Hisako Matsuo

Department of Sociology Portland State University

Portland, OR. 97207

Tel. Office (503) 464-3926 


\section{INTERVIEW SCHEDULE (NISE i)}

SECTION I General information

1 What is your sex?

1 Male

2 Female

2 Please tell me your birth date and place of birth. Date Place (City) (state)

3 a) What is your present marital status?

$\begin{array}{ll}1 & \text { Married } \\ -2 & \text { Single } \\ - & \text { Widowed }\end{array}$

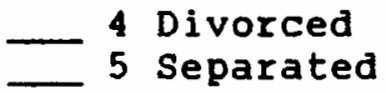

b) If your answer is "married," is this your first marriage?

1 Yes

2 No

4 If ever married, please tell me something about your spouse's background.

a) Where was your spouse born?

City

state

b) Is/Was your spouse...

1 Japanese American

- 2 Non-Japanese Oriental

- 3 Japanese (born in Japan)

4 Caucasian

- 5 other (specify)

c) If your spouse is a Japanese American, is she...

$-\begin{array}{ll}1 & \text { Issei } \\ 2 & \text { Nise } 1\end{array}-4$ Sansei 
5 Please list the year of birth, sex, and marital status of your children, and their spouse's ethnicity if ever married.

\begin{tabular}{|c|c|c|}
\hline ear & $\operatorname{Sex}(M / F)$ & $\begin{array}{l}\text { Marital } \\
\text { status }\end{array}$ \\
\hline
\end{tabular}

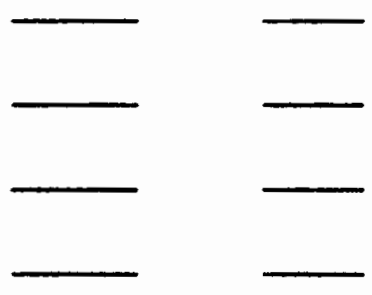

SECTION II Occupation \& Education

1 What is your present occupation (last occupation if retired)?

Please tell me about the job more specifically. (ex. Title, position, routine work etc.)

2 Please list the $k$ ind and length of the occupations you have engaged in and tell me the reason why you changed the job.

Occupation

Year

Reason

(Ex.)Farmer

1925-1940

I opened new business.

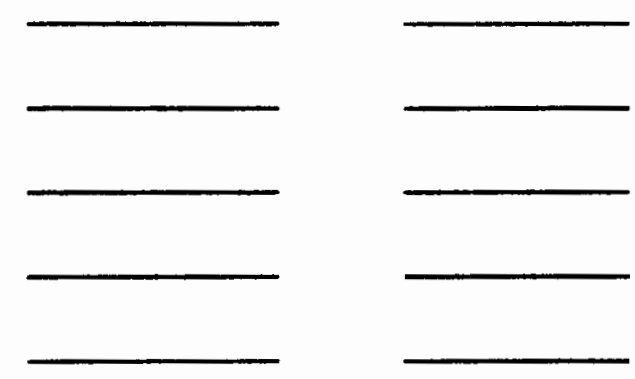


3 What degree of school have you (and your spouse if ever married) completed? Please check only one number which describes your formal schooling.

a) Yourself

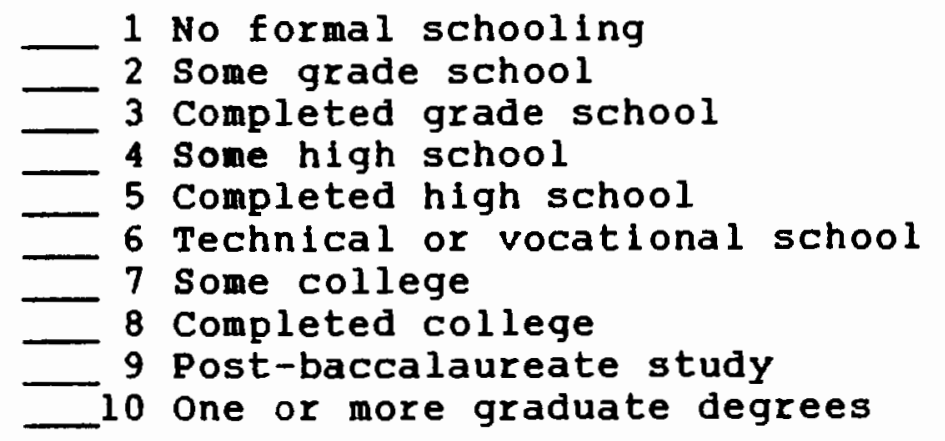

b) Your spouse

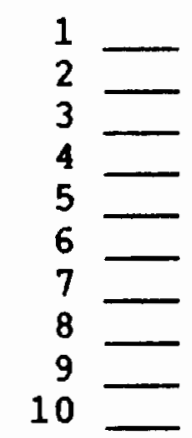

SECTION III Socialization in school days and information on parents and brothers and sisters.

1 When you were in grade school and high school, were most of the students orientals or Caucasians?
a) Grade school
b) High school

2 While you were in grade school and in high school, were most of your friends Japanese Americans, non-Japanese orientals, or Caucasians?
a) Grade school
b) High School

1 Mostly Japanese Americans

2 Mostly Japanese Americans and non-Japanese orientals

3 Mostly Caucasians

- 4 an equal number of all

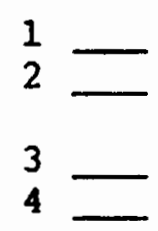

3 Please list the year of birth, sex, marital status, and spouse's ethnicity of your brothers and sisters.

Year $\operatorname{Sex}(M / F)$ Marital status spouse's ethnicity 
4 What part of Japan (prefecture) were your parents Erom? Father

Mother

5 What kind of work did your parents do when you were in your teens?

6 Please tell me what kind of opinions your parents had about your friends. Did your parents say/favor that you (should) socialize with...
a) Father
b) Mother
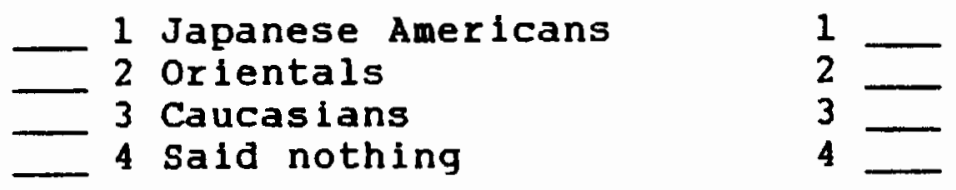

7 What kind of opinion did your parents have about your marriage? Did your parents say/favor that you (should) $\operatorname{maxry} \ldots$
a) Father
b) Mother
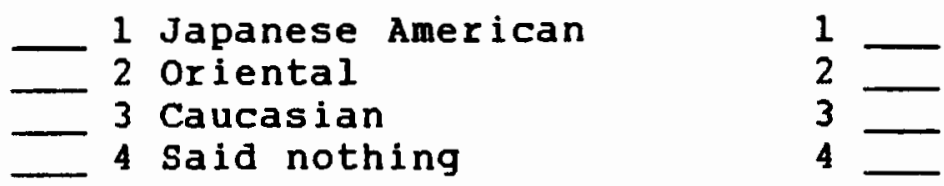

8 How close were you to your parents? Would you say...

a) Father

$$
\text { In your Childhood Adolescence Young adulthood }
$$

1 Very close

2 Somewhat close

3 Nelther close nor distant

4 Somewhat distant

5 very distant 
b) Mother

In your Childhood Adolescence Young Adulthood

1 Very close

2 Somewhat close

3 Neither close nor distant

4 Somewhat distant

5 Very distant

9 Please list the places you have lived in, the length of residence, your age when you were living in that place, the ethnicity and social class (Ex. laborers, selfemployed workers etc.) of neighborhood. (If you moved within the same city, please specify the area.)
Place
Year
Age
Ethnicity
Social class

(Ex.)

Portland

NW

Portland SE

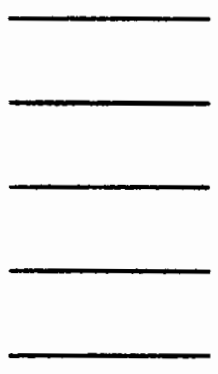

SECTION IV
$1923-1930$

$0-7$

$1931-1937 \quad 8-14$

Mostly

Caucasians

Japanese

Mostly

Americans

Self-employed

Mostly

laborers
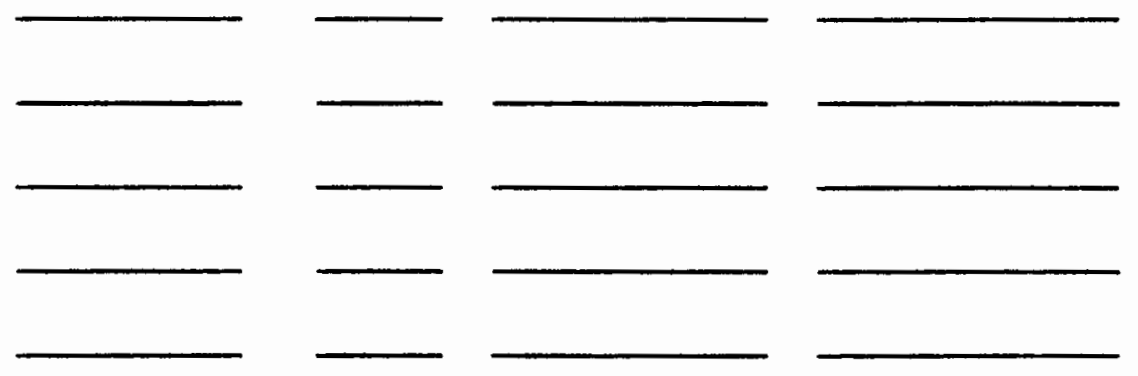

Opinion about your children's socialization and marriage

1 Do /Did you want your children to ...

1 stick pretty much only with Japanese Americans?

- 2 Take an active part mainly with Japanese Americans while socializing with Caucasians

- 3 Makes little difference. socializing with Japanese Americans?

5 stick pretty much only with Caucasians? 
Please tell me why you chose that number.

2 Please tell me about your ethnic preference of your children's spouse. Write in the ranking $(1,2,3, \ldots)$ of your preference.

Japanese American
Japanese born in Japan
Non-Japanese oriental
Caucasian
Other (specify)

Please tell me why you made that decision.

3 In marriage, do you think that ethnic back ground is more important than religious background?

1 Ethnic background is absolutely more important than religious background.

2 Ethnic background is slightly more important than religious background.

3 Makes no difference

4 Religious background is slightly more important than ethnic background.

5 Religious background is absolutely more important than ethnic background.

SECTION V Present socialization

1 How many relatives do you have in the Portland area?

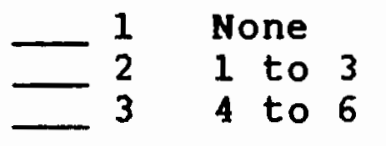

2 Do you still keep in touch with any of your relatives in Japan?

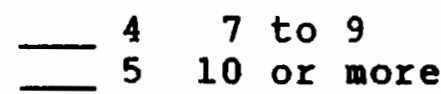

510 or more

2 No 
3 About what proportion of people(co-workers, clients), you see (saw) regularly at work, are (were) Japanese Americans?
a) Co-workers
b) Clients
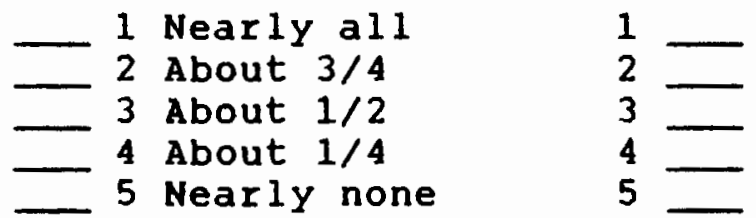

4 If your answer is other than "nearly all," tell me the ethnicity of the rest of the people.
a) Co-workers
b) Clients
三
1 Non-Japanese oriental
2 Caucasian
3 other (specify)

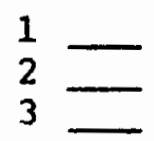

5 About what proportion of your friends are Japanese Americans? (They do not have to live in the Portland area.)

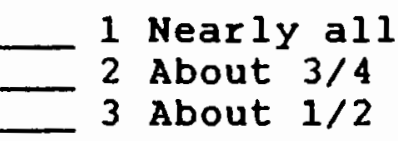

4 About $1 / 4$

5 Nearly none

6 If your answer is other than "nearly all," tell me the ethnicity of the rest of your friends.

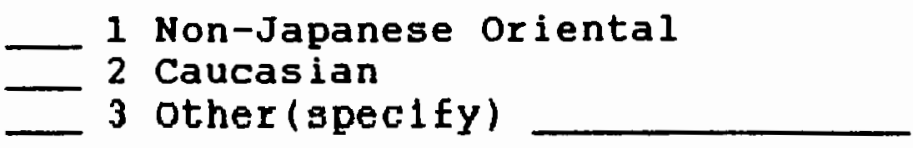

7 Do you see, visit, or invite your Japanese American friends ...

1 More often than your Caucaslan frlends?

- 2 As often as your Caucasian friends? 
8 How often a month do you see, visit, or invite your relatives?

$$
\begin{array}{rrrr}
1 & \text { None } & & 4 \\
2 & 1 \text { to } 3 & 7 \text { to } 9 \\
3 & 4 \text { to } 6 & 10 \text { or more }
\end{array}
$$

9 Tell me something about two of your close friends. (By close friend, I mean someone you talk to when your are in trouble.)

1) Age $\longrightarrow$ Sex

Ethnic background

Educational background

occupation

How long have you known him/her?

How did you get to know him/her?

2) Age

Ethnic background

Educational background

occupation

How long have you known him/her?

How did you get to know him/her?

10 You feel most comfortable when you are with ...

- 1 Japanese Americans

- 2 other Orientals

- 3 Caucasians

- 4 Other (specify)

- 5 Makes little di f́erence 
SECTION VI Religion

1 What is your religion?

\begin{tabular}{ll}
1 & Nonbeliever \\
2 & Buddhist \\
3 & Christian \\
\hline & Other (specify) \\
\hline
\end{tabular}

2 What was your parents' religion?
a) Father
b) Mother

\begin{tabular}{ll}
1 & Nonbeliever \\
-2 & Buddhist \\
3 & Christian \\
\hline & Other(specify)
\end{tabular}

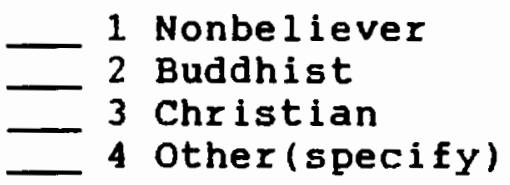

3 If ever married, what is your spouse's religion?
- 1 Nonbeliever
2 Buddhist
- 3 Christian
_ 4 Other (specify)

4 How often do you go to church?
_ 1 Once a week
- 2 Few times a month
- 3 Once a month or less often

5 About what proportion of people you see at church are Japanese Americans?

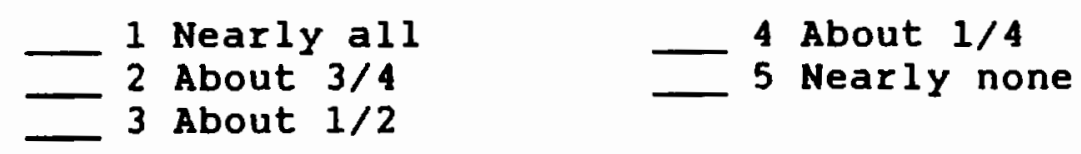

6 If your answer is other than "nearly all," tell me the ethnicity of the rest of the members?

\footnotetext{
$\begin{array}{ll}1 & \text { Non-Japanese oriental } \\ -2 & \text { Caucasians } \\ 3 & \text { Other (specify) }\end{array}$
} 
7 Do you take part in the church activities of different religion? (Ex. Food bazaar at Buddhist church)

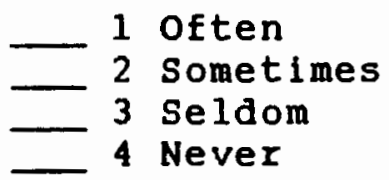

SECTION VII Organizational affiliation

1 How many clubs or organizations do you belong to? (Please exclude church.)

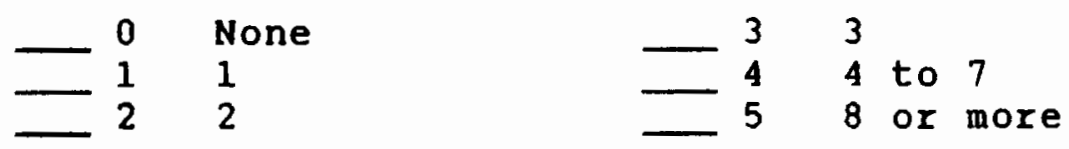

2 Do you belong to Japanese Americans' organizations?
1 Yes
2 No

If "yes," please list the name of the organizations and write in the total number.

Total

3 of all the organizations you belong to, which one do you devote the most time to? please tell me the name and activities of the organization.

4 Do you read Japanese Americans Newspapers? (Ex. Pacific Citizen)

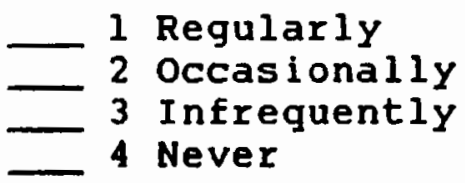


SECTION VIII About culture

1 Do you speak Japanese?

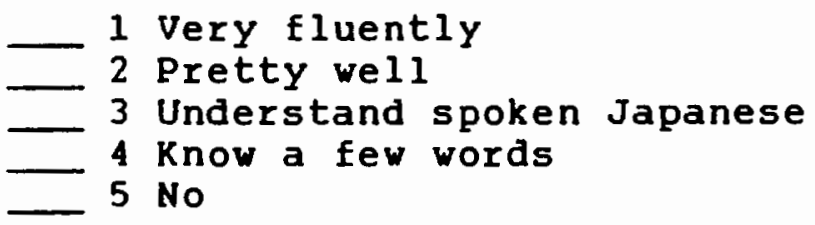

2 Did you go to a Japanese language school when you were in school?
1 Yes
2 No

If "Yes," how long?

years

3 If you do not speak Japanese or do not speak it well, do you want to learn Japanese?

1 Yes 2 No

If "yes," please tell me the reason.

4 Do you think Japanese Americans should preserve something of Japanese culture, or Japanese Americans should blend the culture into main stream of American culture?

- 1 Should preserve own culture

- 2 should blend

- 3 Makes little difference

Please tell me why you chose that number. 
5 When was the last year you celebrated the following holidays?

1 Easter

2 Memorial Day

6 New Year's Day

7 Setsubun (Bean Throwing Festival)

3 Fourth of July

8 Hinamatsuri (Girls' Festival)

4 Thanksgiving

9 Kodomonohi

5 Christmas (Boys' Festival)

10 O-Bon

SECTION IX About discrimination

1 Have you experienced or felt discrimination in housing, at schools, on jobs, or other places because you are a Japanese American?

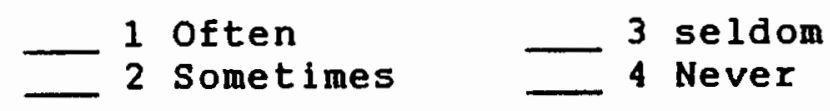

If you ever experienced or felt discrimination, please tell me more specifically.

2 Have you ever heard that your family or your friends had experienced discrimination because they are Japanese Americans?

1 Yes

2 No

If "yes," please tell me more specifically.

3 How much do you think being a Japanese American has hindered your advancement?

1 Very much

-2 Somewhat
3 Only a little
4 Not at all 
If your answer is other than "not at all," please tell me more specifically.

4 Do you think that there is "anti-Japanese sentiment" among Americans because of trade frictions between the United States and Japan?

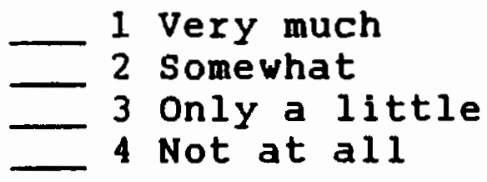

5 Do you think that Japanese Americans are still discriminated against?
$\begin{array}{ll}1 & \text { Very much } \\ 2 & \text { Somewhat }\end{array}$
3 Only a little
-4 Not at all

Will you please explain more specifically?

SECTION $X$ About identity

1 If you won a free trip abroad, which country would you like to visit?

2 Have you ever been to Japan?
1 Yes
2 No

If "Yes," please tell me how old you were at that time and the purpose of travel.

Age

Purpose 
If "No," would you like to visit Japan?
\begin{tabular}{ll}
1 & Very much \\
- & 2 \\
\hline & Somewhat
\end{tabular}
3 A little
4 Not at all

3 Japan became an economic power after World War II. Are you proud of her eminence?
$\begin{array}{ll}1 & \text { Very much } \\ 2 & \text { Somewhat }\end{array}$
$\begin{array}{ll}3 & \text { Makes little difference } \\ - & \text { Not at all }\end{array}$

Please tell me why you chose that number.

4 Suppose that you are watching a volleyball game of the olympics, the U.S. vs. Japan. Which team do you support?

$\begin{array}{ll}1 & \text { Absolutely Japan } \\ 2 & \text { Probably Japan } \\ 3 & \text { Hard to decide } \\ \text { - } 4 \text { Probably the U.S. } \\ 5 \text { Absolutely the U.S. }\end{array}$

5 Given a scale of 1 (a complete Japanese identity) to 10 (a complete American identity), please indicate the number which, in your judgment, most closely describes your identity.

Japanese
\[ \begin{array}{cccccccccc}1 & 2 & 3 & 4 & 5 & 6 & 7 & 8 & 9 & 10 \\ 1---1 & ---1 & ---1 & ---1 & ---1 & ---1 & ---1 & ---1 & ---1 & ---1\end{array} \]

6 Are you proud of being a descendant of Japanese?

1 very much

2 Somewhat

- 3 only a little

- 4 Not at all 
SECTION XI About income

1 What is your total income and family total income of last year before taxes?(Please include income from rents, investments, and interests etc.)

Your income

Family income
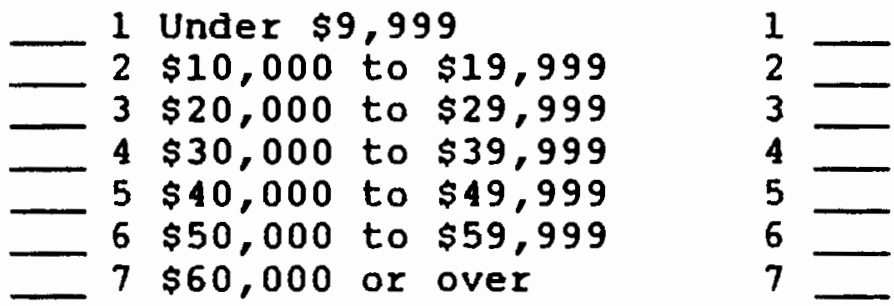

I really appreciate your kind cooperation. 
THE INTRODUCTORY LETTER FOR THE QUESTIONNAIRE

January 1989

Dear friend:

My name is Hisako Matsuo, and I am a candidate for the degree of Master of Arts in Sociology at Portland state University. I am now working on my Master's thesis entitled The Degree of Assimilation of the second and Third Generation of Japanese Americans in the Portland Area.

The purpose of the study is to $f$ ind out the extent to which Japanese Americans are assimilated in this country and to compare the identities of the second and the third generations. I have already interviewed your father/mother within the past few days. In order to complete this study, your participation in a completion of the attached questionnaire is very much needed. Therefore, your cooperation will be greatly appreciated.

Please send back the complete questionnaire and the letter of consent with your signature by January $\angle 1989$, using the enclosed self-addressed envelope.

Thank you very much.

sincerely yours

Hisako Matsuo 
INEORMED CONSENT

I, , hereby agree to serve as a subject in the research project on the assimilation of Japanese Americans in the Portland area.

I understand that the study involves face-to-face interview, telephone interview, and mailed questionnaire.

It has been explained to me that purpose of the study is to learn the present status of Japanese Americans living in the Portland area; 1)the extent to which Japanese Americans are assimilated in American society, 2) how far the third generation is assimilated compared to the second generation, and 3 ) what the identity of the second and third generation of Japanese Americans are.

I may not receive any direct benefit from participation in this study, but my participation may help to increase knowledge which may benefit others in the future.

I have been assured that all information I give will be kept confidential and that the identity of all subjects will remain anonymous. I have also been assured that I may refuse to answer specific questions or terminate the interview at any time.

I have read and understand the foregoing information.

Date

Signature

If you experience problems that are the result of your partlcipation in thls study, please contact the secretary of the Human Subjects Research and Review Committee, office of Grants and Contracts, 303 Cramer Mall, Portland state university, 464-3417. 
The Degree of Assimilation of the second and Third

\section{Generation of Japanese Americans}

As a part of the thesis project of Hisako Matsuo la Candidate of the M.A. degree in Sociology), under the supervision of

$$
\begin{aligned}
& \text { Prof. Leonard Cain (Committee Chair), Ph.D } \\
& \text { Prof. Jan Hajda, Ph.D } \\
& \text { Prof. Robert Shotola, Ph.D }
\end{aligned}
$$

of Sociology Department at Portland state University.

\section{Explanations and Instructions}

1. There are no right or wrong answers to the questions.

2. The only appropriate answer to each question is the one that best applies to you if not given specific instructions.

3. Your participation in this study is completely voluntary.

4. Your response will be kept strictly confidential.

5. If you have any questions regarding this study, call or write to

Hisako Matsuo

Department of Sociology

Portland state University

Portland, OR. 97207

Tel. Office (503) 464-3926 


\section{QUESTIONNAIRE (Sanse 1)}

SECTION I General information

1 What is your sex?

1 Male

2 Female

2 Please tell me your birth date and place of birth. Date Place (City) (state)

3 a) What is your present marital status?

$\begin{array}{ll}1 & \text { Married } \\ -2 & \text { Single } \\ -3 & \text { Midowed }\end{array}$

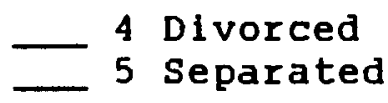

b) If your answer is "married," is this your first marriage?

1 Yes

2 No

4 If ever married, please tell me something about your spouse's background.

a) Where was your spouse born?

city

state

b) Is/Was your spouse...

1 Japanese American

- 2 Non-Japanese oriental

- 3 Japanese (born in Japan)

- 4 Caucasian

- 5 other (specify)

c) If your spouse is a Japanese American, is she... $-\begin{array}{ll}1 & \text { Issei } \\ 2 & \text { Nisei }\end{array}-3$ Sanse $i$ 
5 Please list the year of birth, sex, and marital status of your children, and their spouse's ethnicity if ever married.

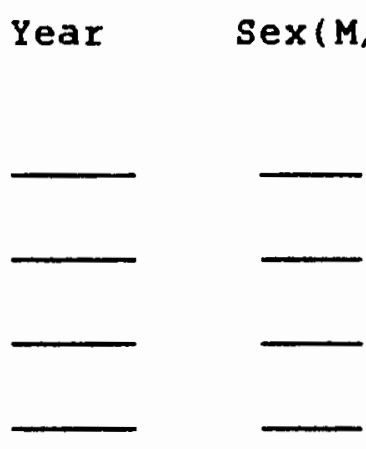

Marital

status

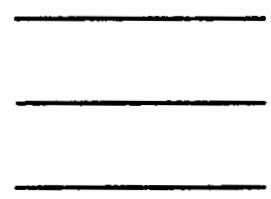

Spouse's

ethnicity

SECTION II Occupation \& Education

1 What is your present occupation?

Please tell me about the job more specifically.

(ex. Title, position, routine work etc.)

2 Please list the kind and length of the occupations you have engaged in and tell me the reason why you changed the job.

Occupation

Year

Reason

(Ex.) Salaried worker 1975-1980

I opened my own business.

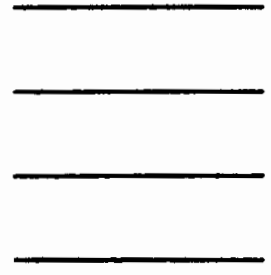


3 What degree of school have you (and your spouse if ever married) completed? please check only one number which describes your formal schooling.
a) Yourself
b) Your spouse

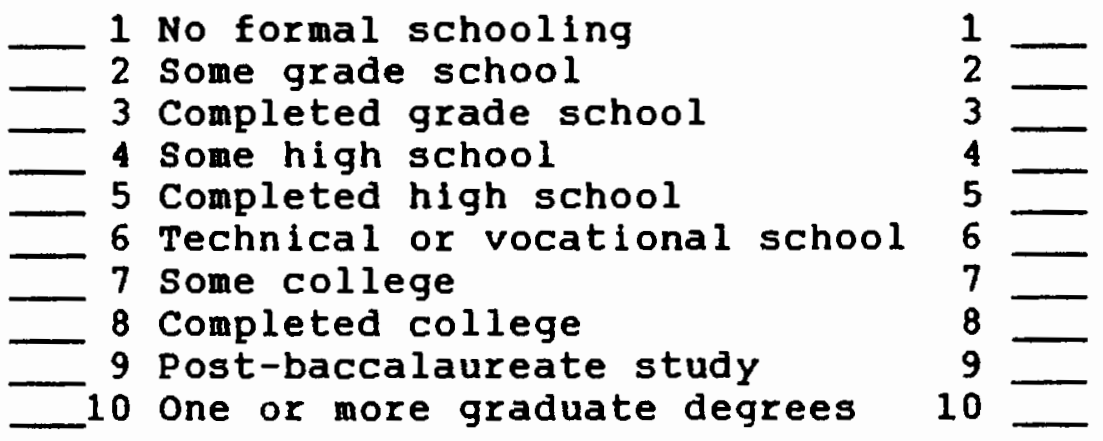

SECTION III Socialization in school days and information on parents and brothers and sisters.

1 While you were in grade school and in high school, were most of your friends Japanese Americans, non-Japanese Orientals, or Caucasians?
a) Grade school
b) HIgh School

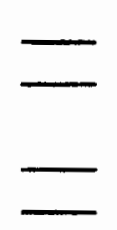

1 Mostly Japanese Americans

2 Mostly Japanese Americans and non-Japanese orientals

3 Mostiy Caucasians

4 An equal number of all

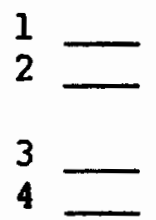

SECTION IV Opinion about your children's socialization and marriage

1 Please tell me about your ethnic preference of your spouse. Write in the ranking $(1,2,3, \ldots)$ of your preference.

\section{Japanese American}

Japanese born in Japan

Non-Japanese Oriental

Caucasian

Other (specify) 
Please tell me why you made that decision.

2 Please tell me about your ethnic preference of your children's spouse. Write in the ranking $(1,2,3, \ldots)$ of your preference.

Japanese American

Japanese born in Japan
Non-Japanese oriental
Caucasian
Other (specify)

Please tell me why you made that decision.

3 Do you want your children to ...

1 stick pretty much only with Japanese Americans?

2 Take an active part mainly with Japanese Americans while socializing with Caucasians

3 Makes little difference.

4 Take an active part mainly with Caucasians while socializing with Japanese Americans?

5 stick pretty much only with Caucasians?

Please tell me why you chose that number.

4 In marriage, do you think that ethnic back ground is more important than religious background?

1 Ethnic background is absolutely more important than religious background.

2 Ethnic background is slightly more important than religious background.

3 Makes no difference

4 Religious background is slightly more important than ethnic background.

5 Religious background is absolutely more important than ethnic background. 
SECTION V Present socialization

1 Is the company or organization that your are working for Japanese affiliated?

$$
\text { - } 1 \text { Yes } 2 \text { No }
$$

2 About what proportion of people(co-workers, clients), you see (saw) regularly at work, are (were) Japanese Americans?
a) Co-workers

$\begin{aligned} 1 & \text { Nearly al1 } \\ -2 & \text { About } 3 / 4 \\ -3 & \text { About } 1 / 2 \\ -4 & \text { About } 1 / 4 \\ -5 & \text { Nearly none }\end{aligned}$
b) Clients

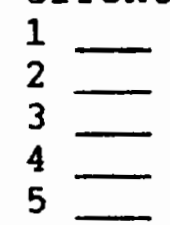

3 If your answer is other than "nearly all," tell me the ethnicity of the rest of the people.
a) Co-workers
- 2 Caucasian
3 other (specify)
1 Non-Japanese Oriental
b) clients

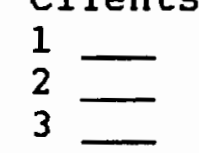

4 About what proportion of your friends are Japanese Americans? (They do not have to live in the portland area.)

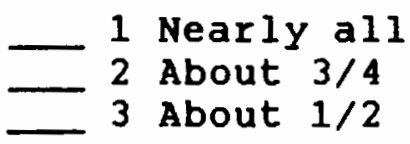

4 About $1 / 4$

5 Nearly none

5 If your answer is other than "nearly all," tell me the ethnicity of the rest of your friends.

1 Non-Japanese oriental

— 2 Caucasian

6 Do you see, visit, or invite your Japanese American Eriends ... 
7 How often a month do you see, visit, or invite your relatives?

$\begin{array}{rlrl}1 & \text { None } & 7 \text { to } 9 \\ 2 & 1 \text { to } 3 & 4 & 10 \text { or more } \\ -3 & 4 \text { to } 6 & -5 & \end{array}$

8 Do you still keep in touch with any of your relatives in Japan?
- 1 Yes
- 2 No

9 Tell me something about two of your close friends. (By close friend, I mean someone you talk to when your are in trouble.)

1) Age $\quad \operatorname{sex}$

Ethnic background

Educational background

Occupation

How long have you known him/her?

How did you get to know him/her?

2)

Age - sex

Ethnic background

Educational background

Occupation

How long have you known him/her?

How did you get to know him/her? 
10 You feel most comfortable when you are with ...

- 1 Japanese Americans

- 2 other orientals

- 3 Caucasians

- 4 Other (specify)

- 5 Makes little difference

SECTION VI Religion

1 What is your religion?

$\begin{array}{ll}1 & \text { Nonbeliever } \\ -2 & \text { Buddhist } \\ -3 & \text { Christian } \\ -4 & \text { Other (specify) }\end{array}$

2 If ever married, what is your spouse's religion?

$\begin{array}{ll}1 & \text { Nonbeliever } \\ -2 & \text { Buddhist } \\ 3 & \text { Christian } \\ -4 & \text { Other (specify) }\end{array}$

3 How often do you go to church?
1 Once a week
- 2 Few times a month
- 3 Once a month or less often
- 4 Never

4 About what proportion of people you see at church are Japanese Americans?

- 1 Nearly all

- 2 About $3 / 4$

3 About $1 / 2$

4 About $1 / 4$

5 Nearly none

5 If your answer is other than "nearly all," tell me the ethnicity of the rest of the members?

$\begin{array}{ll}1 & \text { Non-Japanese or lental } \\ -2 & \text { Caucasians } \\ - & \text { Other (specify) }\end{array}$ 
6 Do you take part in the church activities of different religion? (Ex. Food bazaar at Buddhist church)

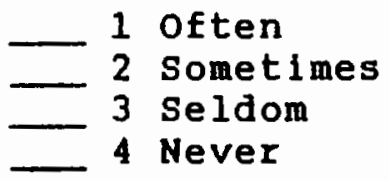

SECTION VII Organizational affiliation

1 How many clubs or organizations do you belong to? (Please exclude church.)

$$
\begin{array}{llll}
0 & \text { None } & -3 & 3 \\
1 & 1 & 4 & 4 \text { to } 7 \\
-2 & 2 & -5 & 8 \text { or more }
\end{array}
$$

2 Do you belong to Japanese Americans' organizations?
1 Yes
2 No

If "Yes," please list the name of the organizations and write in the total number.

Total

3 Of all the organizations you belong to, which one do you devote the most time to? please tell me the name and activities of the organization.

4 Do you read Japanese Americans Newspapers? (Ex. Pacific Citizen) 
SECTION VIII About culture

1 Do you speak Japanese?

$$
\begin{aligned}
& 1 \text { Very fluently } \\
& -2 \text { Pretty well } \\
& -3 \text { Understand spoken Japanese } \\
& 4 \text { Know a few words } \\
& -5 \text { No }
\end{aligned}
$$

2 Did you go to a Japanese language school when you were in school?
- 1 Yes 2 No

If "Yes," how long?

$$
\text { - years }
$$

3 If you do not speak Japanese or do not speak it well, do you want to learn Japanese?

1 Yes 2 No

If "yes," please tell me the reason.

4 Do you think Japanese Americans should preserve something of Japanese culture, or Japanese Americans should blend the culture into main stream of American culture?

1 should preserve own culture

— 3 Makes little difference

Please tell me why you chose that number. 
5 When was the last year you celebrated the following holidays?

1 Easter

2 Memorial Day

3 Fourth of July

4 Thanksgiving

5 Christmas
6 New Year's Day

7 Setsubun (Bean Throwing Festival)

8 Hinamatsuri

(Girls'Festival)

9 Kodomonohi

(Boys' Festival)

10 o-Bon

6 Do you know what part of Japan your ancestors came from?
-1 Yes
2 No

If "Yes," please specify the name of the city or the prefecture.

Grandfather

Grandmother

SECTION IX About discrimination

1 Have you experienced or felt discrimination in housing, at schools, on jobs, or other places because you are a Japanese American?

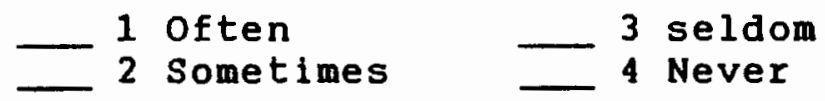

If you ever experienced or felt discrimination, please tell me more specifically.

2 Have you ever heard that your family or your friends had experienced discrimination because they are Japanese Americans?

1 Yes 
If "yes," please tell me more specifically.

3 How much do you think being a Japanese American has hindered your advancement?

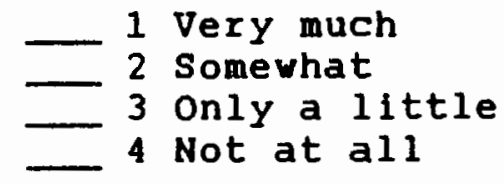

If your answer is other than "not at all," please tell me more specifically.

4 Do you think that there is "anti-Japanese sentiment" among Americans because of trade frictions between the United states and Japan?

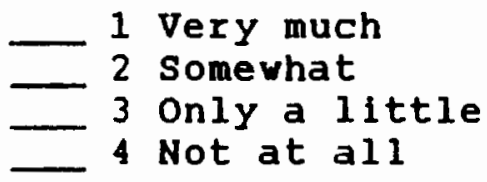

5 Do you think that Japanese Americans are still discriminated against?

\begin{tabular}{ll}
1 & Very much \\
- & 2 \\
\hline & Somewhat
\end{tabular} 3 Only a little
-4 Not at all

Will you please explain more specifically?

SECTION $X$ About identity

1 If you won a free trip abroad, which country would you 11 ke to visit? 
2 Have you ever been to Japan?
1 Yes
2 No

If "Yes," please tell me how old you were at that time and the purpose of travel.

Age

Purpose

If "No," would you like to visit Japan?
- 1 Very much
$-\begin{aligned} & 3 \text { A little } \\ & -4 \text { Not at all }\end{aligned}$

3 Japan became an economic power after world war II. Are you proud of her eminence?

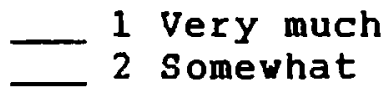

3 Makes little difference

4 Not at all

Please tell me why you chose that number.

4 Suppose that you are watching a volleyball game of the Olympics, the U.S. vs. Japan. Which team do you support?

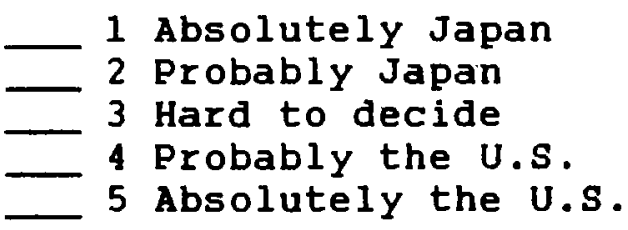

5 Given a scale of 1 (a complete Japanese identity) to 10 (a complete American identity), please indicate the number which, in your judgment, most closely describes your identity.

Japanese

American

$$
\begin{aligned}
& \begin{array}{llllllllll}
1 & 2 & 3 & 4 & 5 & 6 & 7 & 8 & 9 & 10
\end{array} \\
& 1---1---1---1---1---1---1---1---1---1---1
\end{aligned}
$$


6 Are you proud of being a descendant of Japanese?

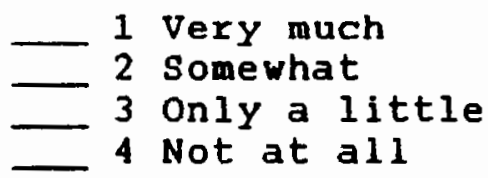

SECTION XI About income

1 What is your total income and family total income of last year before taxes?(Please include income from rents, investments, and interests etc.)

Your income

$$
\text { Family income }
$$
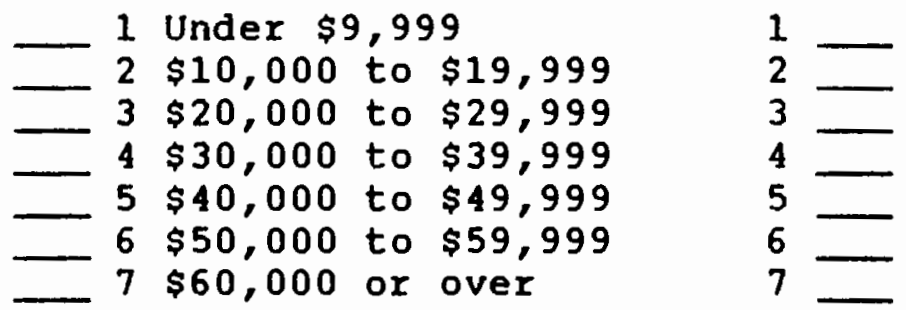

I really appreciate your kind cooperation. 
APPENDIX C

CODING GUIDE 


\section{CODING GUIDE I}

The item numbers for the Nisei are indicated by *, otherwise, the numbers are both for the Nisei and the sansei. The questions, which are not applicable to the Sansei, are indicated by N/A (See the Interview schedule and the Questionnaire in Appendi $x$ ) .

\begin{tabular}{|c|c|c|c|c|}
\hline COLUMN & VAR* & ITEM & I TEM & HON CODED \\
\hline 1 & V 1 & & Generation & $\begin{array}{l}\text { Nise } i=2 \\
\text { Sanse } i=3\end{array}$ \\
\hline $\begin{array}{l}2-3 \\
4\end{array}$ & V 2 & & ID & $\begin{array}{l}\text { Case \# }(1-) \\
\text { Child \#(1-) }\end{array}$ \\
\hline 5 & & & Record \# & 1 \\
\hline 6 & v 3 & $I-1$ & Sex & $\begin{array}{l}\text { Male }=1 \\
\text { Female }=0\end{array}$ \\
\hline $7-8$ & V 4 & $I-2(a)$ & Age & Years of age \\
\hline 9 & V 5 & $I-2(b)$ & $\begin{array}{l}\text { Place of } \\
\text { birth }\end{array}$ & $\begin{array}{l}\text { Portland area } \\
\text { (SMSA) }=1 \text {, oregon=2 } \\
\text { Other Northwest } \\
\text { (BC, wA. Idaho, } \\
\text { Alaska, Montana) }=3 \\
\text { California }=4 \\
\text { Hawai }=5 \\
\text { Other State }=6 \\
\text { Japan }=7 \text { other }=8 \\
\text { Missing variable }=9\end{array}$ \\
\hline 10 & V 6 & $I-3(a)$ & $\begin{array}{l}\text { Marital } \\
\text { status }\end{array}$ & $\begin{array}{l}\text { Married =1 } \\
\text { Single =2 } \\
\text { widowed =3 } \\
\text { Divorced =4 } \\
\text { Separated =5 }\end{array}$ \\
\hline 11 & v 7 & $I-3(b)$ & $\begin{array}{l}\text { First } \\
\text { marriage }\end{array}$ & $\begin{array}{l}\text { Yes }=1 \\
\text { No }=0\end{array}$ \\
\hline 12 & V 8 & $I-4(a)$ & $\begin{array}{l}\text { Spouse's } \\
\text { birth place }\end{array}$ & The same as V 5 \\
\hline
\end{tabular}


13

$$
\text { V } 9 I-4(b)
$$

Spouse's

ethnicity

14

V10 I-4(C)

Spouse's

generation

15

V11 II - I

Occupation

V12 II -3

Education

16

$$
\begin{array}{rl}
\text { II } & I I-3 \\
* & I I-3(a)
\end{array}
$$

Education

17

V13 III-1(a) Friends in *III-2(a) Grade school

18

V14 III-1(b) Friends in *III-2(b) High school 
19

20

21

22

23

24

25

26

27

28

29

30

31

32

$$
\text { I V - 2 }
$$

V15

V16

V17

V18

V19

v20

V21 IV -3

*IV -1

V22 $\begin{array}{r}I V-4 \\ * I V-3\end{array}$

V23 $\begin{array}{r}V-2(a) \\ * V-3(a)\end{array}$

V24 $\begin{array}{r}V-2(b) \\ * V-3(b)\end{array}$

$v 25 \quad v-3(a)$
$\times V-4(a)$

$$
\text { v26 } \begin{array}{r}
V-3(b) \\
* V-4(b)
\end{array}
$$

V27 $\begin{array}{r}V-4 \\ \star V-5\end{array}$

V28 $\begin{array}{r}V-5 \\ * V-6\end{array}$
Preference in children's marriage

Japanese American

Ranking

Japanese born in Japan

Non-Japanese Oriental

Caucasian

$(1,2,3 \ldots$

Missing

variable $=9$ )

Other

Does not matter

Children's

socialization

Stick with JA=1

Mainly JA=2

Does not matter $=3$

Mainly Caucasian $=4$

Stick with $C A=5$

Missing variable $=9$

Ethnicity or

religion

Absolutely

ethnicity $=1$

Probably ethnicity $=2$

Does not matter $=3$

Probably religion $=4$

Absolutely

religion $=5$

Missing variable $=9$

Proportion of Nearly all=1

Japanese

Co-workers

About $3 / 4=2,1 / 2=3$

$1 / 4=4$, Nearly none $=5$

Missing variable $=9$

The same as above

Ethnicity

Co-workers

Non-Japanese

Orientals $=1$

Caucasian $=2$ other $=3$

Missing variable $=9$

The same as above

clients

Proportion of Japanese

friends

Nearly all =1

About $3 / 4=2,1 / 2=3$,

$1 / 4=4$

Nearly none $=5$

Missing variable $=9$

Ethnicity of friends
Non-Japanese

Orienta $1=1$

Caucas 1 an $=2$

Other $=3$,

Missing varlable $=9$ 
33

34

$$
\text { V30 } \begin{array}{r}
V-7 \\
* V-8
\end{array}
$$

35

36

37

38

v34

39

v35

$V 31 \begin{array}{r}V-8 \\ * V-2\end{array}$

v32 V-9

v33

$\operatorname{sex}$

Ethnicity

Education

40

v36

Visiting

pattern

(friends)

visiting

pattern

(relatives) Japan

Friend (1)
Age

Contact with relatives in 


$\begin{array}{llll}41 & V 37 & V-9 & \text { Friend (2) } \\ 42 & V 38 & & \text { Age } \\ 43 & V 39 & & \text { Ethnicity } \\ 44 & V 40 & & \text { Education } \\ 45 & V 41 & & \text { Occupation } \\ 46 & V 42 & V-10 & \text { Comfort }\end{array}$

Religion

Nonbeliever $=1$

Buddh ist $=2$

Christian $=3$

Other $=4$

Missing variable $=9$

48

V44 $\begin{array}{r}V I-2 \\ \times V I-3\end{array}$

Spouse's

religion

The same as above

49

V45 $\begin{array}{r}V I-3 \\ * V I-4\end{array}$

Church

attendance

Once a week $=3$

Few times a month $=2$

Once a month $=1$

Never $=0$

Missing variable $=9$

50

V46 VI - 4

$\star V I-5$

Number of JA

at church

Nearly all $=1$

About $3 / 4=2, \quad 1 / 2=3$

$1 / 4=4$, Nearly one $=5$

Missing variable $=9$

51

V47 VI -5

*VI -6

Ethnicity of Non-Japanese church people

Orientals $=1$

Caucas ians $=2$

other $=3$

Missing variable $=9$

52

V48 VI -6

*VI -7

Participation

of other

church

Often $=1$, Sometimes $=2$

Seldom $=3$, Never $=4$

Missing variable $=9$

53

V49 VII - I

Organizational affiliation
None $=0,1=1,2=2$,

$3=3,4$ to $7=4$,

8 or more $=5$

Missing variable $=9$ 


$\begin{array}{lllll}54-55 & \text { V50 VII-2 } & \begin{array}{l}\text { Fof JA } \\ \text { Organization }\end{array} & \begin{array}{l}\text { Raw score }(0-98) \\ \text { Missing value=99 }\end{array} \\ 56 & \text { V51 VII-4 } & \begin{array}{l}\text { Frequency to } \\ \text { read JA } \\ \text { Newspapers }\end{array} & \begin{array}{l}\text { Regularly=1 } \\ \text { Occasionally=2 } \\ \text { Infrequently=3 } \\ \text { Never }=4 \\ \text { Missing varlable }=9\end{array}\end{array}$

Competence of Japanese
Very fluently $=1$

Pretty well $=2$

Understand $=3$

know a few words $=4$

No $=5$

Missing variable $=9$

Yes $=1, \quad$ No=0

Missing variable $=9$

school

Yes $=1, \quad N o=0$

Missing variable $=9$

Desire to

learn

V55 VIII-4

opinion about culture

Should preserve $=1$

Should blend $=2$

Makes little

difference $=3$

Missing variable $=9$

61 V56 IX-1

Experience of Often $=3$, Sometimes $=2$

discrimination Seldom $=1$, Never $=0$

Missing variable $=9$

62

V57 IX - 2

others'

Yes $=1, \quad$ No $=0$

experience

MIssing variable $=9$

63

V58 IX -3

Disadvantage

of being a JA

Very much $=3$

Somewhat $=2$

Only a little=l

Not at all $=0$

Missing varlable $=9$

Anti-Japanese sentiment
Very much $=3$

Somewhat $=2$

Only a little =1

Not at all=0

Missing variable $=9$ 
65

66

67

68

69

70

71

72

73
V60 IX -5

V61 $x-1$

v62 $x-2(a)$

v63 $x-2(b)$

V64 $x-3$

V65 $x-4$

v66 $x-5$

v67 $x-6$

V68 XI-1(a) Income visit Japan scale
Discrimination Very much $=3$ against JA

Somewhat $=2$

Only a little $=1$

Not at all=0

Missing variable $=9$

Country to

Japan=1, As ia $=2$

Europe $=3$, Other $=4$

Missing variable $=9$

Trip to Japan Yes $=1, N o=0$

Missing variable $=9$

Desire to visit Japan

Very much $=3$

Somewhat $=2$

A little $=1$

Not at all $=0$

Missing variable $=9$

Japan's

eminence

U.S. vs.

Identity

Pride as Japanese

Very much $=3$

Somewhat $=2$

Does not matter $=1$

Not at all=0

Missing variable $=9$

Absolutely Japan=1 Probably Japan $=2$

Hard to decide $=3$

Probably U.S. $=4$

Absolutely U.S $=5$

Missing variable $=9$

Japanese 0 to American 9

Very much $=3$

Somewhat $=2$

Only a little $=1$

Not at all $=0$

Missing variable $=9$

Under $\$ 9,999=1$

$\$ 10,000-\$ 19,999=2$

$\$ 20,000-\$ 29,999=3$

$\$ 30,000-\$ 39,999=4$

$\$ 40,000-\$ 49,999=5$

$\$ 50,000-\$ 59,999=6$

$\$ 60,000$ or over $=7$

Missing value $=9$ 
74 V69 XI-1(b) Family income The same as above

75 v70 N/A Income after Missing value $=9$ $\star X I-1(c) \quad$ retirement

76

V71 N/A $\star X I-1(d)$ Family income Missing value $=9$ after retirement

77

V72 I -5

* of children

$0=0, \quad 1=1, \quad 2=2, \quad 3=3$ 4 or more $=4$ Missing value $=9$

$78-79$

V73 N/A * I I I -3

* of siblings Missing value $=99$ 
CODING GUIDE II

Variable signs, $N$ and $s$ represent questions which are applicable only to the Nisei and to the Sansel respectively.

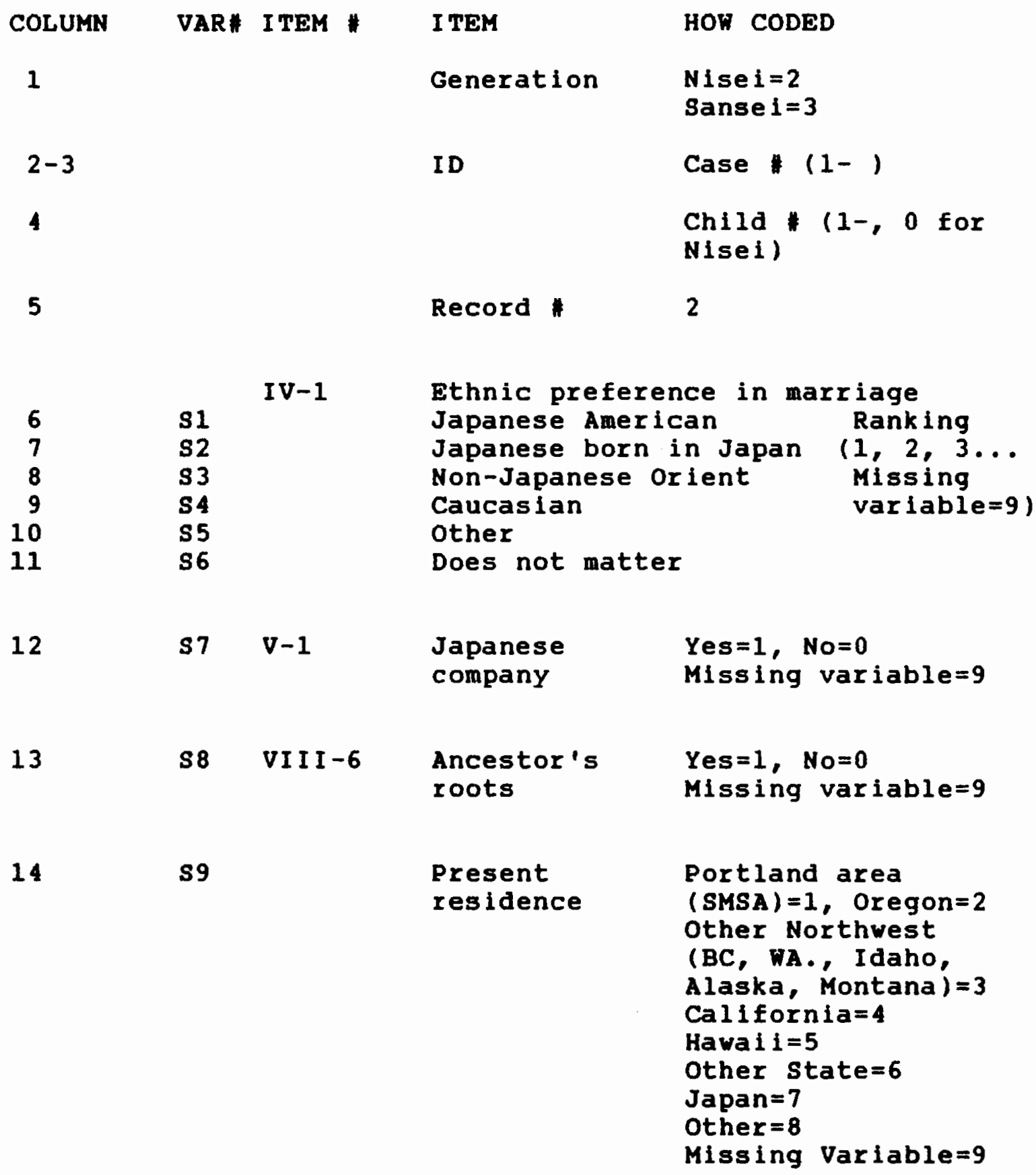


N1 I I-3(b) Spouse's education

Mother's home town

I I I -6

18

19

20

Said nothing $=4$

Parent's opinion in marriage Father Japanese American $=1$ Oriental $=2$

Caucasian $=3$

Said nothing $=4$ Missing variable $=9$ 
N $8 \quad V-1$

Relatives

None $=0$

in Portland

1 to $3=1$

4 to $6=2$

7 to $9=3$

10 or more $=4$

Missing variable $=9$

N9 VI-2(a)

Parents' religion

Father

Nonbeliever $=1$

Buddhist $=2$

Christian=3

other $=4$

Missing variable $=-9$

N10 VI-2(b) Mother

The same as above

$25-26$

27

28

29

30

$31-32$
N12

N13

$I-5$

N11 I-5(1)

N12

Sex

Information about children

Age

Years of age

Missing value $=99$

Male $=1$

Female $=0$

Missing varlable $=9$

Marital status Married $=1$

Single $=2$

Widowed $=3$

Divorced $=4$

Separated $=5$

Missing variable $=9$

N14

Spouse's

ethnicity

Japanese American=1

Non-Japanese

Oriental $=2$

Japanese (born in

Japan $)=3$

Caucasian $=4$

Other $=5$

Missing variable $=9$

Present residence

The same as VAR.S9

The same as above
N16 I -5(2)
Age
Sex
N18
Marital status
N19
Spouse's ethnicity
N20
Residence 


$\begin{array}{llll}37-38 & \text { N21 } & \text { I-5(3) } & \text { Age } \\ 39 & \text { N22 } & \text { Sex } & \text { The same as above } \\ 40 & \text { N23 } & \text { Marital status } \\ 41 & \text { N24 } & \text { Spouse's ethnicity } \\ 42 & \text { N25 } & \text { Residence }\end{array}$

$\begin{array}{llll}43-44 & \text { N26 } & \text { I-5(4) } & \text { Age } \\ 45 & \text { N27 } & \text { Sex } & \text { The same as above } \\ 46 & \text { N28 } & \text { Marital status } \\ 47 & \text { N29 } & \text { Spouse's ethnicity } \\ 48 & \text { N30 } & \text { Residence }\end{array}$

Information about siblings

$49-50$

N31 III-3(1) Age

Years of age

Missing value $=99$

51

N 32

$\operatorname{sex}$

Male $=1$

Female $=0$

Missing variable $=9$

52

N33

Marital status Married $=1$

Single $=2$

Widowed $=3$

Divorced $=4$

Separated $=5$

Missing variable $=9$

53

N34

Spouse's

ethnicity
Japanese American=1

Non-Japanese

Oriental $=2$

Japanese (born in

Japan ) $=3$

Caucasian $=4$

Other $=5$

Missing variable $=9$

The same as above

\begin{tabular}{|c|c|c|c|}
\hline $\begin{array}{l}54-55 \\
56 \\
57 \\
58\end{array}$ & $\begin{array}{l}\text { N35 } \\
\text { N36 } \\
\text { N37 } \\
\text { N } 38\end{array}$ & I I I $-3(2)$ & $\begin{array}{l}\text { Age } \\
\text { Sex } \\
\text { Marital status } \\
\text { Spouse's } \\
\text { ethnicity }\end{array}$ \\
\hline
\end{tabular}

$59-60$

61

62

63
N39

N40

N41

N42
III-3(3) Age

Sex

Marital status

spouse's

ethnicity
The same as above 


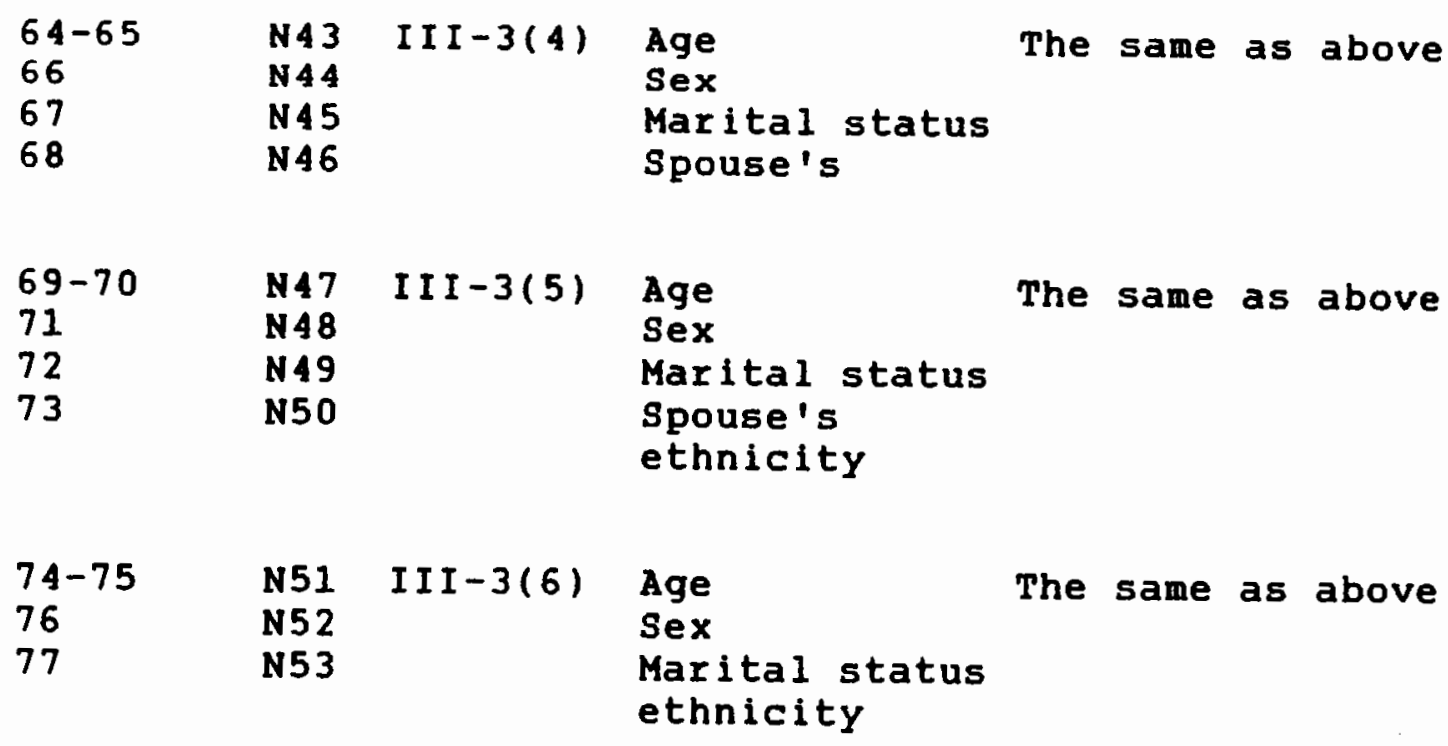

